Aus der Abteilung Gynäkologie und Geburtshilfe

(Prof. Dr. med. G. Emons)

im Zentrum Frauenheilkunde

der Medizinischen Fakultät der Universität Göttingen

\title{
Einfluss von Kisspeptin-10 auf die knochengerichtete Migration und Invasion von Mammakarzinomzellen
}

\author{
INAUGURAL-DISSERTATION \\ zur Erlangung des Doktorgrades \\ der Medizinischen Fakultät \\ der Georg-August-Universität zu Göttingen
}

\author{
vorgelegt von \\ Teresa Olbrich \\ aus \\ Wien/Österreich
}

Göttingen 2010 
Dekan: Prof. Dr. med. C. Frömmel

I. Berichterstatter: Prof. Dr. rer. nat. Gründker

II. Berichterstatter/in: Prof. Dr. med. Binder

III. Berichterstatter/in: Prof. Dr. med., Dr. rer. nat. Crozier

Tag der mündlichen Prüfung: 15. Juni 2011 


\section{INHALTSVERZEICHNIS:}

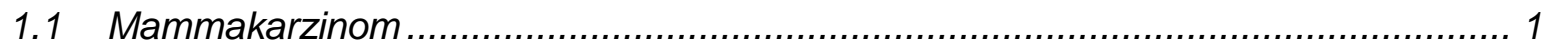

1.1.1 Epidemiologie und Ätiologie ................................................................. 1

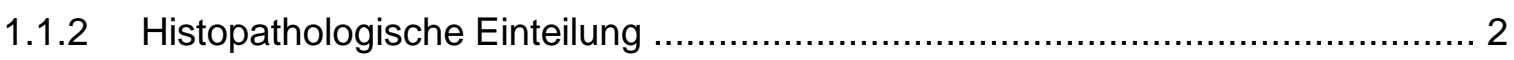

1.1.3 Rezeptorstatus, endokrine und immunologische Therapieoptionen ................... 3

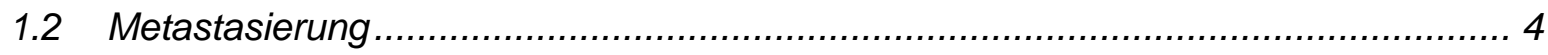

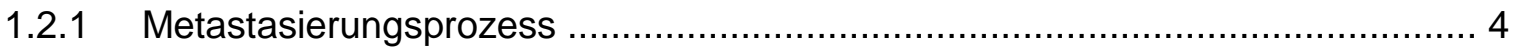

1.2.2 Metastasierung des primären Mammakarzinoms ….................................... 6

1.2.3 Prometastatische Faktoren SDF-1/CXCR4 …........................................... 7

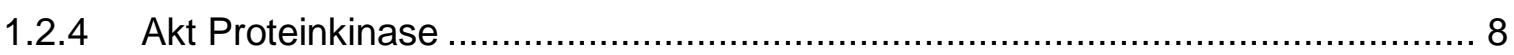

1.3 Therapie des metastasierten Mammakarzinoms............................................. 9

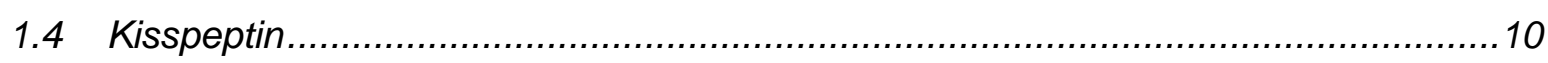

1.4.1 KiSS-1 Gen, Kisspeptin und GPR54 …................................................

1.4.2 KiSS-1 Gen als Metastasesuppressorgen ................................................ 12

1.4.3 Funktionen außerhalb der Tumorbiologie ..................................................12

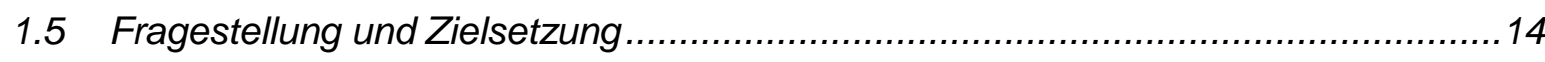

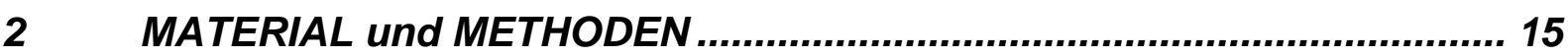

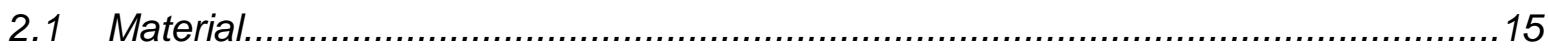

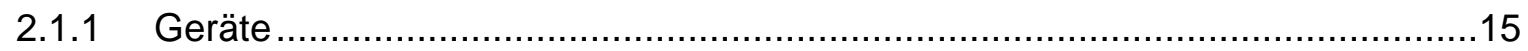

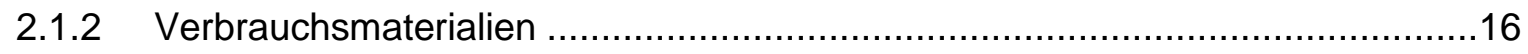

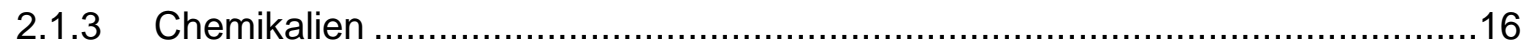

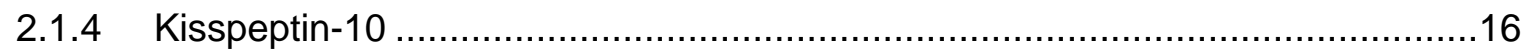

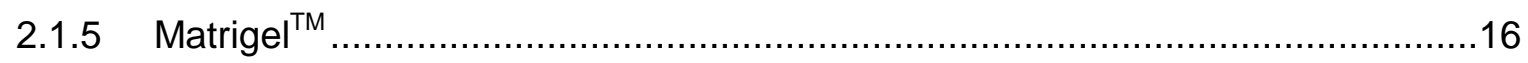

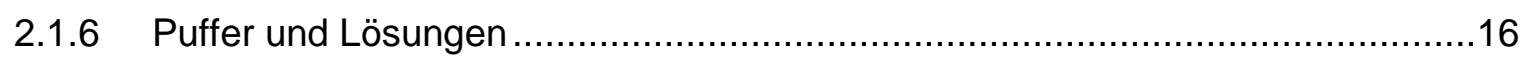

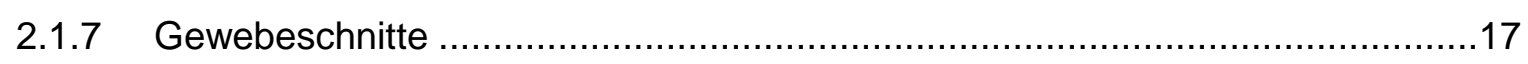

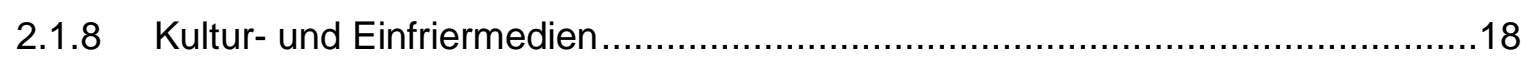

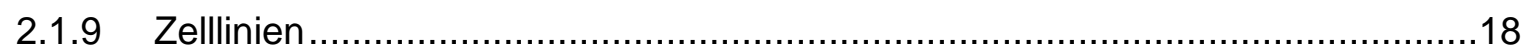

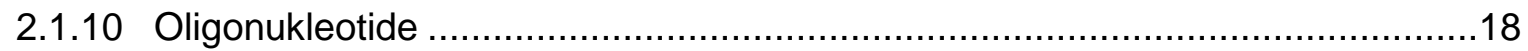

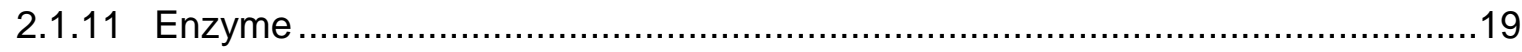

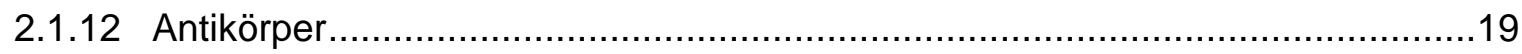




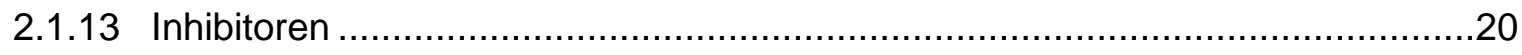

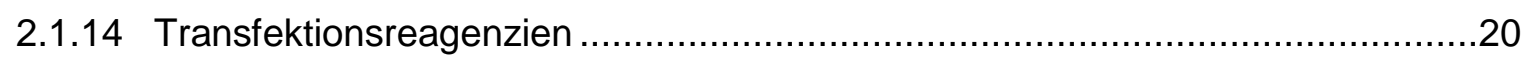

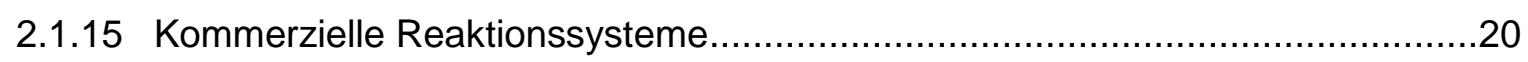

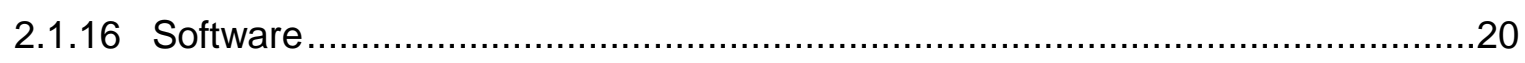

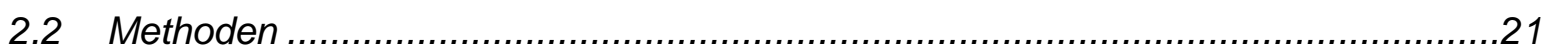

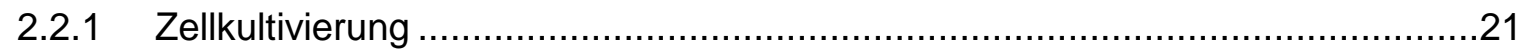

2.2.1.1 Kultivieren und Passagieren adhärenter Zellen .....................................21

2.2.1.2 Kryokonservierung und Auftauen eukaryotischer Zellen .............................21

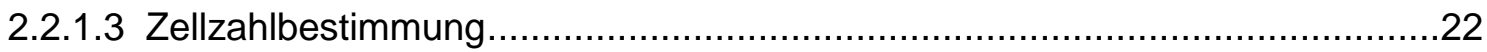

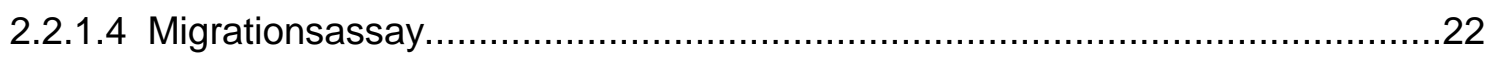

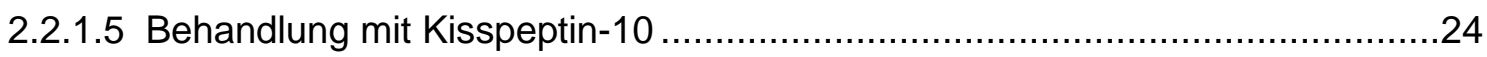

2.2.1.6 Behandlung mit einem SDF-1 Antikörper...............................................24

2.2.1.7 Transiente Transfektion adhärenter Zellen ...........................................25

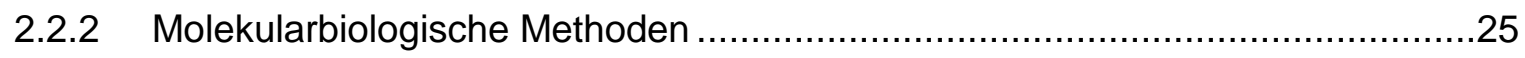

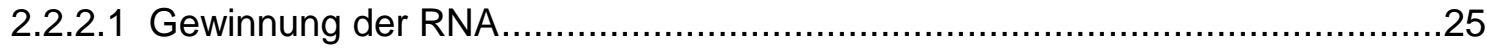

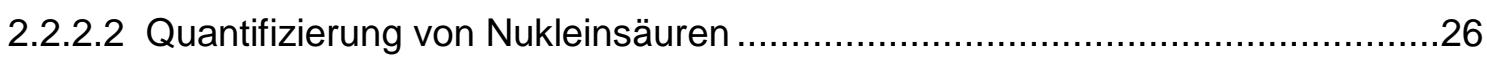

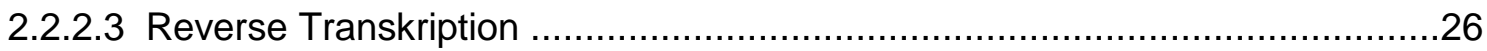

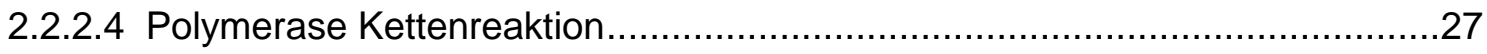

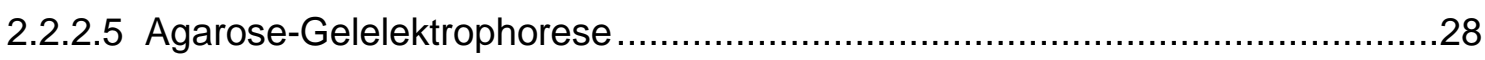

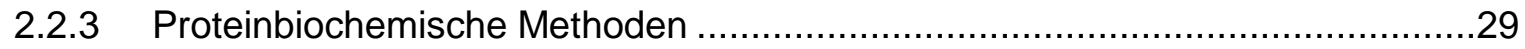

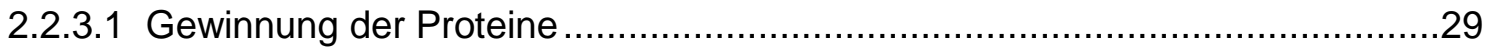

2.2.3.2 Aufbereitung der membranständigen und zytosolischen Proteine..................30

2.2.3.3 Aufbereitung des sekretorischen SDF-1 Proteins .......................................

2.2.3.4 SDS-Polyacrylamid-Gelelektrophorese ...........................................

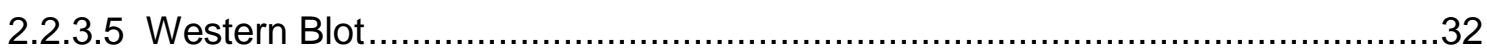

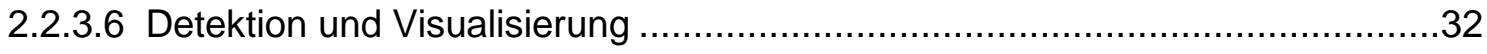

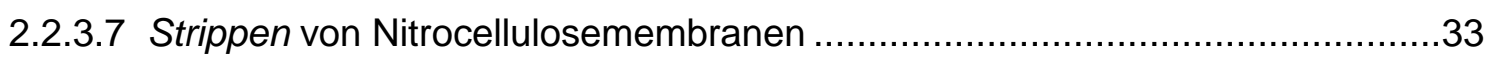

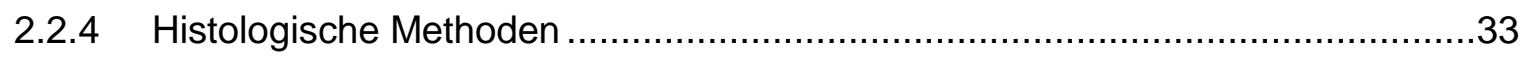

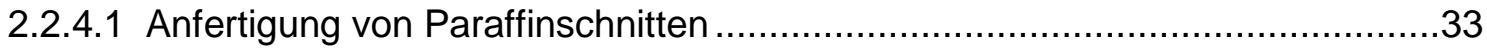

2.2.4.2 Entparaffinierung/Rehydrierung von Paraffinschnitten ...............................34 


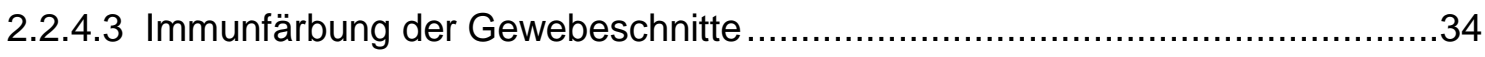

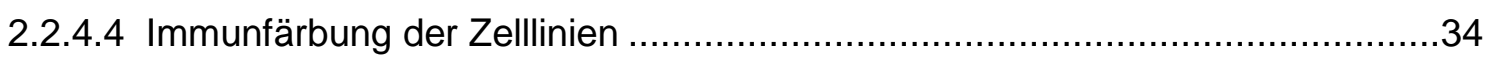

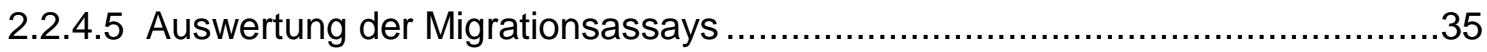

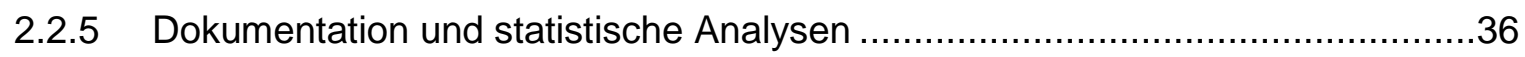

3 ERGEBNISSE

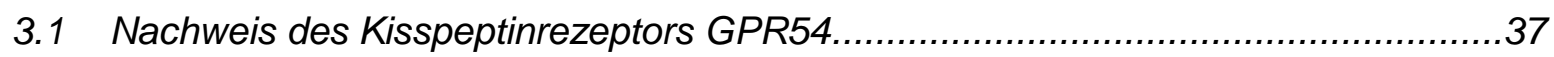

3.1.1 GPR54 Expression in humanem Mammakarzinomgewebe .............................37

3.1.2 GPR54 Expression in den humanen Mammakarzinomzelllinien MCF-7 und MDA-MB-231 sowie in der Osteoblasten-ähnlichen Zelllinie MG-63

3.2 Inhibition der Migrations- und Invasionsfähigkeit von Mammakarzinomzellen durch

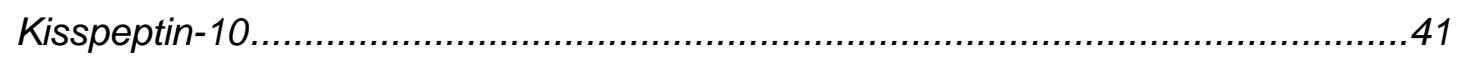

3.2.1 Inhibition der Migrations- und Invasionsfähigkeit der Mammakarzinomzellinie MCF-7 durch Kisspeptin-10.

3.2.2 Inhibition der Migrations- und Invasionsfähigkeit der Mammakarzinomzellinie MDA-MB-231 durch Kisspeptin-10 ........................................................43

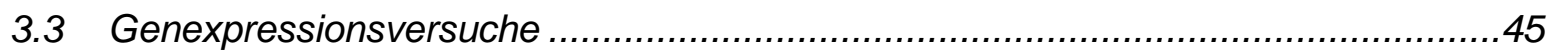

3.3.1 Einfluss von Kisspeptin-10 auf die mRNA-Expression von CXCR4 ..................45

3.3.2 Einfluss von Kisspeptin-10 auf die mRNA-Expression von SDF-1 ...................46

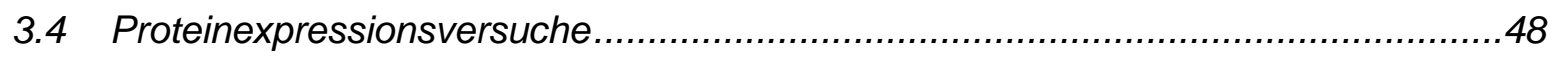

3.4.1 Effekte von Kisspeptin-10 auf die Proteinexpression von CXCR4 ...................48

3.4.2 Effekte von Kisspeptin-10 auf die Proteinsekretion von SDF-1 .......................49

3.4.3 Effekte von Kisspeptin-10 auf die Phosphorylierung der Proteinkinase Akt .......51

3.5 Einfluss von Kisspeptin-10 auf die Proteinexpression nach GPR54 knock down in der Osteoblasten-ähnlichen Zelllinie MG-63 ...................................................52

3.5.1 Nachweis des GPR54 knock downs in der Osteoblasten-ähnlichen Zelllinie MG63

3.5.2 Einfluss von Kisspeptin-10 auf die CXCR4 Proteinexpression nach GPR54 knock down

3.5.3 Einfluss von Kisspeptin-10 auf die SDF-1 Proteinsekretion nach GPR54 knock down

3.5.4 Einfluss von Kisspeptin-10 auf die Phosphorylierung der Proteinkinase Akt nach GPR54 knock down. 
3.6 Einfluss des SDF-1 Antikörpers auf das Migrations- und Invasionsverhalten von MCF-7 Mammakarzinomzellen.

4 DISKUSSION 58

4.1 Untersuchung der GPR54 Expression in humanem Mammakarzinomgewebe .... 58

4.2 Inhibition der Migrations- und Invasionsfähigkeit von Mammakarzinomzellen durch Kisspeptin-10... 59

4.3 Durch Kisspeptin-10 induzierte Signalwege .61

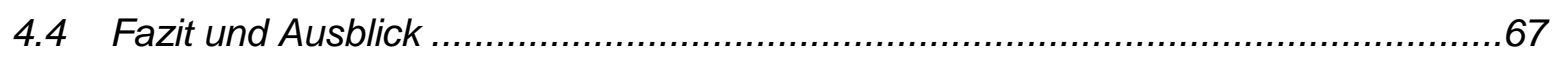

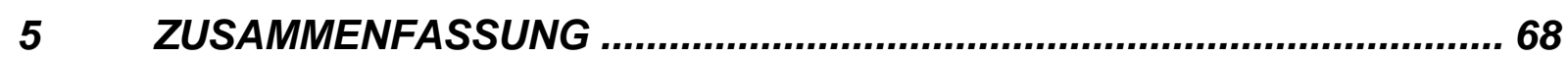

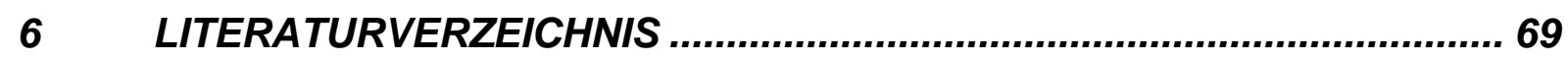

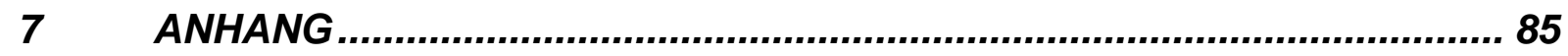

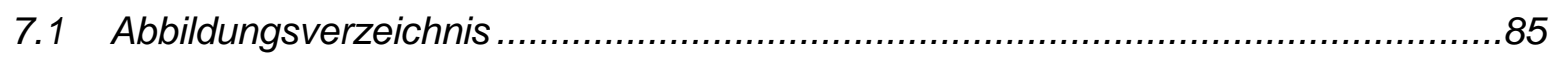

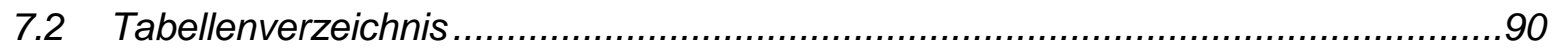

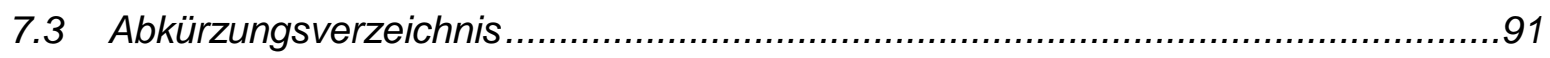

7.4 Aminosäurecode für natürliche Aminosäuren ....................................................93

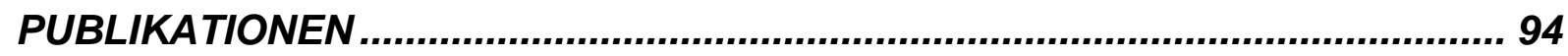




\section{EINLEITUNG}

\subsection{Mammakarzinom}

\subsubsection{Epidemiologie und Ätiologie}

Das Mammakarzinom ist weltweit der häufigste Tumor der Frau und nimmt mit $16 \%$ in der Tumorstatistik der Frauen von allen Tumoren den obersten Platz ein. Im Jahr 2004 sind 519.000 Frauen weltweit an Brustkrebs gestorben, davon lebten $69 \%$ in Entwicklungsländern (WHO 2008). Der hohe prozentuale Anteil der verstorbenen Frauen in den Entwicklungsländern erklärt sich insbesondere durch die meist nicht vorhandenen Präventionsmaßnahmen und die damit verbundene schlechtere Ausgangsposition durch bereits fortgeschrittene Tumore. Dies wird durch folgende Ergebnisse der Concord-Studie, in der die Überlebensrate von an Brustkrebs erkrankten Frauen weltweit untersucht wurde, bestätigt. Patientinnen in Nordamerika, Schweden und Japan zeigten eine 80 \%ige Überlebensrate, während Patientinnen in den mittleren Einkommensstaaten eine $60 \%$ ige Überlebensrate aufwiesen und in Ländern mit niedrigem Einkommen die Überlebensrate bei unter $40 \%$ lag (Coleman, M. P. et al. 2008).

Aktuelle Daten zeigen, dass das Mammakarzinom im Jahr 2008420.800 Neuerkrankte in Europa forderte. Das sind 28,2\% aller diagnostizierten Krebserkrankungen bei Frauen in diesem Jahr. 129.300 Patientinnen sind 2008 in Europa an den Folgen des Mammakarzinoms verstorben (Ferlay et al. 2010).

Das Risiko, an Brustkrebs zu erkranken, ist abhängig von einem Zusammenspiel vieler einzelner Risikofaktoren, von denen einige bis heute noch immer unbekannt sind. Die genetische Prädisposition im Sinne einer BRCA1, BRCA2 und p53 Genmutation ist mittlerweile gut untersucht, aber nur zu ungefähr $5 \%$ ursächlich an der Enstehung des Mammakarzinoms beteiligt. Weitere Risikofaktoren sind u.a. das höhere Alter der Erstgebärenden (Albrektsen et al. 2005) und die postmenopausale Adipositas (van den Brandt et al. 2000). Außerdem führen gewisse reproduktive Faktoren, wie eine frühe Menarche einerseits sowie eine späte Menopause andererseits, zu einem erhöhten Risiko an Brustkrebs. Auch die Einnahme oraler Kontrazeptiva und die Durchführung von Hormon-Ersatztherapien tragen nach 
heutigem Wissensstand zu einem erhöhten Erkrankungsrisiko bei (Lacey et al. 2009).

\subsubsection{Histopathologische Einteilung}

Für die Beurteilung des Tumorgewebes ist u.a. die histopathologische Einteilung von besonderer Bedeutung. Aus dieser ergibt sich zu einem großen Teil das für die Patientin individuell zugeschnittene Therapiekonzept.

Das Carcinoma in situ (CIS) ist die Vorläuferläsion des invasiven Mammakarzinoms und wird anhand der malignen epithelialen Zellen innerhalb der duktal-lobulären Drüsenschläuche charakterisiert. Insgesamt machen sie 5-30\% aller Mammakarzinome aus. Es werden zwei Formen des CIS unterschieden: Das duktale CIS (DCIS) ist mit $95 \%$ aller CIS vertreten, im Vergleich zum lobulären Carcinoma in situ (LCIS) mit $5 \%$. Das DCIS zeigt eine duktale Differenzierung mit kohäsiv wachsenden Tumorzellen. Das LCIS weist eine lobuläre Differenzierung mit Verlust des Zellzusammenhanges auf (Böcker et al. 2004).

Das invasive Mammakarzinom ist charakterisiert durch ein infiltratives Wachstum maligner epithelialer Tumorzellen mit einem CIS als Ursprung. Die Metastasierung erfolgt sowohl hämatogen als auch lymphogen. Auch hier werden folgende Subtypen voneinander unterschieden: Das invasiv lobuläre Karzinom macht 10-15\% aller Mammakarzinome aus und zeigt ein dissoziiertes Wachstumsverhalten der Tumorzellen (Gänsemarschmuster). Zu den invasiv duktalen Karzinomen zählt u.a. die Untergruppe der NOS (not otherwise specified), die $70 \%$ dieses Subtypes ausmacht und keine speziellen histologischen Merkmale aufweist. Sonderformen des duktalen Mammakarzinoms wie das medulläre, das tubuläre, das papilläre oder auch das muzinöse Karzinom sind seltene Erscheinungsbilder (Böcker et al. 2004).

Für die prognostische Beurteilung erfolgt die Einteilung der Tumorerkrankung anhand der TNM-Klassifikation. Hierbei werden die Größe des Tumors (T), der Nodalstatus (N) und die Metastasierung (M) bestimmt (Singletary et al. 2002). Zusammen mit dem histopathologischen Grading nach Bloom \& Richardson (1957), in dem die histo- und zytomorphologischen Eigenschaften des Tumors untersucht werden, sind dies wichtige Informationen, die häufig die Therapie der Tumorerkrankung bestimmen. 


\subsubsection{Rezeptorstatus, endokrine und immunologische Therapieoptionen}

Neben der Untersuchung von histopathologischen Kriterien hat sich im Laufe der Jahre die Bestimmung des Rezeptorstatus beim Mammakarzinom etabliert. Dies hat einerseits eine prognostische Relevanz und andererseits handelt es sich hierbei um potenzielle Zielmoleküle für innovative medikamentöse Therapien.

Der Östrogenrezeptor wird bei 70-80 \% aller Mammakarzinome exprimiert (Kreipe et al. 2010). Der Progesteronrezeptorstatus wird ebenfalls routinemäßig untersucht und gilt eher als prognostischer denn als prädiktiver Marker (Goldhirsch et al. 2009). Weiterhin wird heutzutage auch der Rezeptorstatus von HER2/neu (human epidermal growth factor receptor 2) bestimmt, der zur Familie der epidermalen Wachstumsfaktorrezeptoren (EGFR) zählt. Der HER2/neu-Rezeptor wird bei 25$30 \%$ der Patientinnen exprimiert (Esteva et al. 2002; Slamon et al. 1989) und ist mit einer schlechteren Prognose assoziiert.

Die endokrine Therapie des Mammakarzinoms ist bei einem pathologisch gesicherten positiven Rezeptorstatus heutzutage fest etabliert. Je nach menopausalem Status der Frau ergeben sich folgende Therapieoptionen: Die Behandlung der prämenopausalen Frau erfolgt einerseits durch Antiöstrogene, wie Tamoxifen. Hierbei handelt es sich um selektive Östrogenrezeptor-Modulatoren (SERM, selective estrogen receptor modulators), die zu einer Blockade der Östrogenrezeptoren führen (Legha and Carter 1976; Ward 1973). Weiterhin empfiehlt sich die Einnahme von GnRH-I Analoga, welche eine medikamentöse Kastration hervorrufen und die prämenopausalen Patientinnen in einen postmenopausalen Zustand versetzen (Emons et al. 2003). Für postmenopausal erkrankte Patientinnen waren Antiöstrogene wie Tamoxifen für viele Jahre in der Therapie fest etabliert, werden aber durch Aromatase-Inhibitoren in der heutigen Therapie immer mehr ersetzt. Diese zeigen gegenüber dem Tamoxifen eine bessere Wirksamkeit (Gibson et al. 2007; Riemsma et al. 2010). Eine weitere, immunologische Therapieoption wird bei einem positiven HER2/neu-Rezeptorstatus in Betracht gezogen. Es handelt sich hierbei um Trastuzumab, einen humanisierten monoklonalen Antikörper, der an die extrazelluläre Domäne des HER2 Proteins bindet und somit eine Antikörper-abhängige, zellvermittelte Zytotoxizität verursacht und den Signaltransduktionsprozess der Zelle unterbricht (Mackey et al. 2009). 


\subsection{Metastasierung}

\subsubsection{Metastasierungsprozess}

Bei der Metastasierung handelt es sich um einen Prozess, der bis heute noch nicht vollständig aufgeklärt ist. Metastasen (griechisch) oder auch Filiae (lateinisch) sind Absiedlungen eines primären Tumors in entferntes Gewebe (Coghlin and Murray 2010). In den letzten Jahrzehnten wurden Metastasen als Endprodukt eines kumulativen Prozesses genetischen Umbaus von Tumorzellen aus der primären Tumormasse betrachtet. Transformierte Zellen zeigen von Natur aus genetische Instabilitäten. Dies erklärt wiederum die schnellen genetischen und epigenetischen Änderungen in den Zellen. Somit entsteht eine somatische Evolution der verschiedenen Populationen aus den primären Tumorzellen, welche die Fähigkeit besitzen sich ihrer Mikroumgebung optimal anzupassen. Zellen, die diesen Prozess erfolgreich durchlaufen haben, werden als die „Fittesten der Fitten“ angesehen, migrieren in ein anderes Gewebe und bilden dort eine neue Kolonie (Coghlin and Murray 2010).

Dieses Modell der Metastasierung zeigt, dass es sich hierbei um einen komplexen, aus mehreren Schritten bestehenden Prozess handelt, welcher voraussetzt, dass die Zellen folgende Teilschritte durchlaufen können: Die Destruktion der Basalmembran und die damit verbundene Invasion der extrazellulären Matrix, die Intravasation und das Überleben der zirkulierenden Tumorzellen sowie die sich anschließende Extravasation, Adhäsion, Proliferation und Angiogenese der Tochtergeschwulst (Chambers 1999) (Abb. 1.1). 


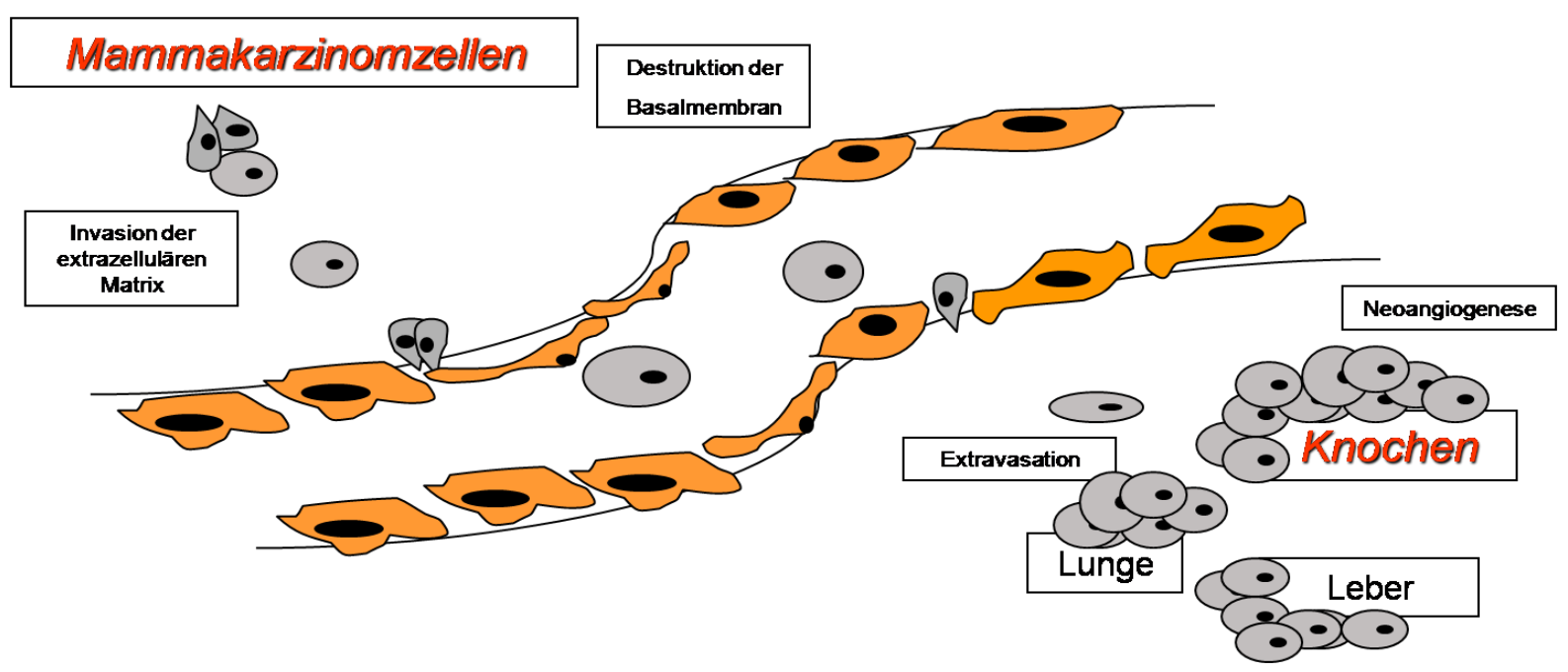

Abb. 1.1: Schematische Darstellung des Metastasierungsprozesses am Beispiel des Mammakarzinoms.

Solide Tumoren zeigen kein zufälliges Verteilungsmuster der Metastasen, wie Paget schon 1889 mit der Seed and Soil Hypothese postulierte (Paget 1989). Er untersuchte in den Autopsien verstorbener Mammakarzinompatientinnen das Metastasierungsverhalten der einzelnen Tumoren und zeigte, dass nur bestimmte Tumorzellen (seeds) in bestimmten, empfänglichen Geweben (soils) kolonisieren.

Dabei spielen einerseits hämodynamische Faktoren und Vaskularisierungsmuster des Primärtumors für die Streuung von Tumorzellen eine Rolle (Hart 2009; KatsUgurlu et al. 2009), andererseits können diese aber nur durch die zugrunde liegenden molekularen Mechanismen erklärt werden.

Die genaue Herkunft der Zellen, die den Metastasierungsprozess erfolgreich durchlaufen können, ist bis heute ungeklärt. In den letzten Jahren haben sich einige Forschungsgruppen auf Tumorstammzellen fokussiert, die eine Population von Tumorzellen darstellt, die die Fähigkeit zur Selbsterneuerung besitzt und somit neues Tumorwachstum initiieren kann (Al-Hajj et al. 2003; Lapidot et al. 1994; Pardal et al. 2003). Bestimmte Eigenschaften von Tumorstammzellen konnten mit einem Progress des Metastasierungsprozesses in Verbindung gebracht werden. So wurden Populationen von Zellen mit Tumor-initiierenden Eigenschaften in mehreren soliden Tumorgeweben wie dem Mammakarzinom und dem Kolonkarzinom nachgewiesen (Al-Hajj et al. 2003; O'Brien et al. 2007). Die Hypothese der migrierenden Tumorstammzelle beschreibt Tumorzellen, die sowohl Stammzelleigenschaften als auch Fähigkeiten der Mobilisierung aufweisen. Dieser Zelltyp unterzieht sich der epithelialen-mesenchymalen Transition (EMT) an der invasiven Front des primären Tumorgewebes und ist anschließend in der Lage zu migrieren und in neues Gewebe 
zu kolonisieren (Brabletz et al. 2005). Die EMT ist somit ein Prozess, durch den die neoplastischen epithelialen Zellen einen mobilen invasiven mesenchymalen Phänotyp einnehmen (Thiery 2003). In diesem Modell sind wachstumsfördernde Faktoren, die von Bindegewebszellen, Entzündungszellen oder Progenitorzellen des Knochenmarks ausgeschüttet werden, in die Tumorgenese und den Metastasierungsprozess aktiv involviert (Coghlin and Murray 2010). Die epithelialemesenchymale Transition wird als reversibles Phänomen beschrieben (Brabletz et al. 2005; Tsuji et al. 2009) und durch eine Vielzahl verschiedener Signalwege wie Wnt, Notch, Hedgehog und den Transkriptionsfaktor Twist reguliert (Yang and Weinberg 2008; Yang et al. 2004).

\subsubsection{Metastasierung des primären Mammakarzinoms}

Das primäre Mammakarzinom metastasiert neben Lunge und Leber vor allem zu 70$80 \%$ in das Knochengewebe. Hierbei sind die langen Röhrenknochen, die Rippen und die Wirbelkörper von Tochtergeschwülsten besonders stark betroffen. Anatomisch gesehen bietet das Trabekelwerk der Metaphyse einen optimalen Nährboden für die sich einnistenden Tumorzellen, da hier ein ausreichender Blutfluss stattfindet, der einerseits guten Zugang in das Gewebe gewährleistet und andererseits für genügend Nährstoffe sorgt (Wang et al. 2006).

Die Knochenmetastasen werden abhängig vom Verhältnis zwischen Knochenaufbau und Knochenabbau in osteolytische, osteoblastische oder gemischtförmige Typen unterschieden (Coleman, R. E. 1997; Kingsley et al. 2007; Steinborn et al. 2000). Der überwiegende Teil der primären Mammakarzinome bildet osteolytische Metastasen, die eine vermehrte Knochenresorption zur Folge haben (Coleman, R. E. 2006; Kozlow and Guise 2005). Brustkrebspatientinnen mit nachweisbaren Knochenmetastasen leiden bis heute an einer unheilbaren Krankheit und werden somit in ein palliatives Therapiekonzept aufgenommen. Während das Auftreten von Knochenmetastasen sehr stark mit der Morbidität der Erkrankung korreliert, sind diese aber selten die Ursache für den Tod der an Brustkrebs erkrankten Frauen (Rose and Siegel 2010). Dennoch entstehen durch Knochenmetastasten schwerwiegende Komplikationen wie chronische Knochenschmerzen, Frakturen, Rückenmarkskompressionen und Hyperkalzämien, die zu drastischen Einschränkungen der Lebensqualität der Erkrankten führen (Costa and Major 2009). 
Unter Patientinnen mit einem Rezidiv eines Mammakarzinoms zeigte sich bei Östrogen-positivem Tumorgewebe ein nahezu doppelt so hohes Risiko, Knochenmetastasen zu entwickeln, gegenüber Patientinnen mit einem Östrogennegativen Tumorgewebe (Hess et al. 2003). Der Zusammenhang von Östrogenpositivem Tumorgewebe und Knochenmetastasen wurde durch Microarray-based Gene-expression Profiling bestätigt. Die Methode des Microarray-based Geneexpression Profiling ermöglichte eine neue Einteilung der Mammakarzinome in verschiedene molekulare Subtypen: luminal A, luminal B, HER2-positive, basal-like und normal-like (Sorlie et al. 2003; Sorlie et al. 2001; Sotiriou et al. 2003). Hierbei wurden Knochenmetastasen in $67 \%$ der luminalen Mammakarzinome (luminal A, luminal B, Östrogen-positiv), in $20 \%$ der HER2-positiven Mammakarzinome, in $7 \%$ der basalen Mammarkarzinome und in $6 \%$ des normalen Subtyps der Mammakarzinome ermittelt (Smid et al. 2008). Dieses unterschiedliche Metastasierungsverhalten der verschiedenen molekularen Subtypen in das Knochengewebe deutet auf unterschiedliche molekulare Mechanismen hin, die den Metastasierungsprozess regulieren (Coleman, R. E. et al. 2008).

\subsubsection{Prometastatische Faktoren SDF-1/CXCR4}

Primäre solitäre Tumoren produzieren eine große Anzahl von Chemokinen, die sowohl lokal in der Mikroumgebung als auch systemisch wirken können (Coghlin and Murray 2010).

CXCR4 (Chemokine (C-X-C motif) receptor 4) ist einer der am häufigsten in der Literatur erwähnten Chemokinrezeptoren, der in humanem Tumorgewebe überexprimiert wird. In mehr als 23 verschiedenen malignen Tumoren, wie dem Mammakarzinom, dem Ovarialkarzinom, dem Melanom und u.a. auch dem Prostatakarzinom, findet eine Erhöhung der CXCR4 Expression statt (Balkwill 2004). Im Vergleich zum Karzinomgewebe ist die CXCR4 Expression in gesundem Brustoder auch Eierstockgewebe niedrig oder nicht nachweisbar (Muller et al. 2001; Scotton et al. 2001). Der entsprechende Ligand des CXCR4 Rezeptors, SDF-1 (Stromal derived factor-1), wird in verschiedenen Gewebetypen sezerniert, bevorzugt jedoch in Geweben, die am häufigsten Fernmetastasen aufweisen wie Knochen, Leber oder Lunge (Wang et al. 2006). Durch Neutralisierung des SDF-1 in einem xenotransplantierten Mausmodell wurde die Metastasierung von Mamma- 
karzinomzellen in die regionalen Lymphknoten und die Lunge vermindert (Muller et al. 2001).

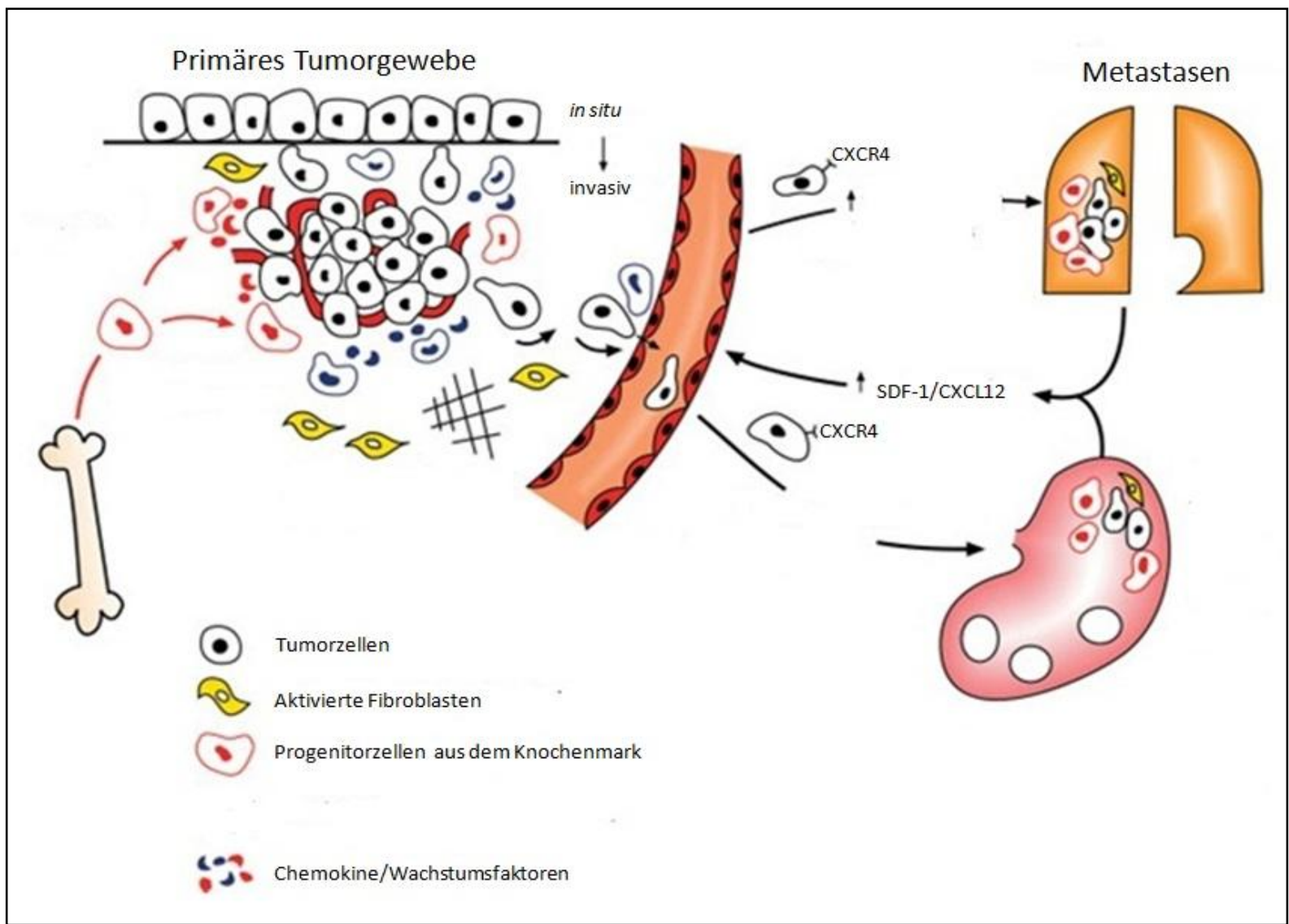

Abb. 1.2: Schematische Darstellung der Mikroumgebung des primären Tumorgewebes und der Metastasen. Progenitorzellen des Knochenmarks, aktivierte Fibroblasten und endotheliale Zellen stehen in ständiger Interaktion mit den Tumorzellen von der in situ Proliferation an, über die Invasion und Intravasation bis hin zur Bildung der Tochtergeschwulst. Prämetastatische zelluläre Anhäufungen sezernieren lösliche Mediatoren wie SDF-1, welches das homing der CXCR4-positiven migrierenden Tumorzellen fördert. Modifiziert nach Coghlin and Murray (2010, S.4).

\subsubsection{Akt Proteinkinase}

Die Akt Proteinkinase (Proteinkinase B) transduziert Signale von Wachstumsfaktoren und Onkogenen, die wiederum äußerst wichtige Elemente der Tumorentwicklung steuern und kontrollieren. Der Akt Signalweg ist einer der am häufigsten hyperaktivierten Signalwege in humanem Tumorgewebe (Crowell et al. 2007). Das Akt Protein gehört zur Familie der Serin/Threoninkinasen und wird durch die Phosphatidylinositol-3-Kinase (PI3K) aktiviert, welche Signale von Zytokinen, Wachstumsfaktoren und Onkoproteinen auf weitere Proteine in der Signalkaskade übermittelt. Die aktivierte PI3K rekrutiert das Akt Protein über eine Pleckstrin 
Homologie Domäne (PH-Domäne) an der Zellmembran, an der das Akt Protein durch Phosphorylierung an $\mathrm{Thr}^{308}$ und $\mathrm{Ser}^{473}$ aktiviert wird. Das phosphorylierte Akt Protein (P-Akt) reguliert eine Vielzahl zellulärer Funktionen wie Zellproliferation, Zellwachstum und verschiedene Schritte im Zellmetabolismus (Crowell et al. 2007).

Neben Tumoren der Lunge, der Prostata, des Kolons und der Haut zeigt sich auch im Mammakarzinom eine erhöhte P-Akt Expression (Crowell et al. 2007). In intraduktalen Hyperplasien, im DCIS und in invasiven Karzinomen der Mamma hingegen ist das phosphorylierte Akt Protein deutlich erhöht (Zhou et al. 2004). In gesundem Brustgewebe und in Fibroadenomen der Brust wird P-Akt hingegen nur sehr schwach exprimiert oder nicht nachgewiesen.

\subsection{Therapie des metastasierten Mammakarzinoms}

Die Therapie des metastasierten Mammakarzinoms basiert heutzutage hauptsächlich auf konservativen Maßnahmen, wie der Gabe von Chemotherapeutika (Taxane), Aromatasehemmern und aktuell auch der Verabreichung von spezifischen Antikörpern wie Trastuzumab oder Bevacizumab (Amar et al. 2009; Miller et al. 2007). Die operative Entfernung des Primärtumors im metastasierten Stadium wird derzeitig kontrovers diskutiert. Möglicherweise hat diese Maßnahme einen positiven Einfluss auf die Prognose der Patientinnen (Ruiterkamp et al. 2009).

Für die Behandlung von Knochenmetastasen mit Primarius in der Mamma existieren derzeit unterschiedliche Therapieansätze wie operative Maßnahmen, Radiotherapie, Chemotherapie oder die spezielle Medikamentenklasse der Bisphosphonate (Rose and Siegel 2010). Die Radiotherapie sowie die orthopädisch-chirurgische Operation können Schmerzen lindern und Metastasen-bedingte Frakturen stabilisieren. Dies wiederum erhöht die Mobilität der Erkrankten und führt zu einer längeren Überlebenszeit (Williams et al. 2009). Bisphosphonate verhindern den Prozess der Knochenresorption (Rose and Siegel 2010). Hierbei handelt es sich um chemische Analoga des Pyrophosphats, welche eine hohe Bindungsaffinität zum Kalziumphosphat besitzen und die Bildung, Aggregation sowie Auflösung von Kristallen des Kalziumphosphats im Knochen hemmen (Fleisch 2002). Sie werden bei hyperkalzämischen Krisen eingesetzt und reduzieren bei regelmäßiger Anwendung das Auftreten neuer durch Metastasen hervorgerufener Frakturen, 
besitzen aber auch direkte antitumorale Eigenschaften (Brown et al. 2004; NevilleWebbe et al. 2010).

\subsection{Kisspeptin}

\subsubsection{KiSS-1 Gen, Kisspeptin und GPR54}

Das KiSS-1 Gen wurde im Jahr 1996 auf der Suche nach pro- und antimetastatischen Faktoren sowie deren Gene entdeckt und zunächst als Metastase-Suppressorgen für verschiedene Melanomzellinien identifiziert (Lee, J. H. et al. 1996). Der dazugehörige Rezeptor GPR54 (G protein-coupled receptor 54, KiSS1R) wurde 1999 aus Rattengewebe isoliert und weist einen hohen Verwandtschaftsgrad mit der Galanin-Rezeptorfamilie auf. Dennoch besitzt der GPR54 keine Bindungsaffinität zu dem Neuropeptid Galanin (Lee, D. K. et al. 1999).

Tab. 1.1: Gewebespezfische Expression des KiSS-1 Gens und des GPR54 (Makri et al. 2008, S.684)

\begin{tabular}{|lll|}
\hline Humanes Gewebe & KiSS-1 Gen Expression & GPR54 Expression \\
\hline \hline Plazenta & $\mathbf{+ + + + +}$ & $\mathbf{+ + + + +}$ \\
Testis & $\mathbf{+ + + +}$ & $\mathbf{+ + + +}$ \\
Leber & ++ & + \\
Dünndarm & ++ & + \\
Pankreas & ++ & +++ \\
Kolon & + & + \\
Milz & + & \\
Lymphozyten & + & + \\
Gehirn & + & + \\
\hline
\end{tabular}

Der dazugehörige Ligand, Kisspeptin-54, wurde erstmals von Ohtaki et al. (2001) beschrieben. Hierbei wurde Kisspeptin-54 aus dem Gewebe der Plazenta isoliert. Die Expression des GPR54 konnte weiterhin in unterschiedlichen Geweben, wie im zentralen Nervensystem, im Darm und in endokrinen Organen nachgewiesen werden (Tab. 1.1). Die höchste sowie auch die biologisch aktivste Expression des Rezeptors wurde im humanen Plazentagewebe ermittelt (Kotani et al. 2001). Außerdem gelang es, die biologisch aktiven Produkte des KiSS-1 Gens und zugleich auch die 
natürlichen Agonisten des GPR54 zu extrahieren. Das Vorläuferpeptid Kisspeptin145 kann durch Prozessierung in das biologisch aktive Peptid, Kisspeptin-54, gespalten werden (Kotani et al. 2001). Weitere biologisch aktive Kisspeptine (Kisspeptin-14, Kisspeptin-13) entstehen durch Furin- oder Prohormonkonvertasen (Harms et al. 2003; Ohtaki et al. 2001) (Abb. 1.3).

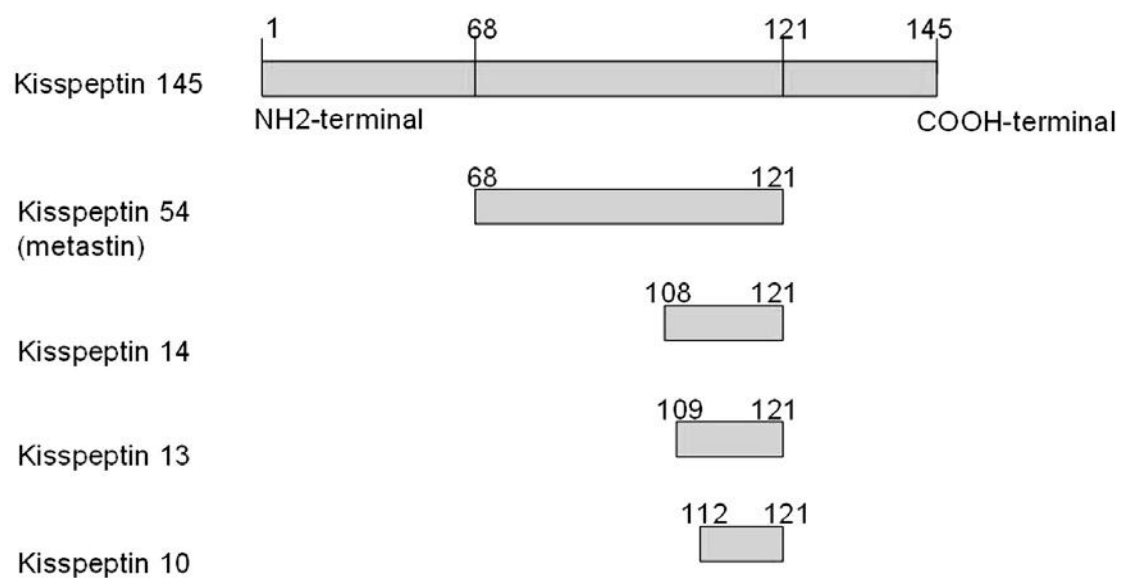

Abb. 1.3: Proteolyse des Vorläufermoleküls von Kisspeptin-10. Die biologisch aktiven Kisspeptine entstehen intrazellulär durch spezfifische Proteolyse aus dem Vorläuferpeptid Kisspeptin-145 (Makri et al. 2008, S.685).

Die unterschiedlichen Kisspeptine sind entsprechend der Anzahl ihrer Aminosäuren benannt. Das kleinste Peptid, Kisspeptin-10, besteht somit aus zehn Aminosäuren (Abb. 1.4) und kann nicht durch offensichtliche Schnittstellen im Kisspeptin-145 erklärt werden, sodass davon ausgegangen wird, dass es sich um ein Degradationsprodukt handelt (Harms et al. 2003). Dennoch zeigt Kisspeptin-10 im Vergleich zu den anderen biologisch aktiven Kisspeptinen die höchste Affinität zum GPR54 mit den gleichen Bindungs- und Funktionseigenschaften (Ohtaki et al. 2001).

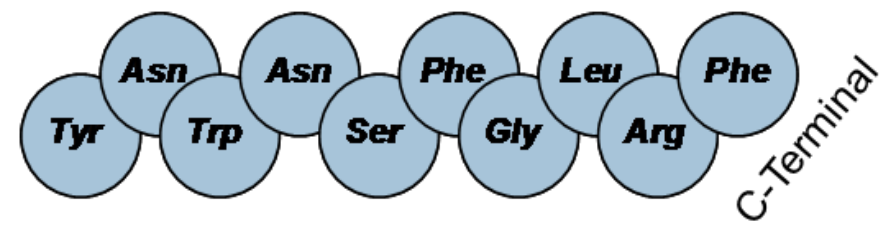

Abb. 1.4: Aminosäuresequenz von Kisspeptin-10. Kisspeptin-10 besteht aus zehn Aminosäuren und zeigt die höchste Affinität zum GPR54 im Vergleich zu den restlichen biologisch aktiven Kisspeptinen. 
Sowohl Kisspeptin-145 als auch Kisspeptin-54 weisen eine Aminosäuresequenz auf, die auf eine rasche Ubiquitinierung und deren anschließenden Abbau in Proteasomen hindeutet. Dies könnte mit einer möglichen, sehr geringen Halbwertszeit der Peptide in Zusammenhang stehen (Harms et al. 2003).

\subsubsection{KiSS-1 Gen als Metastasesuppressorgen}

Das KiSS-1 Gen wurde 1996 von Lee, J. H. et al. (1996) zunächst als MetastaseSuppressorgen für verschiedene Melanomzelllinien identifiziert. Schon damals konnte in dieser Arbeit gezeigt werden, dass in Tumorzelllinien mit hohem Metastasierungspotential keine KiSS-1 mRNA-Expression nachweisbar ist und es einen Zusammenhang geben muss zwischen dem Metastasierungsverhalten von Zellen und deren KiSS-1 Genexpressionmustern. Ein Jahr später konnte die Arbeitsgruppe im Nacktmausmodell auch an der Mammakarzinomzellinie MDA-MB435, die das KiSS-1 Gen exprimiert, eine signifikante Abnahme der Metastasierungsfähigkeit feststellen (Lee, J. H. and Welch 1997). Dieses Phänomen wurde auch beim Blasenkarzinom beobachtet. Der Funktionsverlust des KiSS-1 Gens ist daher mit einer schlechteren Prognose assoziiert (Sanchez-Carbayo et al. 2003). Eine Untersuchung von Kostadima et al. (2007) zeigte in Mammatumoren, die

aus einer Kohorte von 272 Lymphknoten-positiven Mammakarzinompatientinnen stammten, eine nicht nachweisbare KiSS-1 Genexpression. Durch das Fehlen der KiSS-1 Genexpression blieb den Tumorzellen ihre Metastasierungsfähigkeit erhalten. In einer Studie von Stark et al. (2005) war die KiSS-1 mRNA-Expression in Hirnmetastasen des Mammakarzinoms ebenfalls signifikant reduziert.

\subsubsection{Funktionen außerhalb der Tumorbiologie}

Ein anderer großer Forschungsbereich beschäftigt sich mit dem Zusammenhang zwischen Kisspeptin, der Pubertät und deren Regulation. Die Arbeitsgemeinschaft Seminara et al. (2003) entdeckte im Jahr 2003, dass Menschen und Mäuse, die eine GPR54 Mutation aufweisen, an einer sexuellen Entwicklungsstörung im Rahmen der Pubertät leiden. Dies konnte u.a. anhand niedriger Sexualhormon- und Gonadotropinwerte gezeigt werden. Weiterhin wurde der Einfluss des KiSS-1/GPR54 
Systems auf die Freisetzung des luteinisierenden Hormones (LH) untersucht. Hier wurde gezeigt, dass die LH-Freisetzung in Säugetieren nach Gabe von Kisspeptin ansteigt (Gottsch et al. 2004; Shahab et al. 2005). Außerdem konnte auch ein Einfluss von Kisspeptin auf den Östrogen-positiven und -negativen Feedbackmechanismus festgestellt werden, welcher wiederum auf die Gonadotropinsekretion einwirkt (Adachi et al. 2007; Maeda et al. 2007; Roa and Tena-Sempere 2007).

Auch der bisher noch ungeklärte Zusammenhang zwischen der Melatoninsekretion und dem Reproduktionszyklus lässt sich möglicherweise durch das KiSS-1/GPR54 System erklären. Dies wurde durch Untersuchungen des photoneuroendokrinen Systems ermittelt (Revel et al. 2007). In einer weiteren Untersuchung wurde gezeigt, dass es in der Menopause von Frauen zu einem Anstieg der hypothalamischen Kisspeptinexpression kommt (Rometo et al. 2007).

Den Kisspeptinen wird auch ein hemmender Einfluss auf die Invasion des Trophoblasten zugesprochen. Hiermit erklärt sich auch die bereits erwähnte hohe Expressionsrate des GPR54 im Plazentagewebe. Der Invasionsprozess des Trophoblasten erinnert stark an den Vorgang der Tumorzellinvasion (Bilban et al. 2004; Hiden et al. 2007). Untersuchungen an Schwangeren ergaben einen hohen Anstieg des zirkulierenden Kisspeptinlevels, der fünf Tage postpartum auf die Ausgangswerte vor der Schwangerschaft zurück ging (Horikoshi et al. 2003). Weitere Analysen zeigten, dass im Vergleich zur späten, reifen Plazenta im frühen Plazentagewebe ein höherer GPR54 Genexpressionslevel erreicht wird. Dies wird durch eine höhere und aggressivere Invasionsfähigkeit des Trophoblasten, die eine Gegenregulation benötigt, erklärt (Janneau et al. 2002).

Außerdem wird über einen möglichen Einfluss des KiSS-1/GPR54 Systems bei der veränderten Gonadotropinsekretion von Typ-I-Diabetikern diskutiert (Castellano et al. 2006). Weiterhin gibt es Hinweise auf eine vasokonstriktorische Funktion der Kisspeptine (Mead et al. 2007). 


\subsection{Fragestellung und Zielsetzung}

In der vorliegenden Arbeit soll der Nachweis des GPR54 in Mammakarzinomgeweben verschiedener Patientinnen erbracht werden, da die GPR54 Expression die Voraussetzung einer Targettherapie mit Kisspeptin beim Mammakarzinom ist. Des Weiteren werden die Grundlagen der Wirkung von Kisspeptin-10 auf die knochengerichtete Migration humaner Mammakarzinomzellinien untersucht.

Zunächst wird mittels Immunhistochemie Tumorgewebe von Mammakarzinompatientinnen auf die GPR54 Expression untersucht und ein möglicher Zusammenhang mit dem jeweiligen Östrogen-, Progesteron- und HER2/neuRezeptorstatus hergestellt. Weiterhin soll ebenfalls der Nachweis erbracht werden, dass die in dieser Arbeit verwendeten Mammakarzinomzellinien MCF-7 und MDAMB-231 sowie die Osteoblasten-ähnliche Zelllinie MG-63 für den Kisspeptinrezeptor GPR54-positiv sind.

Alle weiteren in vitro Untersuchungen erfolgen unter Verwendung eines in unserer Arbeitsgruppe etablierten Kokultursystems, welches es ermöglicht, humane Mammakarzinomzellen mit Osteoblasten-ähnlichen Zelllinien zu kultivieren. Zunächst gilt es die Konzentration zu erforschen, in der Kisspeptin-10 die Migration der humanen Mammakarzinomzellen maximal inhibiert.

Eine Expressionsregulation der prometastatischen Faktoren CXCR4 und SDF-1 und des Onkogens P-Akt wird in der humanen Mammakarzinomzelllinie MCF-7 ohne und während der Kokultur sowie nach Behandlung der MCF-7 Zellen mit unterschiedlichen Konzentrationen von Kisspeptin-10 untersucht. Dafür werden RTPCR und Western Blot Analysen durchgeführt. Zudem wird die Auswirkung eines SDF-1 Antikörpers auf das Migrationsverhalten der MCF-7 Zellen in der Kokultur untersucht.

Nach Durchführung eines GPR54 knock downs in der Osteoblasten-ähnlichen Zelllinie MG-63 wird der Einfluss von Kisspeptin-10 auf die CXCR4, SDF-1 und P-Akt Expression mittels Western Blot Verfahrens analysiert.

Die Untersuchungsergebnisse sollen einen Beitrag dazu leisten, die Wirkung sowie die molekularen Mechanismen von Kisspeptin-10 in vitro zu erforschen und einen möglichen in der Zukunft liegenden klinisch-therapeutischen Einsatz zu forcieren. 


\section{MATERIAL Und METHODEN}

\subsection{Material}

\subsubsection{Geräte}

Geräte

Analysenwaage BP161

Autoklav, 2540 EL

Biofuge pico

Brutschrank, Model 3121 S/N 28439532

Elektrophoresekammer, DNA

Labofuge 400R

Magnetrührer MR3000

Mini-ProteanTM III Cell and Systems

Mikroskop Axiovert 25

Mikroskop BH-2

Mikroskop, IX51

Mikrowaage, elektronisch, M2P

pH-Meter CG22

Power Supply, Pac Basic ${ }^{\mathrm{TM}}$

Power Supply, Standard Power Pack P25

Rotations-Mikrotom CUT 4050

Schüttler Titramax 1000

Spektralphotometer (Biophotometer)

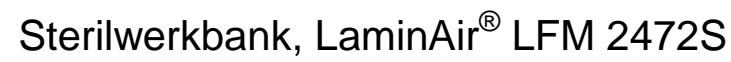

Thermocycler T3000

Thermomixer compact

Ultrazentrifuge $3 \mathrm{~K} 30$

UV-Transilluminator

Vortex Genie 2TM

Wasserbad 1083

X-Ray Film Prozessor, SRS-101A
Hersteller

Sartorius

Tuttnauer

Heraeus Holding

Forma Scientific

OWL Seperation Systems

Heraeus Holding

Heidolph

Bio-Rad

Zeiss

Olympus

Olympus

Sartorius

Schott Geräte

Bio-Rad

Biometra

Slee Mainz

Heidolph

Eppendorf

Heraeus Holding

Biometra

Eppendorf

Sigma

Biometra

Bender \& Hobein

GFL

Konica 


\subsubsection{Verbrauchsmaterialien}

Die Verbrauchsmaterialien (Einmalartikel), die in dieser Arbeit verwendet wurden, haben folgende Firmen in ihrem Sortiment: Eppendorf, Greiner bio-one, WU Mainz, Millipore, Nunc und Sarstedt.

\subsubsection{Chemikalien}

Die in dieser Arbeit verwendeten Chemikalien wurden von folgenden Firmen bezogen: Aventis, Merck, PAA, Roth und Sigma-Aldrich.

\subsubsection{Kisspeptin-10}

Kisspeptin-10 (Metastin, Sequenz: Tyr-Asn-Trp-Asn-Ser-Phe-Gly-Leu-Arg-Phe) wurde in unserem Auftrag von Peptide Specialty Laboratories, Heidelberg synthetisiert. Die Anlieferung erfolgte als Lyophilisat, aus der eine Stammlösung mit

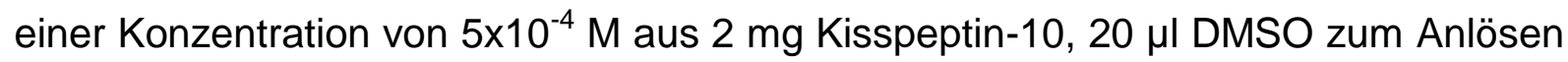
des Pulvers und $2980 \mu \mathrm{l}$ Ampuwa-Wasser zum weiteren Gebrauch hergestellt wurde.

\subsubsection{Matrigel $^{T M}$}

Die Matrige ${ }^{T M}$ Basement Membrane Matrix wurde von der Firma BD Biosciences bezogen und wird aus Engelberth-Holm-Swarm (EHS)-Maussarkomzellen gewonnen.

\subsubsection{Puffer und Lösungen}

Für das Ansetzten von Puffern und anderen Lösungen wurde, falls nicht gesondert erwähnt, autoklaviertes, doppelt destilliertes Wasser verwendet. 


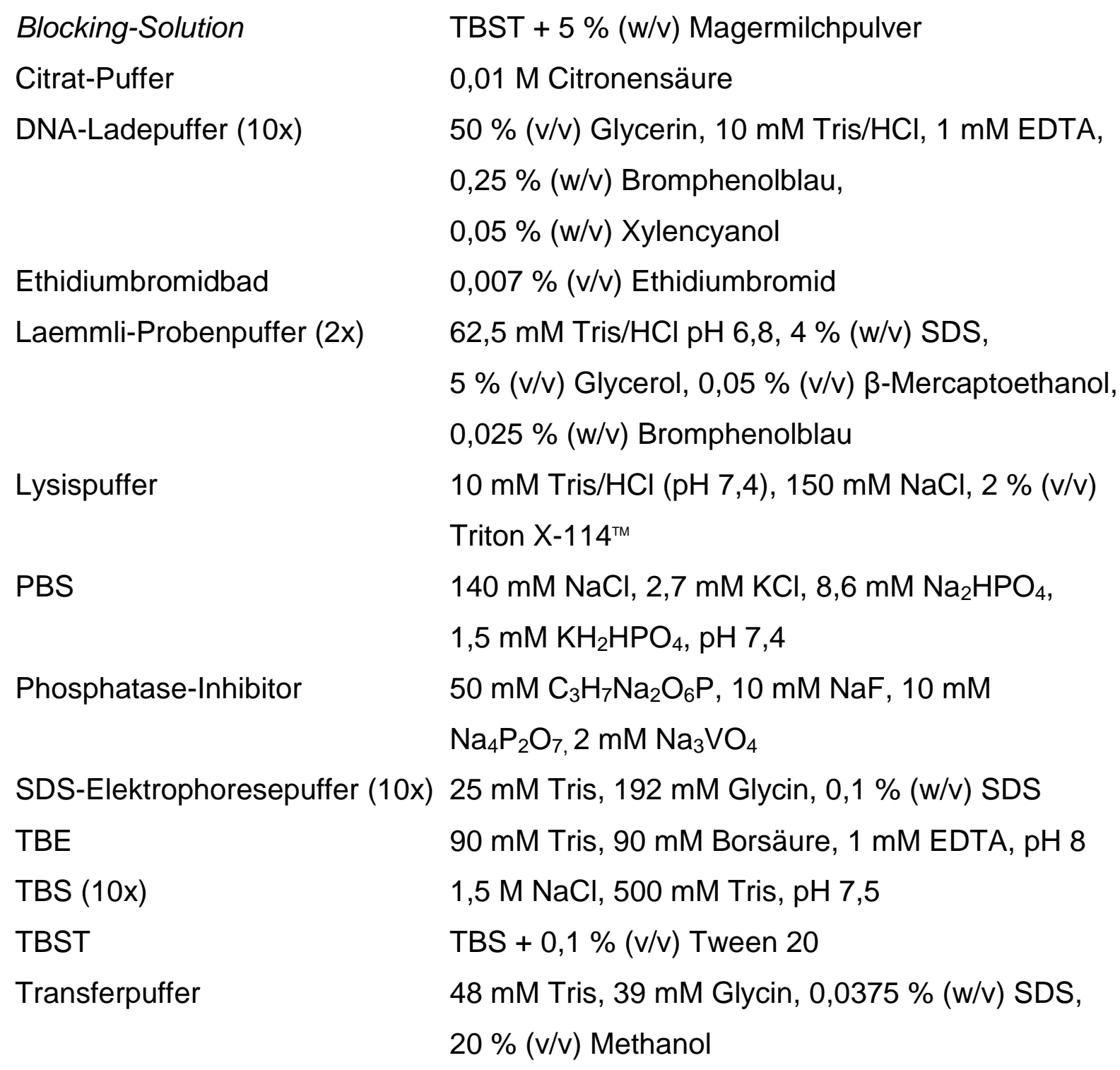

\subsubsection{Gewebeschnitte}

Die Gewebeschnitte dieser Arbeit wurden freundlicherweise von Herrn PD Dr. med. Stefan Schweyer aus dem Archiv des Pathologischen Instituts des Universitätsklinikums Göttingen zur Verfügung gestellt. Es handelte sich hierbei um in Paraffin eingebettetes Mammakarzinomgewebe von 98 Patientinnen (gemäß Ethikvotum 4/4/01: Durchführung von Grundlagenforschung an überschüssigem Tumormaterial und malignen Effusionen von gynäkologischen Malignomen inklusive des Mammakarzinoms). 


\subsubsection{Kultur- und Einfriermedien}

Die für die Zellkultur erforderlichen Medien und ihre Zusätze wurden von folgenden Firmen bezogen: Biochrom, Invitrogen, PAA und Sigma-Aldrich.

DMEM w/o Phenolrot

DMEM w/o Phenolrot

DMEM Kulturmedium w Phenolrot

MEM-Earl Kulturmedium w Phenolrot

Einfriermedium ohne Zusätze

$10 \%(v / v)$ CD-FCS, $1 \%(v / v) P / S$,

$1 \%(v / v)$ L-Gln

$10 \%(v / v)$ FCS, $1 \%(v / v) P / S$,

$1 \%(v / v)$ L-GIn

$10 \%$ (v/v) FCS, $1 \%$ (v/v) P/S, 50 IU Insulin $0,1 \%(\mathrm{v} / \mathrm{v})$ Transferrin

MEM-Earl Kulturmedium + $10 \%$ DMSO

\subsubsection{Zelllinien}

Die folgenden Zelllinien wurden von der American Type Culture Collection (ATCC) bezogen:

Tab. 2.1: In der Arbeit verwendete Zelllinien

\begin{tabular}{llll}
\hline Zelllinie & Herkunft & Histologie & Referenz \\
\hline MDA-MB-231 & Pleuraerguss & Adenokarzinom & Brinkley et al. (1980) \\
MCF-7 & Pleuraerguss & Adenokarzinom & Soule et al. (1973) \\
MG-63 & Primärtumor & Osteosarkom & Billiau et al. (1977) \\
\hline
\end{tabular}

\subsubsection{Oligonukleotide}

Die Oligonukleotide wurden von der Firma MWG Biotech AG synthetisiert.

CXCR4: for rev
5، - AGC TGT TGG TGA AAA GGT CTA TG - 3،

5' - GCG CTT CTG GTG GCC CTT GGA GTG TG - 3' 


$\begin{array}{lll}\text { SDF-1: } & \text { for } & 5^{\prime} \text { - CCG CGC TCT GCC TCA GCG ACG GGA AG - 3' } \\ & \text { rev } & 5^{\prime} \text { - CTT GTT TAA AGC TTT CTC CAG GTA CT - 3' } \\ \text { L7: } & \text { for } & \text { 5' - AGA TGT ACA GAA CTC AAA TTC - 3' } \\ & \text { rev } & 5^{\prime} \text { - ATT TAC CAA GAG ATC GAG CAA -3'}\end{array}$

2.1.11 Enzyme

SuperScript $^{\mathrm{TM}}$ II Reverse Transcriptase

Taq DNA Polymerase

Trypsin/EDTA $(0,05 \% / 0,02 \%$ in D-PBS)
Invitrogen

Roche

PAA

\subsubsection{Antikörper}

Die in dieser Arbeit verwendeten Antikörper wurden nach Angaben des Herstellers eingesetzt.

Tab. 2.2: Primärantikörper

\begin{tabular}{lll}
\hline Antikörper & Herkunft & Referenz \\
\hline Anti-Aktin & Kaninchen, monoklonal, 1:1000 & Epitomics \\
Anti-Akt & Kaninchen, polyklonal, 1:1000 & Cell Signaling \\
Anti-CXCR4 & Maus, monoklonal, 1:1000 & Abcam \\
Anti-GPR54 & Kaninchen, polyklonal, 1:10000 & Acris Antibodies \\
Anti-PhosphoAkt & Kaninchen, monoklonal, 1:1000 & Cell Signaling \\
Anti-SDF-1 & Ziege, polyklonal, 1:1000 & Abcam \\
\hline Tab. 2.3: Sekundärantikörper & & \\
\hline Antikörper & Herkunft & Referenz \\
\hline Anti-Goat lgG & Kaninchen, 1:80000 & Sigma \\
Anti-mouse lgG & Schaf, 1:10000 & ECL \\
Anti-rabbit lgG & Esel, 1:20000 & ECL $^{\text {TM }}$ \\
\hline
\end{tabular}




\subsubsection{Inhibitoren}

Protease-Inhibitor-Cocktail

Sigma Aldrich

RNasin ${ }^{\circledR}$ plus RNase Inhibitor

Promega

2.1.14 Transfektionsreagenzien

$\begin{array}{ll}\text { OPTI-MEM }^{\circledR} \text { I Reduced Serum Medium } & \text { Invitrogen } \\ \text { Oligofectamine }{ }^{\mathrm{TM}} \text { Reagent } & \text { Invitrogen } \\ \text { KISS1 Stealth RNAi }{ }^{\mathrm{TM}} \text { SiRNA } & \text { Invitrogen }\end{array}$

2.1.15 Kommerzielle Reaktionssysteme
ECL Immobilon ${ }^{\mathrm{TM}}$ Western
Millipore
Histostain ${ }^{\circledR}$ Bulk Kit
Invitrogen
RNeasy ${ }^{\circledR}$ Mini Kit
Qiagen

\subsubsection{Software}

Adobe Photoshop 7.0

Adobe Systems

Axio Vision 3.1

Carl Zeiss Vision $\mathrm{GmbH}$

Bio Doc Analyze 2.1 Software

Biometra

EndNote X2

Thomson

GraphPad Prism ${ }^{\circledR}$ (Version 5.00)

GraphPad Software Inc.

Microsoft ${ }^{\circledR}$ Office 2007

Microsoft Corporation 


\subsection{Methoden}

\subsubsection{Zellkultivierung}

\subsubsection{Kultivieren und Passagieren adhärenter Zellen}

Die verwendeten Zelllinien wurden in einer wasserdampfgesättigten Atmosphäre mit $5 \% \quad \mathrm{CO}_{2}$-Anteil bei $37^{\circ} \mathrm{C}$ in Zellkulturflaschen der Firma Nunc kultiviert. Als Nährmedium diente den Mammakarzinomzellen ein MEM-Earl Kulturmedium w Phenolrot und der Osteoblasten-ähnlichen Zelllinie MG-63 ein DMEM Kulturmedium w Phenolrot, welche alle zwei bis drei Tage erneuert wurden. In jeder Zellkulturflasche $\left(75 \mathrm{~cm}^{2}\right)$ befanden sich $10 \mathrm{ml}$ Nährmedium. Je nach Wachstumseigenschaften der Zellinien wurden die Zellen bei Erreichen einer 80 \%igen Konfluenz in regelmäßigen Abständen passagiert. Hierzu wurde zuerst das Medium mit einer Pasteurpipette abgesaugt und die Zellen mit $8 \mathrm{ml}$ PBS gewaschen. Anschließend wurden $2 \mathrm{ml}$ Trypsin/EDTA hinzugefügt und die Zellen bei $37^{\circ} \mathrm{C}$ für 10 $15 \mathrm{~min}$ inkubiert. Nach Ablösen der Zellen wurde die Reaktion mit $5 \mathrm{ml}$ des entsprechenden Zellkulturmediums abgestoppt und die Zellsuspension bei $300 \times \mathrm{g}$ und RT für 5 min abzentrifugiert. Das dadurch entstandene Zellpellet wurde mit $5 \mathrm{ml}$ des entsprechend der Zelllinien vorgesehenen Zellkulturmediums resuspendiert und je nach Bedarf rekultiviert, kryokonserviert oder für entsprechende Versuche verwendet.

\subsubsection{Kryokonservierung und Auftauen eukaryotischer Zellen}

Um die eukaryotischen Zellen für einen längeren Zeitraum zu lagern, ist es notwendig das Zellpellet mit $1 \mathrm{ml}$ des entsprechenden Zellkulturmediums zu resuspendieren. Im Anschluss werden $5 \%$ DMSO hinzugefügt. Die Zellen wurden zunächst bei $-80^{\circ} \mathrm{C}$ eingefroren und nach $12-24 \mathrm{~h}$ in flüssigem Stickstoff gelagert.

Bei Bedarf wurden die Zellen im Wasserbad bei $37^{\circ} \mathrm{C}$ für wenige min aufgetaut und bei $300 \times \mathrm{g}$ für 5 min abzentrifugiert. Das entstandene Zellpellet wurde in dem zugehörigen Kulturmedium resuspendiert und anschließend in Zellkulturflaschen überführt. Bevor die Zellen für Versuche verwendet wurden, waren diese für mindestens drei Tage kultiviert. 


\subsubsection{Zellzahlbestimmung}

Die Bestimmung der Zellzahl wurde mit Hilfe einer Neubauer-Zählkammer durchgeführt. Diese besteht aus neun Quadraten, welche jeweils eine Fläche von $1 \mathrm{~mm}^{2}$ und eine Tiefe von 0,1 mm besitzen. Somit besitzt jedes der Quadrate ein Volumen von 0,1 $\mu \mathrm{l}$. Mit Hilfe eines Lichtmikroskops werden die Zellen in den vier Eckquadraten ausgezählt, der Mittelwert errechnet und mit dem Faktor 10.000 multipliziert. Das Ergebnis spiegelt die Zellkonzentration pro Milliliter wider. Die Gesamtzellzahl ergibt sich aus dem Volumen der Zellsuspension mal der Zellzahl pro Milliliter.

\subsubsection{Migrationsassay}

Der Migrationsassay ist ein in vitro Modell der Metastasierung und wurde in unserer Abteilung entwickelt (von Alten et al. 2006). Die Methode ist in Abbildung 2.1 dargestellt.

A

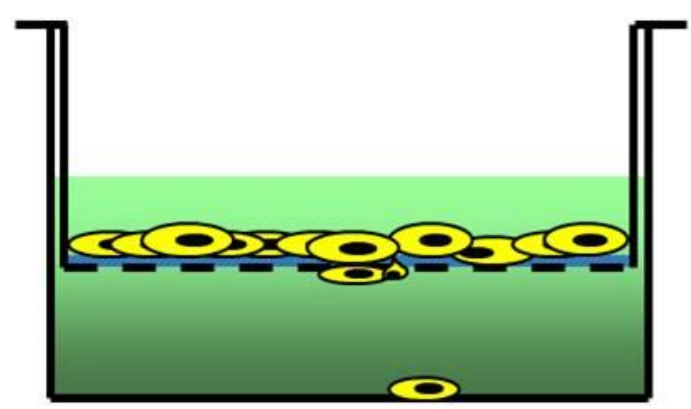

\section{MCF-7}

\section{Medium}

B

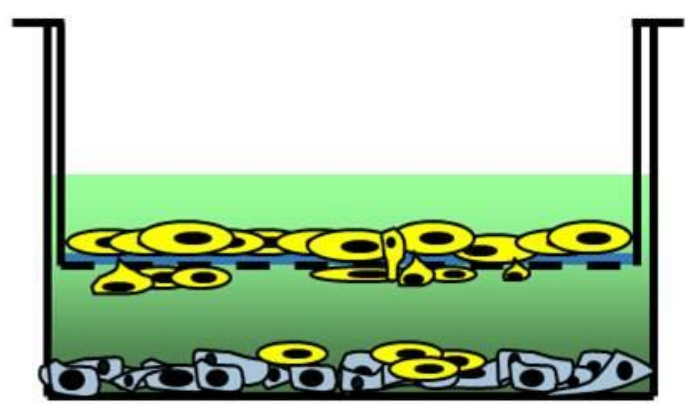

Abb. 2.1: Schematische Darstellung des Migrationsassays. Die MCF-7 Mammakarzinomzellen sind gelb dargestellt und werden auf Inserts ausgesät, die mit Matrigel beschichtet sind. In der Wellplatte befindet sich Medium (A). Unterhalb der auf dem Insert sitzenden Mammakarzinomzellen MCF-7 befindet sich blau dargestellt die Osteoblasten-ähnliche Zelllinie MG-63. Dies ist das in unserem Labor etablierte Kokultursystem (B).

Für die Aussaat der Zellen wurde eine 6- oder 24-Wellplatte mit den entsprechenden Inserts (Porendurchmesser: $8 \mu \mathrm{m}$ ) verwendet, die zuvor mit Matrigel beschichtet 
wurden. Die 6-Wellplatten wurden für die Gewinnung von RNA und Proteinen benötigt, die 24-Wellplatten dienten der mikroskopischen Auswertung der Migrationsassays.

Das Matrigel simuliert die Extrazellulärmatrix in vitro und wird mit DMEM w/o Phenolrot und ohne Zusätze im Verhältnis von 1:2 verdünnt. Je nach Größe der Wellplatte wurde die in Tabelle 2.4 angegebene Menge des verdünnten Matrigels auf die Inserts aufgetragen und für $30 \mathrm{~min}$ bei $37^{\circ} \mathrm{C}$ ausgehärtet.

Bei Erreichen einer Konfluenz von $80 \%$ wurden die Zellen wie in Kapitel 2.2.1.1 erläutert, abtrypsiniert, abzentrifugiert und sorgfältig mit DMEM w/o Phenolrot resuspendiert. Um die in Tabelle 2.5 aufgeführten Zellzahlen in die Wellplatten und Inserts auszusäen, wurde die Anzahl der Zellen in der jeweiligen Zellsuspension mit Hilfe der Neubauerzählkammer, wie in Kapitel 2.2.1.3 beschrieben, bestimmt. Zunächst wurden die MG-63 Zellen in die Wellplatten und die MCF-7 Zellen seperat in die Inserts ausgesät und anschließend für $12 \mathrm{~h}$ getrennt voneinander inkubiert. Danach wurden die Inserts in die Wellplatten überführt und die Zellen von diesem Zeitpunkt ( $\left.\mathrm{t}_{0}\right)$ an kokultiviert.

Tab. 2.4: Aufbereitung des Matrigels

Matrigel $[\mu l] \quad$ DMEM ohne Zusätze $[\mu l]$

6-Well Insert $106 \quad 106$

24-Well Insert $\quad 15 \quad 15$

Tab. 2.5: Anzahl der ausgesäten Zellen pro Insert oder Well

RNA-Gewinnung Protein-Gewinnung Mikroskopische Auswertung

6-Wellplatte (MG-63) $\quad 150.000 / 2 \mathrm{ml} \quad 207.000 / 2 \mathrm{ml}$

6-Well Insert (MCF-7) $\quad 290.000 / 1,5 \mathrm{ml} \quad 400.000 / 1,5 \mathrm{ml}$

24-Wellplatte (MG-63) - $\quad$ - 20.000/600 $\mu \mathrm{l}$

24-Well Insert (MCF-7, - - $\quad$ - $10.000 / 400 \mu l$ MDA-MB-231) 


\subsubsection{Behandlung mit Kisspeptin-10}

Die Behandlung der Mammakarzinomzellen mit Kisspeptin-10 erfolgte in unterschiedlichen Konzentrationen und zu unterschiedlichen Behandlungszeitpunkten. Die angegebenen Konzentrationen wurden in einer Verdünnungsreihe mit DMEM w/o Phenolrot hergestellt.

Migrationsassay:

Konzentration $[\mathrm{M}]: 1 \times 10^{-7}, 1 \times 10^{-8}, 1 \times 10^{-9}, 1 \times 10^{-10}, 1 \times 10^{-11}, 1 \times 10^{-12}, 1 \times 10^{-13}, 1 \times 10^{-14}$,

$$
1 \times 10^{-15}
$$

Behandlungszeitpunkte $[h]: t_{0}, t_{12}, t_{24}, t_{36}, t_{48}, t_{60}, t_{72}, t_{84}$

Versuchsendpunkt [h]: t96

RNA-Gewinnung:

Konzentration [M]: $1 \times 10^{-9}$

Behandlungszeitpunkte $[h]: t_{0}, t_{12}, t_{24}, t_{36}$

Versuchsendpunkte [h]: $\mathrm{t}_{24}, \mathrm{t}_{48}$

Protein-Gewinnung:

Konzentration [M]: $1 \times 10^{-7}, 1 \times 10^{-8}, 1 \times 10^{-9}, 1 \times 10^{-10}, 1 \times 10^{-11}, 1 \times 10^{-12}$

Behandlungszeitpunkte [h]: $\mathrm{t}_{0}, \mathrm{t}_{12}$

Versuchsendpunkt [h]: $\mathrm{t}_{24}$

\subsubsection{Behandlung mit einem SDF-1 Antikörper}

Die Behandlung der MG-63 Zellen mit einem SDF-1 Antikörper wurde über $96 \mathrm{~h}$ alle $24 \mathrm{~h}$ durchgeführt. Die Konzentration des Antikörpers von $1 \times 10^{-7} \mathrm{M}$ wurde in einer Verdünnungsreihe mit DMEM w/o Phenolrot hergestellt.

Migrationsassay:

Konzentration [M]: $1 \times 10^{-7}$

Behandlungszeitpunkte $[\mathrm{h}]: \mathrm{t}_{0}, \mathrm{t}_{24}, \mathrm{t}_{48}, \mathrm{t}_{72}$

Versuchsendpunkt [h]: t96 


\subsubsection{Transiente Transfektion adhärenter Zellen}

Die transiente Transfektion der Osteoblasten-ähnlichen Zelllinie MG-63 wurde mittels Oligofectamine $^{T M}$ gemäß den Angaben des Herstellers durchgeführt. Die kationischen Lipide bilden dabei mit der negativ geladenen DNA einen NukleinsäureLiposomen-Komplex, der im Anschluss mit der Plasmamembran von eukaryotischen Zellen fusionieren kann. Für die Transfektion wurde die KISS1 Stealth RNAi ${ }^{\mathrm{TM}}$ siRNA von Invitrogen verwendet.

Die Zellen wurden bei einer Konfluenz von $50 \%$ transfiziert und für $24 \mathrm{~h}$ im Transfektionsmedium kultiviert bevor die Migrationsassays durchgeführt wurden. Für den Transfektionsnachweis erfolgte eine immunzytochemische Färbung wie in Kapitel 2.2.4.4 beschrieben.

\subsubsection{Molekularbiologische Methoden}

\subsubsection{Gewinnung der RNA}

Für die RNA-Gewinnung wurden 6-Well-Platten verwendet. Die Behandlung mit Kisspeptin-10 erfolgte wie in Kapitel 2.2.1.5 dargestellt.

Für die Ernte der RNA wurde ein Gemisch aus $\beta$-Mercaptoethanol und RLT-Puffer im Verhältnis 1:100 angesetzt. Das Insert wurde vom Matrigel-Gemisch und den darauf kultivierten MCF-7 Zellen mit Hilfe eines Spatels abgetrennt und die Probe in das Mercaptoethanol-RLT-Gemisch überführt. Die MG-63 Zellen wurden direkt in der Wellplatte mit dem Gemisch inkubiert und nach Ablösung der Zellen ebenfalls überführt.

Die Isolierung der RNA wurde mit Hilfe des RNeasy ${ }^{\circledR}$ Mini Kits der Firma Qiagen durchgeführt. Hierbei wird die RNA spezifisch an eine Silika-Gel-Membran gebunden, durch mehrere Waschschritte gereinigt und anschließend eluiert. Die Aufarbeitung der Zellen erfolgte nach Angaben des Herstellers. Die anschließende Lagerung der Proben erfolgte bei $-80^{\circ} \mathrm{C}$. 


\subsubsection{Quantifizierung von Nukleinsäuren}

Die Quantifizierung der Nukleinsäuren wurde im UV-Photometer der Firma Eppendorf durchgeführt. Die Bestimmung der Konzentration erfolgt bei $\lambda=260 \mathrm{~nm}$ $\left(A_{260}\right)$, da Nukleinsäuren bei dieser Wellenlänge ihr Absorptionsmaximum besitzen. Proteine, die während der Aufbereitung als Verunreinigung auftreten, weisen ein Absorptionsmaximum bei $\lambda=280 \mathrm{~nm}\left(\mathrm{~A}_{280}\right)$ auf. Das Verhältnis der Extinktionen von $A_{260}$ zu $A_{280}$ spiegelt somit die Reinheit der Nukleinsäureprobe wider und sollte zwischen 1,8 und 2 liegen (Glasel 1995).

Tab. 2.6: Faktor zur Konzentrationsbestimmung von RNA

Umrechnungsfaktor $\quad$ RNA: $A_{260} 40 \mu \mathrm{g} / \mathrm{ml}$

\subsubsection{Reverse Transkription}

Die Reverse Transkription (RT) dient dazu RNA in einen komplementären DNAStrang (complementary DNA, cDNA) umzuschreiben, der das Ausgangsmaterial der Polyermase Kettenreaktion bildet.

Die Methode wurde von Veres et al. (1987) beschrieben und wird von RNAabhängigen DNA-Polymerasen durchgeführt. Die verwendeten Oligo-dt-Primer hybridisieren an den terminalen Poly A-Schwanz der RNA, von dem aus die cDNA enzymatisch synthetisiert wird.

Im ersten Reaktionsschritt wurde $1 \mu \mathrm{g}$ RNA mit $1 \mu$ I DNAse und $1 \mu$ l RNasin für 3 min bei $70^{\circ} \mathrm{C}$ inkubiert. Anschließend wurde der Enzym-Mix (Tab. 2.7) hinzugegeben und für $60 \mathrm{~min}$ bei $37^{\circ} \mathrm{C}$ inkubiert sowie für $5 \mathrm{~min}$ bei $90^{\circ} \mathrm{C}$ denaturiert. Die so entstandene cDNA wurde bei $-20^{\circ} \mathrm{C}$ gelagert. 
Tab. 2.7: Enzym-Mix für Reverse Transkription

\begin{tabular}{lcc}
\hline Material & Einsatz $[\mu \mathrm{l}]$ & Ausgangskonzentration \\
\hline RT-Puffer & 8 & $5 x$ \\
DTT & 4 & $0,1 \mathrm{M}$ \\
dNTPs & 4 & $0,01 \mathrm{M}$ \\
dt 15 Primer & 8 & \\
Superscript II & 2 & \\
\hline
\end{tabular}

\subsubsection{Polymerase Kettenreaktion}

Die Polymerase Kettenreaktion (polymerase chain reaction, PCR) ist ein Verfahren, mit dem DNA-Fragmente selektiv exponentiell amplifiziert werden (Mullis et al. 1986). Durch eine DNA-abhängige DNA-Polymerase wird anhand der Nukleinsäure-Matrize und ausgehend von DNA-Oligonukleotiden ein komplementärer DNA-Strang synthetisiert.

Die Denaturierung der doppelsträngigen DNA erfolgt bei $94^{\circ} \mathrm{C}$. Anschließend findet primerspezifisch das Annealing statt, welches das Anlagern der jeweiligen Primer an die cDNA beschreibt. Im weiteren Verlauf synthetisiert die DNA-Polymerase vom Primer ausgehend den komplementären Strang zur Matrize (Elongation). Die Elongation erfolgt bei $72^{\circ} \mathrm{C}$, dem Temperatur-Optimum der Taq-Polymerase (Saiki et al. 1988), die in dieser Arbeit als DNA-Polymerase eingesetzt wurde. Diese einzelnen Reaktionsschritte werden in Folge zyklisch wiederholt, sodass die Matrize exponentiell amplifiziert wird.

Zur Kontrolle der semiquantitativen PCR Methode dient die Amplifikation von L7, einem housekeeping gene. L7 ist ein ribosomales Protein, das in allen Geweben exprimiert wird. Der Standardreaktionsansatz ist in Tabelle 2.8 und die PCRProgramme der jeweiligen Gene sind in Tabelle 2.9 zusammengefasst. 
Tab. 2.8: Standard-Reaktionsansatz für die PCR

\begin{tabular}{lcl}
\hline Material & Einsatz $[\mu \mathrm{l}]$ & Ausgangskonzentration \\
\hline DEPC $\mathrm{H}_{2} \mathrm{O}$ & 10,5 & $20 \mu \mathrm{M}$ \\
Sense-Primer & 0,3 & $20 \mu \mathrm{M}$ \\
Antisense-Primer & 0,3 & $10 \mathrm{x}$ \\
Puffer & 1,5 & $1 \mathrm{mM}$ \\
dNTPs & 1,2 & $10-100 \mathrm{ng} / \mu \mathrm{l}$ \\
cDNA & 1,2 & $5 \mathrm{U} / \mu \mathrm{l}$ \\
Taq-Polymerase & 0,075 & \\
Gesamtvolumen & 15 & \\
\hline
\end{tabular}

Tab. 2.9: PCR-Programme: Temperatur und Zeit

\begin{tabular}{lcccc}
\hline Gen & Denaturierung & Annealing & Elongation & Zyklen \\
\hline CXCR4 & $30 \mathrm{sec}, 94^{\circ} \mathrm{C}$ & $30 \mathrm{sec}, 58^{\circ} \mathrm{C}$ & $60 \mathrm{sec}, 72^{\circ} \mathrm{C}$ & 24 \\
SDF-1 & $30 \mathrm{sec}, 94^{\circ} \mathrm{C}$ & $60 \mathrm{sec}, 64^{\circ} \mathrm{C}$ & $60 \mathrm{sec}, 72^{\circ} \mathrm{C}$ & 27 \\
$\mathrm{~L} 7(\mathrm{MG}-63)$ & $30 \mathrm{sec}, 94^{\circ} \mathrm{C}$ & $60 \mathrm{sec}, 54^{\circ} \mathrm{C}$ & $120 \mathrm{sec}, 72^{\circ} \mathrm{C}$ & 17 \\
$\mathrm{L7}(\mathrm{MCF}-7)$ & $30 \mathrm{sec}, 94^{\circ} \mathrm{C}$ & $60 \mathrm{sec}, 54^{\circ} \mathrm{C}$ & $60 \mathrm{sec}, 72^{\circ} \mathrm{C}$ & 18 \\
\hline
\end{tabular}

Die PCR-Produkte wurden anschließend über die Agarose-Gelelektrophorese aufgetrennt.

\subsubsection{Agarose-Gelelektrophorese}

Die Agarose-Gelelektrophorese bietet die Möglichkeit Nukleinsäuren anhand ihrer Größe aufzutrennen (McDonell et al. 1977). Dabei dient das Agarosegel als Sieb für die Nukleinsäuren. Je höher die Konzentration der Agarose, desto kleiner sind die Poren, die in diesem Gel entstehen. Durch das Anlegen einer Gleichspannung werden die negativ geladenen Nukleinsäuren aufgetrennt, wobei die kleineren Nukleinsäuren sich schneller durch das Gel bewegen können. Anschließend werden die Nukleinsäuren durch interkalierende und fluoreszierende Farbstoffe wie 
Ethidiumbromid nachgewiesen. Die Wellenlänge der UV-Strahlung zur Detektion liegt bei $\lambda=302 \mathrm{~nm}$.

Zur Herstellung der Gele wurden $6 \mathrm{~g}$ Agarose mit $400 \mathrm{ml}$ 1/2x TBE in der Mikrowelle aufgekocht und anschließend $30 \mathrm{ml}$ in die vorgesehene Gelkammer mit eingestecktem Kamm ohne Luftblasen gegossen. Nach Aushärtung des Gels wird die Kammer mit 1/2x TBE aufgefüllt und der Kamm gezogen. Je $10 \mu \mathrm{l}$ der Nukleinsäureproben wurden mit $2 \mu \mathrm{l}$ DNA-Ladepuffer gemischt und anschließend $10 \mu \mathrm{l}$ der Proben in die Geltaschen pipettiert. Als Größenstandard wurde ein DNAFragmentlängen-Standard (100 bp Ladder, Invitrogen) verwendet.

Anschließend laufen die Gele bei $85 \mathrm{~V}$ durchschnittlich $45 \mathrm{~min}$. Aufgrund der Farbbande des DNA-Ladepuffers ist eine Abschätzung der Laufstrecke möglich. Danach wurden die Gele für $20 \mathrm{~min}$ im Ethidiumbromidbad gefärbt, in $\mathrm{ddH}_{2} \mathrm{O}$ gewaschen und die Ergebnisse mit der Bio Doc Analyze 2.1 Software von Biometra festgehalten und ausgewertet.

\subsubsection{Proteinbiochemische Methoden}

\subsubsection{Gewinnung der Proteine}

Zunächst wurden entsprechend der RNA-Gewinnung die verwendeten Zelllinien wie in Kapitel 2.2.1.4 beschrieben in 6-Wellplatten ausgesät und $12 \mathrm{~h}$ später zu einem Kokultursystem zusammengefügt. Wie in Kapitel 2.2.1.5 dargestellt, erfolgte die Stimulation mit den unterschiedlichen Kisspeptin-10 Konzentrationen in einem Abstand von $12 \mathrm{~h}$ für insgesamt $24 \mathrm{~h}$.

Die Ernte der MCF-7 Zellen erfolgte mit Hilfe eines Spatels mitsamt dem Matrigel und anschließendem Lösen in PBS. Die Proben wurden bei $300 \mathrm{xg}$ für $5 \mathrm{~min}$ abzentrifugiert und sogleich in Stickstoff gefroren. Die Lagerung der Proben erfolgte bei $-80^{\circ} \mathrm{C}$.

Das SDF1-Protein wurde aus dem Überstand der MG-63 Zellen gewonnen, da es sich um ein sekretorisches Protein handelt. Dazu wurden die Überstände von drei unabhängig voneinander durchgeführten Experimenten gepoolt und bei $3000 \times \mathrm{g}$ für 90 min ultrazentrifugiert, um das Protein aufzukonzentrieren. Das Ultrazentrifugieren der Proben wurde mit Vivaspin-6 $\mathrm{ml}$ von Sartorius Biotech durchgeführt. Hierbei handelt es sich um Zentrifugenröhrchen mit 2 Kammern, die durch eine Membran 
getrennt sind. Diese Membran ist so konfiguriert, dass diese für alle Proteine $<5 \mathrm{kDa}$ durchlässig ist. Das SDF-1 Protein weist eine Größe von 10 kDa auf und kann somit in der oberen Kammer aufkonzentriert werden. Die Proben wurden bei $-80^{\circ} \mathrm{C}$ bis zur weiteren Verwendung gelagert.

\subsubsection{Aufbereitung der membranständigen und zytosolischen Proteine}

Zunächst wurden die Zellpellets für die Herstellung von Zelllysaten mit PBS gewaschen und bei $300 \times \mathrm{g}$ für 5 min zentrifugiert. Anschließend erfolgte die Resuspension der Zellpellets in Triton X-114 ${ }^{\mathrm{TM}}$-Puffer (Sigma-Aldrich) nach Bordier (1981) und die Zugabe eines Protease-Inhibitor-Cocktails (Sigma-Aldrich), um den Abbau der Proteine zu verhindern. Diese wurden bei $4^{\circ} \mathrm{C}$ über Nacht im Überkopfschüttler (Heto, Allered, DK) inkubiert. Am nächsten Tag erfolgte das Abtrennen unlöslicher Rückstände in der Kühlzentrifuge bei $12000 \times \mathrm{g}$ und $4^{\circ} \mathrm{C}$ für $25 \mathrm{~min}$. Im Anschluss wurde der Überstand abgenommen und für 10 min bei $37^{\circ} \mathrm{C}$ und $800 \mathrm{rpm}$ im Thermomixer inkubiert. Daraufhin folgte ein Zentrifugationsschritt für 5 min bei $10000 \times g$ und RT. Hierbei wurde das Zelllysat in zwei Phasen, die zytosolische (obere Phase) und membranständige (untere Phase) Proteinfraktion aufgetrennt. Durch Zugabe von fünf Volumenteilen Aceton wurde die benötigte Proteinfraktion über Nacht bei $-20^{\circ} \mathrm{C}$ gefällt. Es folgte ein Zentrifugationsschritt (25 min, $12000 \times \mathrm{g}, 4^{\circ} \mathrm{C}$ ). Der Überstand wurde verworfen und die gewonnenen Proteinpellets in der SDS-Polyacrylamid-Gelelektrophorese aufgetrennt.

\subsubsection{Aufbereitung des sekretorischen SDF-1 Proteins}

Für die Denaturierung des SDF-1 Proteins wurden die Proben im Thermomixer für $10 \mathrm{~min}$ bei $37^{\circ} \mathrm{C}$ und $800 \mathrm{rpm}$ inkubiert. Bis zur weiteren Verwendung erfolgte die Lagerung der Proben auf Eis. 


\subsubsection{SDS-Polyacrylamid-Gelelektrophorese}

Die SDS-Polyacrylamid-Gelelektrophorese (SDS-PAGE) ist eine Methode, welche Proteine nach ihrer Größe auftrennt. Das SDS (sodium dodecyl sulfate) ist ein anionisches Detergens, das an die Proteine bindet und diese somit eine negative Ladung erhalten.

Bei dem verwendeten Verfahren nach Laemmli werden die Proben in einem Sammelgel mit $5 \%$ Polyacrylamid (Tab. 2.10) konzentriert und danach im $10 \%$ igen oder 15 \%igen Trenngel (Tab. 2.11) separiert (Laemmli 1970). Für die SDS-Page wurde die Mini-PROTEAN III Electrophoresis Cell Apparatur von Bio-Rad verwendet und nach Angaben des Herstellers aufgebaut.

Tab. 2.10: 5 \%iges Sammelgel

\begin{tabular}{lc}
\hline Material & Einsatz \\
\hline $\mathrm{ddH}_{2} \mathrm{O}$ & $3,1 \mathrm{ml}$ \\
Prosieve 50 Gel Solution (Cambrex) & $0,5 \mathrm{ml}$ \\
$1,0 \mathrm{mM}$ Tris & $1,3 \mathrm{ml}$ \\
$10 \%$ SDS & $50 \mu \mathrm{l}$ \\
$10 \%$ APS & $50 \mu \mathrm{l}$ \\
TEMED & $4 \mu \mathrm{l}$ \\
\hline
\end{tabular}

Tab. 2.11: $10 \%$ iges und $15 \%$ iges Trenngel

\begin{tabular}{lcc}
\hline Material & $\mathbf{1 0} \%$ Trenngel & $\mathbf{1 5 \%}$ Trenngel (SDF-1) \\
\hline $\mathrm{ddH}_{2} \mathrm{O}$ & $5,3 \mathrm{ml}$ & $4,3 \mathrm{ml}$ \\
Prosieve 50 Gel Solution (Cambrex) & $2,0 \mathrm{ml}$ & $3 \mathrm{ml}$ \\
$1,0 \mathrm{mM}$ Tris & $2,5 \mathrm{ml}$ & $2,5 \mathrm{ml}$ \\
$10 \%$ SDS & $100 \mu \mathrm{l}$ & $100 \mu \mathrm{l}$ \\
$10 \%$ APS & $100 \mu \mathrm{l}$ & $100 \mu \mathrm{l}$ \\
TEMED & $4 \mu \mathrm{l}$ & $4 \mu \mathrm{l}$ \\
\hline
\end{tabular}


Das Sammelgel wurde in der ersten Geltasche mit einem Molekularmassenmarker (peqGOLD Protein Marker, Peqlab) beladen, in alle weiteren Geltaschen erfolgte das Auftragen der Proben. Vor dem Auftragen der Proben in die Geltaschen des Sammelgels wurden diese mit zweifach konzentriertem Laemmli-Probenpuffer versetzt.

Die Elektrophorese erfolgte zunächst bei $80 \mathrm{~V}_{\text {const }}$ für $30 \mathrm{~min}$ und im Anschluss bei $150 \mathrm{~V}_{\text {const }}$ für $60 \mathrm{~min}$ in SDS-Elektrophorese-Puffer.

Die aufgetrennten Proteine konnten nun im Western Blot Verfahren auf Nitrocellulose-Membranen transferiert und nachgewiesen werden.

\subsubsection{Western Blot}

Das Western Blot Verfahren dient dazu, die elektrophoretisch aufgetrennten Proteine auf eine Trägermembran zu übertragen und diese im Anschluss über spezifische Antikörper nachzuweisen (Towbin et al. 1979).

Die Apparaturvorrichtung (Bio-Rad) wurde laut den Angaben des Herstellers aufgebaut. Hierfür wurde das SDS-Gel auf die Nitrocellulosemembran (Hybond$\mathrm{ECL}^{\mathrm{TM}}$, Amersham Bioscience) luftblasenfrei aufgebracht und zwischen je zwei in Transferpuffer getränkte Filterpapiere (Whatman, Schleicher \& Schuell) gelegt. Beim Einspannen des Sandwiches zwischen zwei Schaumstoffschichten war zu beachten, dass die Nitrocellulosemembran der Anode zugewandt ist. Anschließend konnte der Transfer bei $100 \mathrm{~V}_{\text {const }}$ für $1 \mathrm{~h}$ durchgeführt werden. Als Transferkontrolle diente der vorgefärbte Molekularmassenmarker.

\subsubsection{Detektion und Visualisierung}

Nach dem Transfer erfolgte die Inkubation der Nitrocellulosemembran mit einer Blocking-Solution für $1 \mathrm{~h}$, um unspezifische Bindungsstellen abzusättigen. Im Anschluss wurde die Membran mit TBST für 15 min gewaschen. Dieser Waschgang wurde insgesamt viermal wiederholt. Danach erfolgte die Inkubation mit dem Primärantikörper über Nacht bei $4^{\circ} \mathrm{C}$. 
Im Folgenden wurde der oben genannte Waschgang wiederum viermal durchgeführt, um im Anschluss den Peroxidase-gekoppelten Sekundärantikörper für $1 \mathrm{~h}$ bei RT zu inkubieren.

Nach erneuter Durchführung der vier Waschgänge konnte nun die Detektion des gebundenen Sekundärantikörpers mittels ECL (enhanced chemiluminescens reaction, Immobilon ${ }^{\mathrm{TM}}$ Western, Millipore) erfolgen. Das ECL zeigt bei der katalytischen Umsetzung durch die Peroxidase eine Chemilumineszenz mit einem Maximum bei $\lambda=430 \mathrm{~nm}$, mit der Röntgenfilme (Kodak) belichtet werden können. Die Exposition erfolgte in einer Röntgenfilmkassette (X-Ray $\mathrm{GmbH}$ ) und der Film wurde anschließend in einer Dunkelkammer im X-Ray Film Prozessor SRS-101A entwickelt.

\subsubsection{Strippen von Nitrocellulosemembranen}

Um eine Nitrocellulosemembran erneut mit einem Primärantikörper zu hybridisieren, muss die Membran gestrippt werden. Dies bedeutet, dass die Membran von den schon gebundenen Antikörpern befreit wird. Der dazu benötigte Antibody Stripping Buffer wurde von der Firma Uptima Interchim bezogen. Die Membran wurde für $15 \mathrm{~min}$ bei RT und $1000 \mathrm{rpm}$ mit diesem Puffer inkubiert. Es folgte ein Waschvorgang mit $\mathrm{ddH}_{2} \mathrm{O}$ und anschließend konnte die Membran erneut geblockt und mit dem neuen Primärantikörper behandelt werden.

\subsubsection{Histologische Methoden}

\subsubsection{Anfertigung von Paraffinschnitten}

Die Paraffinschnitte wurden direkt aus dem Paraffinblock des fixierten Tumorgewebes mit einer Schnittdicke von $4 \mu \mathrm{m}$ am Rotations-Mikrotom (Slee Mainz) hergestellt. Daraufhin folgte die Streckung der Schnitte bei $37^{\circ} \mathrm{C}$ im Wasserbad und deren faltenfreie Auftragung auf einen Shandon Histoslide Objektträger (Thermo Scientific). Die Schnitte wurden im Anschluss über Nacht bei $42^{\circ} \mathrm{C}$ getrocknet. 


\subsubsection{Entparaffinierung/Rehydrierung von Paraffinschnitten}

Für die Entfernung sämtlicher Paraffinrückstände wurden die Schnitte bei $60^{\circ} \mathrm{C}$ für 30 min erwärmt. Dies ist zwingend erforderlich, da Paraffinrückstände die Hintergrundfärbung erhöhen. Das flüssige Paraffin konnte durch jeweils zweimaliges Waschen mit Xylol und Propanol entfernt werden. Die anschließende Rehydrierung der Schnitte wurde durch das Durchlaufen einer absteigenden Ethanolreihe (100\%, $90 \%, 80 \%, 70 \%$ ) erreicht. Die Inkubation erfolgte jeweils für 5 min.

\subsubsection{Immunfärbung der Gewebeschnitte}

Für die Immunfärbung musste zunächst die endogene Peroxidase blockiert werden. Hierfür wurden die Schnitte mit einer 3 \%igen $\mathrm{H}_{2} \mathrm{O}_{2}$ Lösung in $\mathrm{ddH}_{2} \mathrm{O}$ für 20-30 min inkubiert. Anschließend wurden die Schnitte dreimal in $\mathrm{ddH}_{2} \mathrm{O}$ gewaschen und in Citratpuffer für $5 \mathrm{~min}$ in der Mikrowelle $(600 \mathrm{~W})$ aufgekocht. Damit wird eine Demaskierung der Antigene erreicht.

Die Immunfärbung wurde mit Hilfe des Histostain ${ }^{\circledR}$ Bulk Kit der Firma Invitrogen nach Angaben des Herstellers durchgeführt. Die Inkubation des primären Antikörpers erfolgte über Nacht in einer feuchten Kammer bei $4^{\circ} \mathrm{C}$. Als Chromogen diente die gebrauchsfertige AEC + High Sensitivity Substrate Chromogen-Lösung der Firma Dako, die auf die Schnitte aufgebracht wurde. Nach 10 min wurden die Schnitte mit $\mathrm{ddH}_{2} \mathrm{O}$ gespült, mit Hämalaun gegengefärbt und mit Aquatex ${ }^{\circledR}$ der Firma Merck wässrig eingedeckt.

\subsubsection{Immunfärbung der Zelllinien}

Die Zellen wurden auf einen Objektträger (Lab-Tek ${ }^{\mathrm{TM}}$ Chamber Slides ${ }^{\mathrm{TM}}$ Systeme, Nunc) mit einer Konfluenz von $70 \%$ ausgesät und über $24 \mathrm{~h}$ inkubiert. Für die immunzytochemische Färbung wurde der Histostain ${ }^{\circledR}$ Bulk Kit der Firma Invitrogen nach Angaben des Herstellers verwendet. Die Inkubation mit dem entsprechenden Primärantikörper wurde bei $4^{\circ} \mathrm{C}$ über Nacht durchgeführt. Die Detektion erfolgte ebenfalls mit der AEC + High Sensitivity Substrate Chromogen-Lösung der Firma Dako. Nach einer Einwirkungszeit von $30 \mathrm{~min}$ ohne Lichtzufuhr, folgte ein 
Waschvorgang mit Aqua dest. Daraufhin folgte der Färbevorgang mit der HämalaunLösung für $30 \mathrm{sec}$. Durch Leitungswasser wurden die Proben gebläut. Das Eindecken erfolgte mit Aquatex ${ }^{\circledR}$ der Firma Merck.

\subsubsection{Auswertung der Migrationsassays}

Für die Auswertung der Migrationsassays wurde wie in Kapitel 2.2.1.4 beschrieben ein Migrationsassay in einer 24-Wellplatte angesetzt. Nach getrennter Inkubationszeit der Zellen von $12 \mathrm{~h}$ wurden diese zum Zeitpunkt $t_{0}$ in das Kokultursystem überführt und über insgesamt $96 \mathrm{~h}$ alle $12 \mathrm{~h}$ mit den in Kapitel 2.2.1.5 dargestellten Kisspeptin-10 Konzentrationen stimuliert.

Nach Beendigung des Versuches wurden die Mammakarzinomzellen oberhalb und unterhalb des Filters mit Methanol fixiert und mit Mayers Hämalaunlösung in mehreren Schritten angefärbt (Tab. 2.12.). Anschließend wurden die Mammakarzinomzellen mitsamt dem Matrigel oberhalb des Filters abgeschabt und die Filter vom Insert herausgelöst. Die gefärbten Filter wurden mit Kaisers Glyceringelatine auf einem Objekträger eingedeckelt. Die Auswertung der invadierten Mammakarzinomzellen (alle Zellen, die sich unterhalb des Filters befanden) erfolgte am Mikroskop IX 51, Olympus und mit der Software Axion Vision 3.1, Carl Zeiss Vision $\mathrm{GmbH}$. Hierbei wurden die Filter abfotografiert und die einzelnen Zellen ausgezählt.

Tab. 2.12: Hämalaunfärbung

\begin{tabular}{lcc}
\hline Ablauf & Zeit [min] & Menge [ml] \\
\hline PBS Waschschritt & 5 & 1 \\
Spülung mit Aqua dest. & 1 \\
Fixierung mit Methanol 100\% & $10-15$ & 1 \\
Spülung mit Aqua dest & $5-10$ & 1 \\
Hämalaunlösung & & 1 \\
Spülung mit Aqua dest & 1 \\
Bläuung mit Leitungswasser & & 1 \\
Spülung mit Aqua dest & & \\
\hline
\end{tabular}




\subsubsection{Dokumentation und statistische Analysen}

Zur mikroskopischen Analyse der Gewebeschnitte stand das Mikroskop BH-2 der Firma Olympus zur Verfügung. Die mikroskopische Auswertung und die Aufnahmen der Migrationsassays erfolgten mit Hilfe des Mikroskop IX51 der Firma Olympus, die Auszählung der Zellen wurde durch die Axio Vision 3.1. Software erleichtert.

Die Dokumentation und Analyse der Western Blots wurde mit der Software Bio Doc Analyze 2.1 von Biometra durchgeführt. Mit Hilfe des UV-Transilluminators von Biometra und der Software Bio Doc Analyze 2.1 erfolgten die Dokumentation sowie die Auswertung der Agarosegele. Die Daten wurden aus mindestens drei unabhängig voneinander wiederholten Versuchen gewonnen. Zur statistischen Auswertung und graphischen Darstellung der Ergebnisse diente die Software GraphPad Prism $^{\circledR}$ (Version 5.00). Als statistische Tests wurden der one-way ANOVA, gefolgt vom Student-Newman-Keuls Test oder der t-Test (gepaart) angewendet. 


\section{ERGEBNISSE}

\subsection{Nachweis des Kisspeptinrezeptors GPR54}

\subsubsection{GPR54 Expression in humanem Mammakarzinomgewebe}

Um den Nachweis zu erbringen, dass in humanem Mammakarzinomgewebe der GPR54 exprimiert wird, wurden 98 Mammakarzinome mit unterschiedlichem Rezeptorstatus untersucht. Die Einteilung der Karzinome anhand ihres Hormon- und HER2/neu-Rezeptorstatus erfolgte durch die zuständigen Pathologen aus der Abteilung der Pathologie des Universitätsklinikums Göttingen.

Zunächst wurde die Einteilung der histopathologischen Tumorschnitte in Schnitte mit sichtbarer Tumorfront und Schnitte, in denen keine Tumorfront erkennbar war vorgenommen. In der Gruppe, die Tumorfronten aufwiesen, wurde nur die Tumorfront selbst auf die Expression des GPR54 untersucht. In den restlichen Tumorschnitten erfolgte die prozentuale Auswertung der GPR54 Expression im gesamten Tumorgewebe.

Es zeigte sich an den Tumorschnitten mit angeschnittener Tumorfront folgende GPR54 Expression: Die triple negativen Tumoren (Östrogenrezeptor negativ, Progesteronrezeptor negativ, HER2/neu-Rezeptor negativ) zeigten in $50 \%$ der untersuchten Fälle eine GPR54 Expression von über $80 \%$ und in den anderen $50 \%$ der Fälle eine Rezeptorexpression von 50-80\%. In der Gruppe der Östrogen- und Progesteronrezeptor negativen aber HER2/neu-Rezeptor positiven Tumoren waren $100 \%$ der Tumoren GPR54-positiv. Bei Tumoren, die als Östrogenrezeptor-positiv, Progesteronrezeptor-negativ und HER2/neu-Rezeptor-positiv klassifiziert wurden, zeigten $50 \%$ der Fälle eine über $80 \%$ ige GPR54 Expression und die anderen $50 \%$ eine GPR54 Expression von 10-49\%. Östrogenrezeptor positive, aber Progesteronund HER2/neu-Rezeptor negative Gewebeschnitte wiesen eine über $80 \%$ ige GPR54 Expression an der Tumorfront in $100 \%$ der Gewebeproben auf. In der Gruppe der Östrogen- und Progesteronrezeptor positiven aber HER2/neu-Rezeptor negativen Tumorschnitte zeigte sich, dass $50 \%$ der Schnitte an der Tumorfront zu über $80 \%$ GPR54-positiv waren. In weiteren 38,9\% der Schnitte war eine 50-80\%ige und in den restlichen 11,1\% eine 10-49\%ige GPR54 Expression nachweisbar. Bei den Östrogen-, Progesteron- und HER2/neu-Rezeptor positiven Tumorschnitten zeigte 
sich in $100 \%$ der Fälle an der Tumorfront eine GPR54 Expression von über $80 \%$. In Tabelle 3.1 ist die GPR54 Expression an der Tumorfront in humanem Mammakarzinomgewebe mit unterschiedlichem Östrogen-, Progesteron- und HER2/neu-Rezeptorstatus zusammengefasst.

Tab. 3.1: GPR54 Expression an der Tumorfront in humanem Mammakarzinomgewebe

\begin{tabular}{|c|c|c|c|c|c|c|}
\hline \multicolumn{3}{|c|}{ Rezeptorstatus } & \multicolumn{4}{|c|}{ GPR54 Expression [\%] } \\
\hline Östrogen & Progesteron & HER2/neu & $>80$ & $50-80$ & $10-49$ & $<10$ \\
\hline negativ & negativ & negativ & 50 & 50 & 0 & 0 \\
\hline negativ & negativ & positiv & 100 & 0 & 0 & 0 \\
\hline positiv & negativ & positiv & 50 & 0 & 50 & 0 \\
\hline positiv & negativ & negativ & 100 & 0 & 0 & 0 \\
\hline positiv & positiv & negativ & 50 & 38,9 & 11,1 & 0 \\
\hline positiv & positiv & positiv & 100 & 0 & 0 & 0 \\
\hline
\end{tabular}

Für Tumorschnitte, in der keine Tumorfront angeschnitten war, wurde folgende prozentuale GPR54 Expression nachgewiesen:

In der Gruppe der triple negativen Mammakarzinome (Östrogen-, Progesteron- und HER2/neu-Rezeptor-negativ) waren 7,1\% über $80 \%$ GPR54-positiv und 29,6\% hatten eine GPR54 Expression von 50-80\%. Eine GPR54 Expression von 10-49\% zeigten 29,6\% der triple negativen Karzinome, 35,7\% wiesen eine GPR54 Expression von unter $10 \%$ auf. 28,6\% der Mammakarzinome, die Östrogen- und Progesteronrezeptor-negativ aber HER2/neu-Rezeptor-positiv waren, zeigten eine GPR54 Expression von über $80 \%$, die restlichen $71,4 \%$ dieser Mammakarzinome wiesen eine 50-80\%ige GPR54 Expression auf. 11,1\% der Mammakarzinome, die Östrogenrezeptor-positiv aber Progesteron- und HER2/neu-Rezeptor negativ waren, zeigten eine über $80 \%$ ige Expression des GPR54, eine 50-80\%ige GPR54 Expression wiesen 44, $4 \%$ der Karzinome auf. Weiterhin waren aus dieser Gruppe 33,3 \% der Mammakarzinome zu 10-49 \% GPR54-positiv und 11,1\% zeigten eine GPR54 Expression von unter 10\%. In der Gruppe der Östrogen- und Progesteronrezeptor-positiven aber HER2/neu-Rezeptor-negativen Mammakarzi- 
nome zeigten sich 9,1\% zu über $80 \%$ GPR54-positiv, 39,4 \% wiesen eine GPR54 Expression von 50-80 \% auf, $3 \%$ waren zu 10-49 \% GPR54-positiv und 48,9 \% der Karzinome zeigten eine GPR54 Expression von unter $10 \%$. $20 \%$ der Mammakarzinome, die sowohl für den Östrogen-, Progesteron- und HER2/neuRezeptor-positiv waren, zeigten eine über 80 \%ige GPR54 Expression. In dieser Gruppe waren weitere $20 \%$ der Karzinome zu 10-49\% GPR54-positiv und die restlichen $60 \%$ wiesen eine GPR54 Expression von unter $10 \%$ auf. Die Tabelle 3.2 zeigt die GPR54 Expression in humanem Mammakarzinomgewebe.

Tab. 3.2: GPR54 Expression in humanem Mammakarzinomgewebe ohne angeschnittene Tumorfront

\begin{tabular}{|c|c|c|c|c|c|c|c|}
\hline \multicolumn{3}{|c|}{ Rezeptorstatus } & \multicolumn{4}{|c|}{ GPR54 Expression [\%] } & \\
\hline Östrogen & Progesteron & HER2/neu & $>80$ & $50-80$ & $10-49$ & $<10$ & \\
\hline negativ & negativ & negativ & 7,1 & 29,6 & 29,6 & 35,7 & $\stackrel{\oplus}{\varepsilon}$ \\
\hline negativ & negativ & positiv & 28,6 & 71,4 & 0 & 0 & $\stackrel{N}{N}$ \\
\hline positiv & negativ & negativ & 11,1 & 44,4 & 33,3 & 11,1 & $E$ \\
\hline positiv & positiv & negativ & 9,1 & 39,4 & 3 & 48,9 & 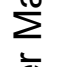 \\
\hline positiv & positiv & positiv & 20 & 0 & 20 & 40 & 우 \\
\hline
\end{tabular}

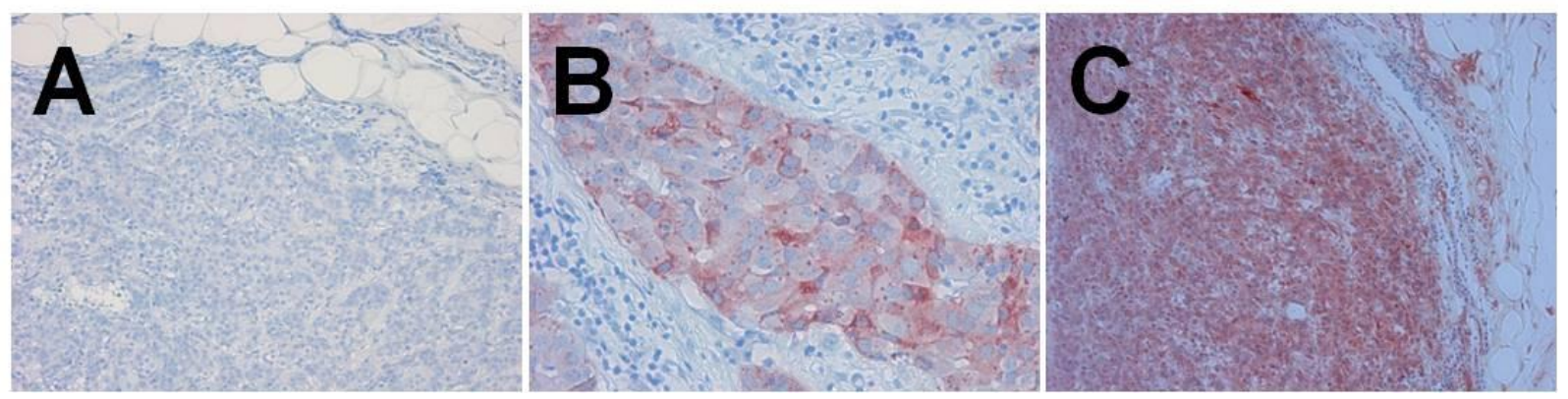

Abb. 3.1: Immunhistochemischer Nachweis des GPR54 in humanem Mammakarzinomgewebe. Nach Aufarbeitung der Tumorgewebe und anschließender immunhistochemischer Färbung mit dem GPR54 Antikörper zeigten die Karzinome eine unterschiedliche GPR54 Expression. Exemplarisch handelt es sich in der Abbildung um Östrogen- und Progesteronrezeptor positive aber HER2/neu Rezeptor negative Mammakarzinome, die einerseits für den Kisspeptinrezeptor GPR54-negativ (A) und andererseits zu über 80 \% GPR54-positiv sind (B und C). 
3.1.2 GPR54 Expression in den humanen Mammakarzinomzellinien MCF7 und MDA-MB-231 sowie in der Osteoblasten-ähnlichen Zellinie MG-63

Für die in vitro Experimente wurde zunächst der Nachweis erbracht, dass die in dieser Arbeit verwendeten Zelllinien (MCF-7, MDA-MB-231 und MG-63) für den Kisspeptin-10 Rezeptor GPR54-positiv sind. Dies erfolgte mit Hilfe einer immunzytochemischen Färbung, in welcher der Primärantikörper gegen GPR54 gerichtet war. Die Mammakarzinomzellinien MCF-7 und MDA-MB-231 sowie die Osteoblasten-ähnliche Zelllinie MG-63 zeigten eine hohe GPR54 Proteinexpression (Abbildung 3.2).
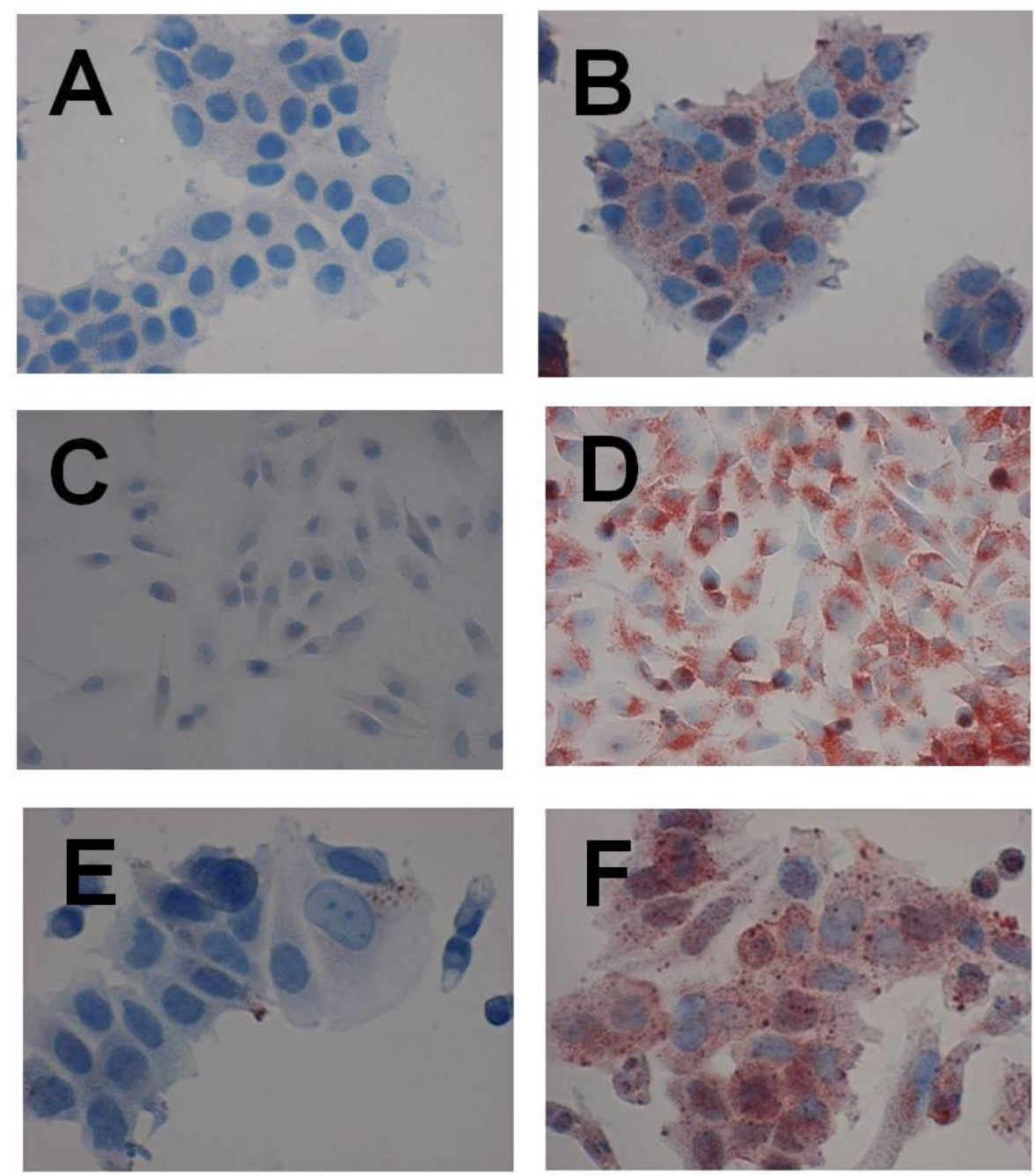

Abb. 3.2: Immunzytochemischer Nachweis von GPR54 in den Mammakarzinomzelllinien MCF-7 und MDA-MB-231 sowie in der Osteoblasten-ähnlichen Zelllinie MG-63. Die Rezeptor-positiven MCF-7 Zellen (B) sind ebenso wie die Rezeptor-positiven MDA-MB-231 Zellen (D) sowie die Rezeptor-positiven MG-63 Zellen (F) durch ihre rötliche Färbung im Vergleich zur Kontrolle (MCF-7 Zellen (A), MDA-MB-231 Zellen (C) und MG-63 Zellen (E)), in der die Zellen ohne Primärantikörpern inkubiert wurden, deutlich zu erkennen. 


\subsection{Inhibition der Migrations- und Invasionsfähigkeit von Mammakarzinomzellen durch Kisspeptin-10}

In vorangegangenen Arbeiten zeigte sich, dass Kisspeptin-10 tatsächlich einen hemmenden Einfluss auf die Migrations- und Invasionsfähigkeit der mit humanem Osteoblastenüberstand kokultivierten MCF-7 Mammakarzinomzellen besitzt (Daten nicht publiziert). Aufgrund dieser Ergebnisse sollte zunächst das Konzentrationsspektrum bestimmt werden, in dem Kisspeptin-10 seine stärkste Wirkung entfaltet. In mindestens drei voneinander unabhängig durchgeführten Versuchen pro Konzentration wurden in den Migrationsassays folgende Ergebnisse erhoben.

3.2.1 Inhibition der Migrations- und Invasionsfähigkeit der Mammakarzinomzellinie MCF-7 durch Kisspeptin-10

Bei Kokultivierung der Mammakarzinomzelllinie MCF-7 mit der Osteoblastenähnlichen Zelllinie MG-63 über 96 h zeigte sich ein signifikanter Anstieg (KK = 1375,0 $\pm 94,3 \% ; \mathrm{p}<0,001)$ der invadierten MCF-7 Zellen im Vergleich zur Kontrolle ( $\mathrm{K}=$ $100 \%$ ) (Abb. 3.3 A und B, Abb. 3.4).
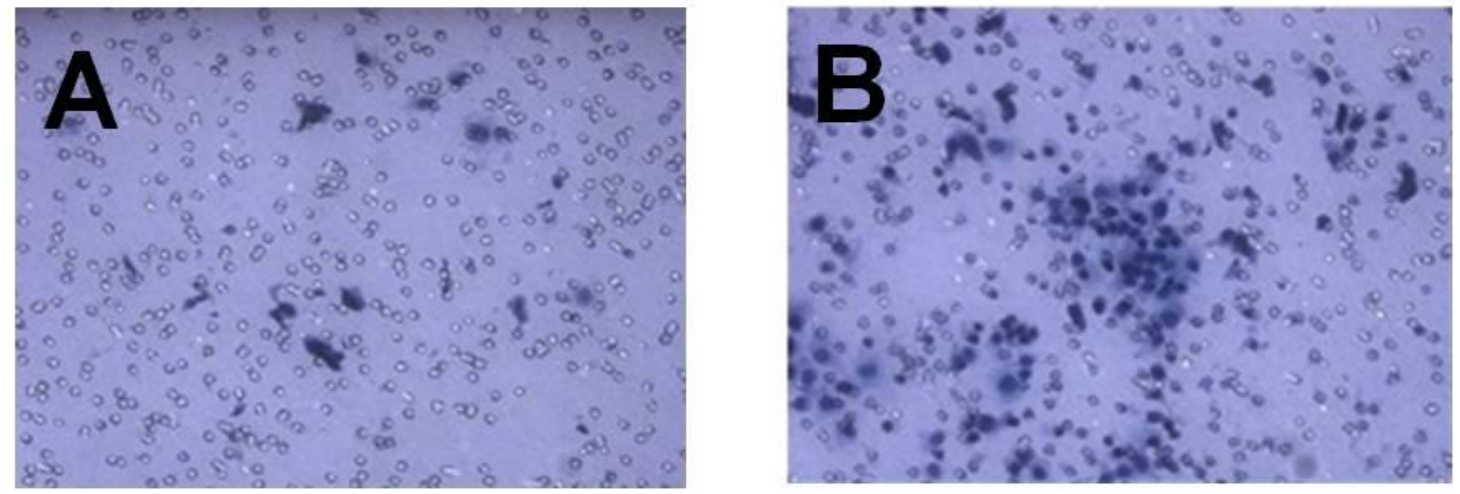

Abb. 3.3: Invasion von MCF-7 Zellen ohne und während der Kokultur mit MG-63 Zellen (Hämalaunfärbung). Die Kokultivierung der Zellen erfolgte über $96 \mathrm{~h}$. Monokultivierte MCF-7 Mammakarzinomzellen über Medium zeigten ein weniger starkes Invasionsvermögen (A) als kokultivierte MCF-7 Mammakarzinomzellen über MG-63 Zellen (B). 


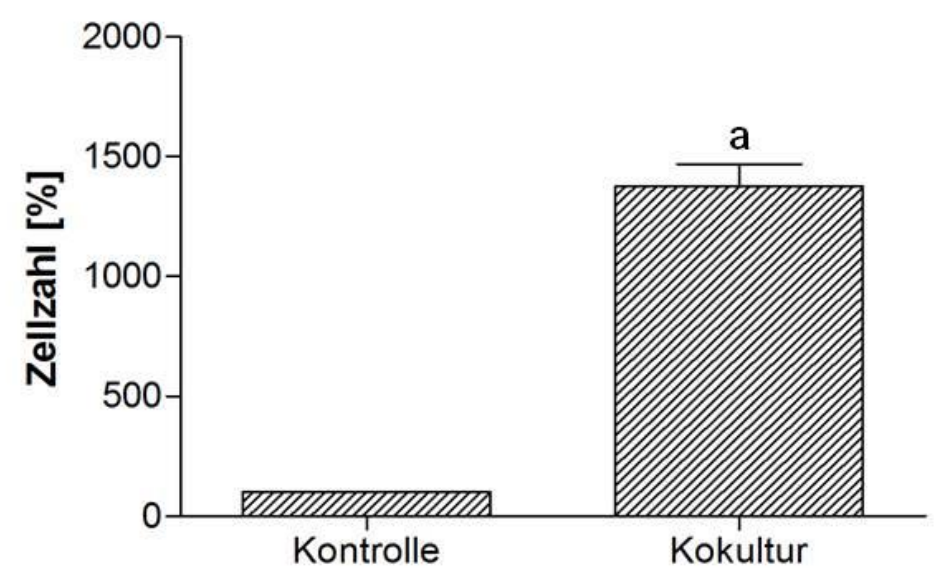

Abb. 3.4: Invasionsverhalten von monokultivierten und kokultivierten MCF-7 Mammakarzinomzellen. In der Kontrolle wurden die MCF-7 Zellen mit Medium kultiviert und in der Kokultur mit der Osteoblasten-ähnlichen Zelllinie MG-63 kokultiviert. Es zeigte sich ein signifikanter Anstieg der invadierten Mammakarzinomzellen während der Kokultur im Vergleich zur Kontrolle. Angegeben sind MW \pm SEM, die Daten wurden mittels t-Test (gepaart) auf signifikante Unterschiede geprüft: $a, p<0,001$ vs. Kontrolle.

Weiterhin zeigte sich, dass die Migrations- und Invasionsfähigkeit der MCF-7 Zellen bei einer Behandlung mit bestimmten Kisspeptin-10 Konzentrationen, die über einen Zeitraum von $96 \mathrm{~h}$ alle $12 \mathrm{~h}$ durchgeführt wurde, im Vergleich zur Kokultur (KK = $100 \%)$ signifikant gehemmt wird $\left(1 \times 10^{-15} \mathrm{M}: 99,5 \pm 8,5 \%\right.$ (n.s. vs. Kokultur), $1 \times 10^{-}$ ${ }^{14} \mathrm{M}: 91,6 \pm 8,5 \%$ (n.s. vs. Kokultur); $1 \times 10^{-13} \mathrm{M}: 97,0 \pm 18,1 \%$ (n.s. vs. Kokultur); $1 \times 10^{-12} \mathrm{M}: 85,7 \pm 12,5 \%$ (n.s. vs. Kokultur); $1 \times 10^{-11} \mathrm{M}: 63,9 \pm 6,3 \%(\mathrm{p}<0,05$ vs. Kokultur); $1 \times 10^{-10} \mathrm{M}: 60,4 \pm 6,9 \%$ ( $\mathrm{p}<0,05$ vs. Kokultur); $1 \times 10^{-9} \mathrm{M}: 62,7 \pm 6,9 \%$ ( $\mathrm{p}<0,05$ vs. Kokultur); $1 \times 10^{-8} \mathrm{M}: 84,9 \pm 10,2 \%$ (n.s. vs. Kokultur); $1 \times 10^{-7} \mathrm{M}: 108,0 \pm$ $14,6 \%$ (n.s. vs. Kokultur)). Das Konzentrationsspektrum, in dem dieses Phänomen zu beobachten war, befand sich bei $1 \times 10^{-11} \mathrm{M}$ bis $1 \times 10^{-9} \mathrm{M}$ (Abbildung $3.5 \mathrm{~B}$ und $\mathrm{C}$, Abbildung 3.6). Es handelt sich dabei um einen Fenstereffekt, da Kisspeptin-10 nur in diesem bestimmten Bereich seine hemmende Wirkung auf die Migration und Invasion entfaltet. 

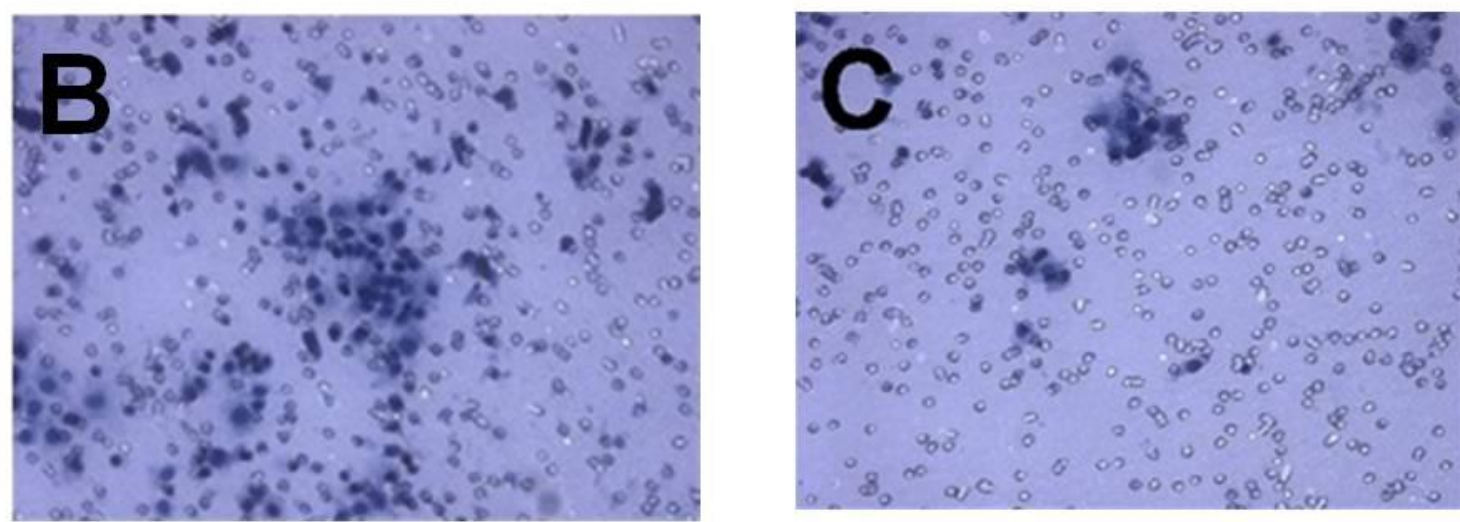

Abb. 3.5: Hemmung der Invasionsfähigkeit von kokultivierten MCF-7 Zellen durch Kisspeptin-10 (Hämalaunfärbung). Die Kokultivierung der Zellen erfolgte über $96 \mathrm{~h}$. Bei einer Behandlung der MCF-7 Zellen mit Kisspeptin-10 (1x10-9 M) alle $12 \mathrm{~h}$ (C) war eine Reduzierung der Anzahl der invadierten Mammakarzinomzellen im Vergleich zur unbehandelten Kokultur (B) deutlich zu beobachten.

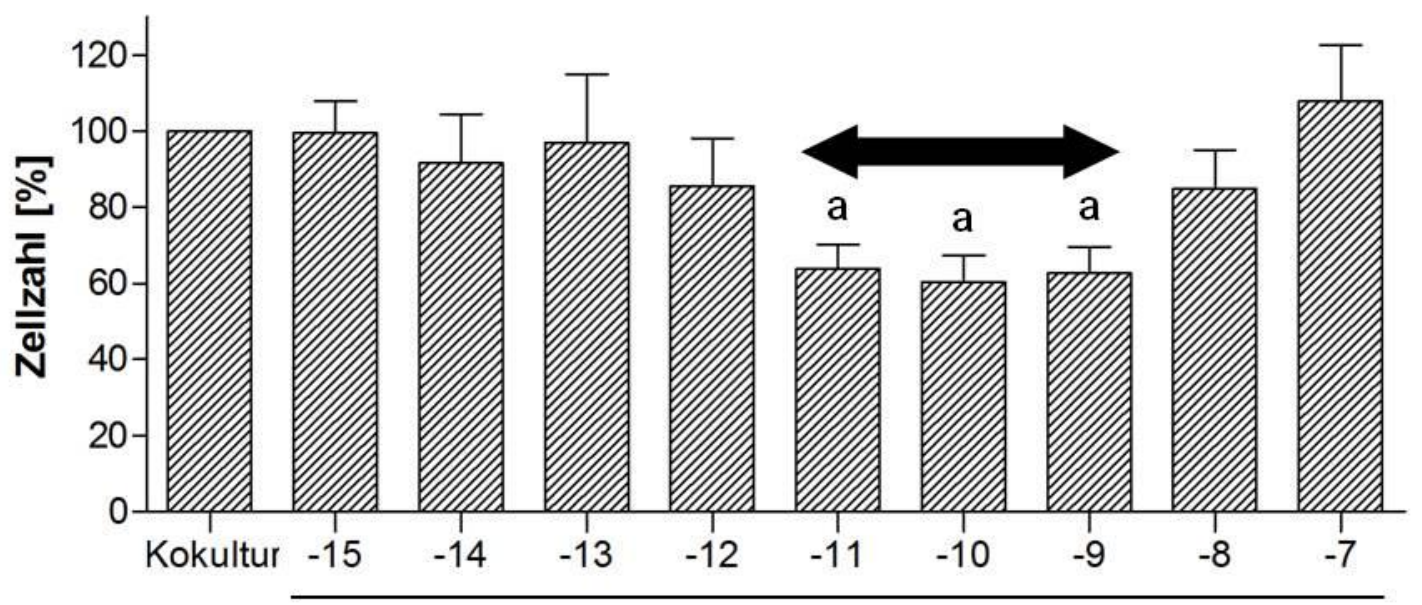

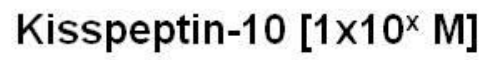

Abb. 3.6: Effekte von Kisspeptin-10 auf das Migrations- und Invasionsverhalten kokultivierter MCF-7 Mammakarzinomzellen. Die dosisabhängige Behandlung der kokultivierten Mammakarzinomzellen mit Kisspeptin-10 wurde alle $12 \mathrm{~h}$ über $96 \mathrm{~h}$ durchgeführt. Eine signifikante Hemmung zeigte sich in einem Konzentrationsbereich von $1 \times 10^{-11} \mathrm{M}$ bis $1 \times 10^{-9} \mathrm{M}$. Hierbei handelt es sich um einen Fenstereffekt, da Kisspeptin-10 nur in diesem Konzentrationsbereich die hemmende Wirkung entfaltet. Angegeben sind MW \pm SEM, die Daten wurden mittels one-way Analysis of Variance (ANOVA) gefolgt vom Student-Newman-Keuls Test auf signifikante Unterschiede geprüft: $a, p<0,05$ vs. Kokultur.

\subsubsection{Inhibition der Migrations- und Invasionsfähigkeit der Mamma- karzinomzellinie MDA-MB-231 durch Kisspeptin-10}

Die Mammakarzinomzellinie MDA-MB-231 zeigte während der Kokultur mit der Osteoblasten-ähnlichen Zelllinie MG-63 über $96 \mathrm{~h}$ ebenfalls ein signifikant erhöhtes Migrations- und Invasionsverhalten ( $K K=388,1 \pm 59,0 \% ; p<0,001)$ im Vergleich zur Kontrolle (K=100\%) (Abb. 3.7). 


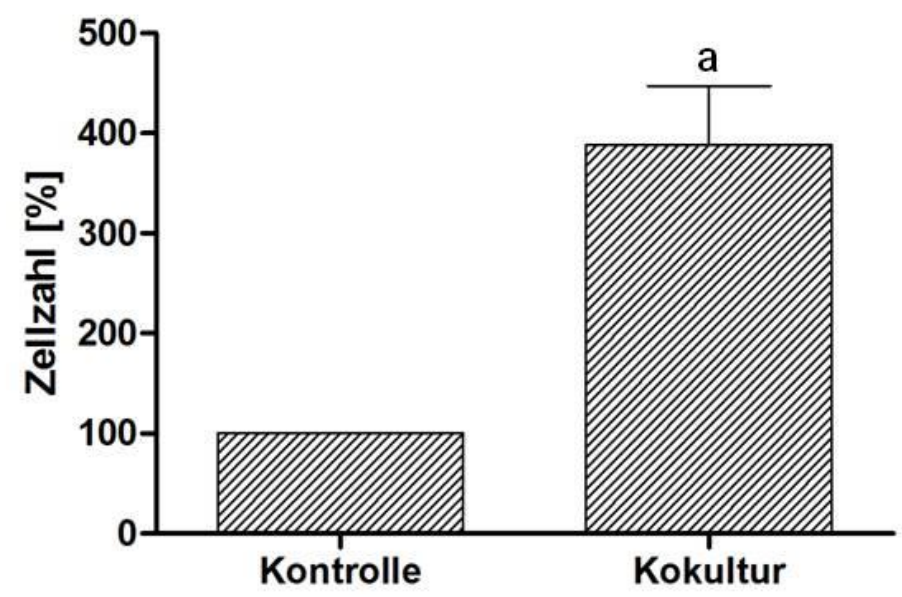

Abb. 3.7: Invasionsverhalten monokultivierter und kokultivierter MDA-MB-231 Mammakarzinomzellen. In der Kontrolle wurden die MDA-MB-231 Mammakarzinomzellen mit Medium kultiviert und in der Kokultur mit der Osteoblasten-ähnlichen Zellinie MG-63 kokultiviert. Es zeigte sich ein signifikanter Anstieg der invadierten Mammakarzinomzellen während der Kokultur im Vergleich zur Kontrolle. Angegeben sind MW \pm SEM, die Daten wurden mittels t-Test (gepaart) auf signifikante Unterschiede geprüft: $a, p<0,001$ vs. Kontrolle.

Die Migrations- und Invasionsfähigkeit der MDA-MB-231 Zellen wurden bei einer Behandlung mit Kisspeptin-10, die über einen Zeitraum von $96 \mathrm{~h}$ alle $12 \mathrm{~h}$ durchgeführt wurde, in einer Konzentration von $1 \times 10^{-10} \mathrm{M}$ im Vergleich zur Kokultur (KK $=100 \%)$ signifikant reduziert $\left(1 \times 10^{-12} \mathrm{M}: 102,3 \pm 14,6 \%\right.$ (n.s. vs. Kokultur); $1 \times 10^{-11}$ M: $117,8 \pm 13,0 \%$ (n.s. vs. Kokultur); $1 \times 10^{-10} \mathrm{M}: 73,6 \pm 6,8 \%$ ( $\mathrm{p}<0,05$ vs. Kokultur); $1 \times 10^{-9}$ M: $97,4 \pm 8,1 \%$ (n.s. vs. Kokultur); $1 \times 10^{-8}$ M: 108,9 $\pm 10,5 \%$ (n.s. vs. Kokultur)).

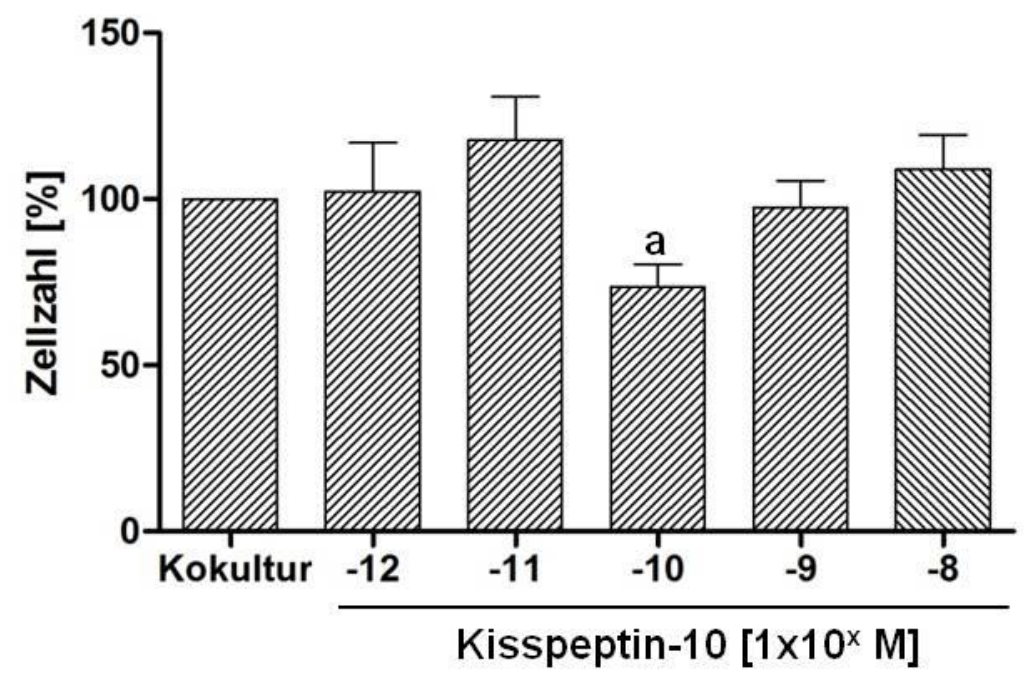

Abb. 3.8: Effekte von Kisspeptin-10 auf die Migration und Invasion kokultivierter MDA-MB-231 Mammakarzinomzellen. Die dosisabhängige Behandlung der kokultivierten Mammakarzinomzellen mit Kisspeptin-10 wurde alle $12 \mathrm{~h}$ über $96 \mathrm{~h}$ durchgeführt. Eine signifikante Hemmung der Migrations- und Invasionsfähigkeit wurde bei einer Konzentration von $1 \times 10^{-10} \mathrm{M}$ erreicht. Angegeben sind MW \pm SEM, die Daten wurden mittels one-way Analysis of Variance (ANOVA) gefolgt vom StudentNewman-Keuls Test auf signifikante Unterschiede geprüft: $a, p<0,05$ vs. Kokultur. 


\subsection{Genexpressionsversuche}

Um die Mechanismen aufzuklären, die dem hemmenden Einfluss von Kisspeptin-10 auf die Migration und Invasion zugrunde liegen, wurden Genexpressionsversuche mit der Mammakarzinomzellline MCF-7 durchgeführt. Hierbei wurden Gene ausgewählt, die in der Literatur im Zusammenhang mit der Förderung von Metastasierungsprozessen stehen. Die Analysen wurden mittels RT-PCR durchgeführt.

\subsubsection{Einfluss von Kisspeptin-10 auf die mRNA-Expression von CXCR4}

Durch RT-PCR konnte bereits nachgewiesen werden, dass die Mammakarzinomzelllinie MCF-7 den membranständigen Rezeptor CXCR4 exprimiert (von Alten et al. 2006). Im folgenden Versuch wurde untersucht, ob Kisspeptin-10 die CXCR4 mRNA-Expression der MCF-7 Mammakarzinomzellen beeinflusst:

Der Versuch wurde über $24 \mathrm{~h}$ angesetzt und die Behandlung mit Kisspeptin-10 [1×10${ }^{9} \mathrm{M}$ ] wiederum alle $12 \mathrm{~h}$ durchgeführt. Somit wurde die Konzentration gewählt, bei der Kisspeptin-10 in den Migrationsassays seine hemmende Wirkung zeigte (Kapitel 3.3.1). Die Daten wurden aus drei voneinander unabhängig durchgeführten Versuchen erhoben und innerhalb der RT-PCR jeweils dreimal voneinander unabhängig wiederholt. Der quantitative Abgleich erfolgte mit dem housekeeping gene L7.

Es zeigte sich in der Kokultur ein signifikanter Anstieg der CXCR4 mRNA-Expression von $144,6 \pm 8,3 \%(p<0,001)$ im Vergleich zur Kontrolle ( $K=100 \%)$. Bei Behandlung der Kokultur mit Kisspeptin-10 konnte festgestellt werden, dass hier eine signifikante Reduzierung der CXCR4 mRNA-Expression von 126,4 \pm 9,5\% $(p<0,05)$ im Vergleich zur unbehandelten Kokultur erreicht wurde. Bei Behandlung der Kontrolle mit Kisspeptin-10 zeigte sich kein Effekt (97,1 $\pm 4,7 \%$ n.s. vs. Kontrolle). 
A

B
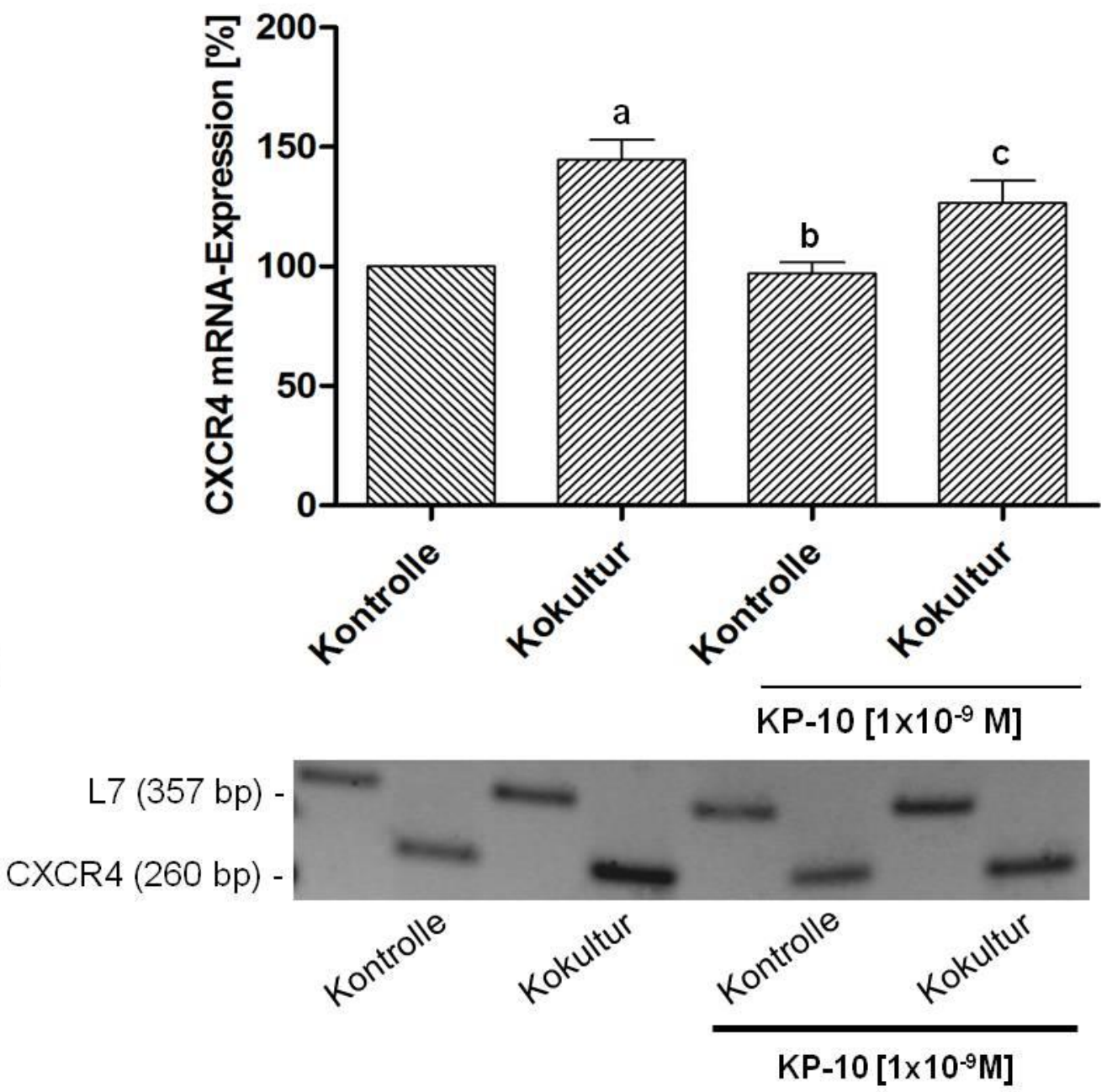

Abb. 3.9: Effekte von Kisspeptin-10 auf die CXCR4 mRNA-Expression. Die Inkubation erfolgte für $24 \mathrm{~h}$ mit einem Gemisch aus $0,06 \%$ DMSO in Ampuwa Wasser (Kontrolle und Kokultur) und mit Kisspeptin-10 [1 $\left.10^{-9} \mathrm{M}\right]$ in der behandelten Kontrolle und Kokultur. Die quantitative Bestimmung der CXCR4 mRNA-Expression erfolgte mittels RT-PCR im Bezug auf das housekeeping gene L7 (B). Ein Anstieg der CXCR4 mRNA-Expression in der Kokultur $(p<0,001)$ im Vergleich zur Kontrolle war zu beobachten. Bei Behandlung mit Kisspeptin-10 zeigte sich eine signifikante Abnahme der CXCR4 mRNA-Expression im Vergleich zur unbehandelten Kokultur. Angegeben sind MW $\pm \mathrm{SEM}$, die Daten wurden mittels one-way Analysis of Variance (ANOVA) gefolgt vom Student-Newman-Keuls Test auf signifikante Unterschiede geprüft: $a, p<0,001$ vs. Kontrolle; $b, p<0,001$ vs. Kokultur; $c, p<0,05$ vs. Kokultur (A).

\subsubsection{Einfluss von Kisspeptin-10 auf die mRNA-Expression von SDF-1}

Der in der Literatur beschriebene Ligand des membranständigen Rezeptors CXCR4 ist das SDF-1 Protein. SDF-1 ist ein sekretorisches Protein, welches von Knochenzellen oder den Osteoblasten-ähnlichen Zellen (MG-63) synthetisiert wird. Daher wurde auch hier die mRNA-Expression von SDF-1 untersucht. Vorangegangene Versuche zeigten, dass in der Kokultur die mRNA-Expression von 
SDF-1 um das 2,3-fache erhöht ist im Vergleich zu monokultivierten MG-63 Zellen (von Alten et al. 2006).

Die Zellen wurden über $24 \mathrm{~h}$ kokultiviert und die Behandlung mit Kisspeptin-10 [1×10${ }^{9} \mathrm{M}$ ] erfolgte alle $12 \mathrm{~h}$. Um die SDF-1 mRNA-Expression zu quantifizieren, erfolgte hier ebenfalls ein Abgleich mit dem housekeeping gene L7. Es wurden drei voneinander unabhängig durchgeführte Versuche und hiervon wiederum drei voneinander unabhängige RT-PCRs ausgewertet.

Die Ergebnisse spiegelten die der CXCR4 mRNA-Expression wider: Auch hier war zu beobachten, dass eine signifikante Reduktion der SDF-1 mRNA-Expression unter Behandlung mit Kisspeptin-10 stattfand. Während der Kokultur wurde die SDF-1 mRNA signifikant vermindert exprimiert $(82,4 \pm 6,4 \% ; p<0,05)$ im Vergleich zur unbehandelten Kokultur (KK = $100 \%)$ auf.

A
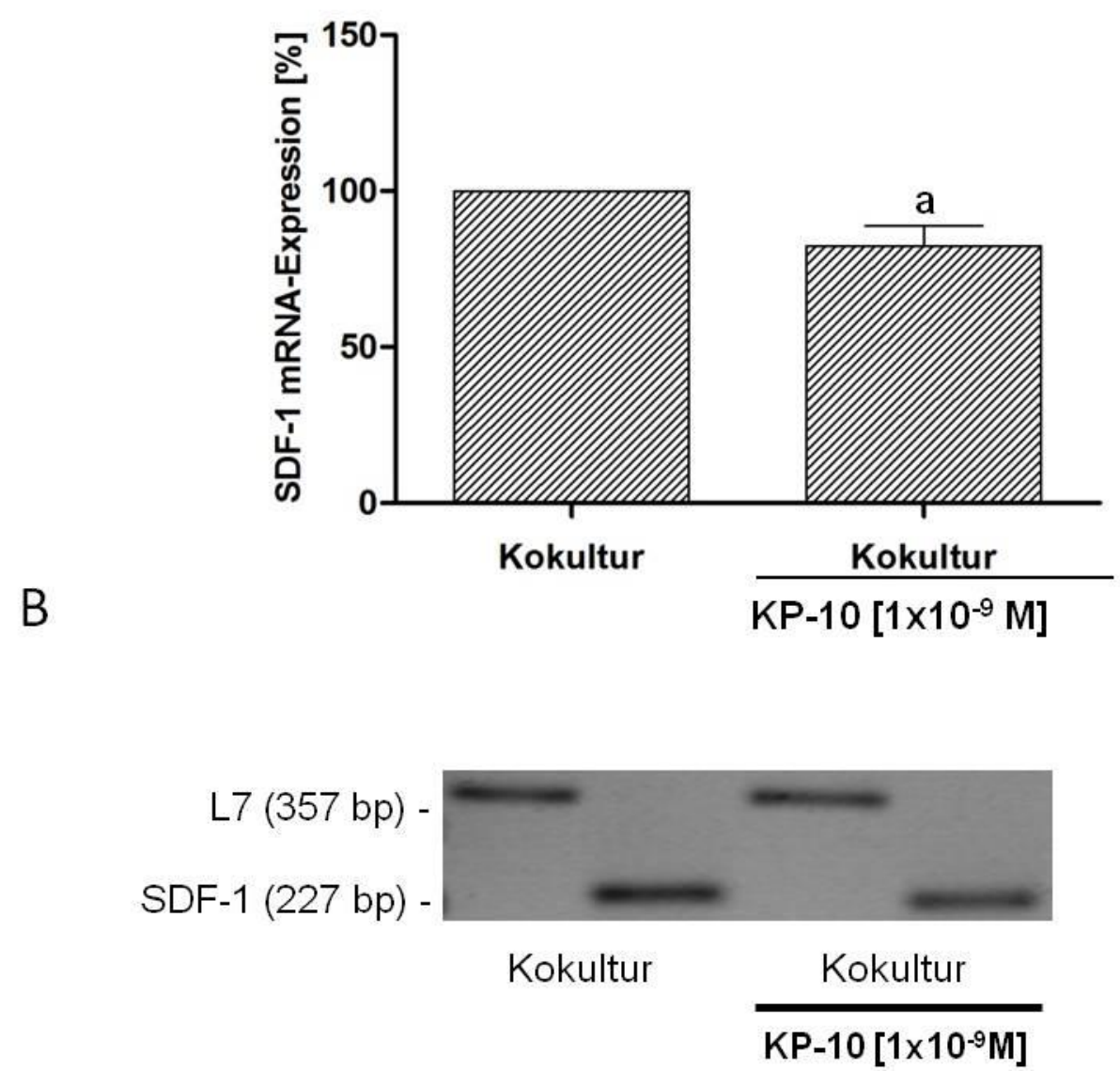

Abb. 3.10: Effekte von Kisspeptin-10 auf die SDF1 mRNA-Expression. Die Kokultivierung der Zellen erfolgte über 24 h, die Behandlung mit Kisspeptin-10 $\left[1 \times 10^{-9} \mathrm{M}\right]$ wurde alle $12 \mathrm{~h}$ durchgeführt. Die quantitative Bestimmung der mRNA-Expression wurde mittels RT-PCR und Abgleich durch das housekeeping gene L7 durchgeführt (B). Zu beobachten war eine signifikante Abnahme der SDF-1 mRNA-Expression bei den kokultivierten MG-63 Zellen in der behandelten Kokultur im Vergleich zur unbehandelten Kokultur. Angegeben sind MW \pm SEM, die Daten wurden mittels t-Test (gepaart) auf signifikante Unterschiede geprüft: $a, p<0,05$ vs. Kokultur (A). 


\subsection{Proteinexpressionsversuche}

Um die Mechanismen der Signaltransduktion von Kisspeptin-10 aufzuklären, wurden die prometastatischen Faktoren, SDF-1 und CXCR4 auf Proteinebene und ein in der Literatur in engem Zusammenhang mit dem SDF-1/CXCR4 System beschriebenes Protein, die phosphorylierte Akt Proteinkinase, untersucht. Der Nachweis erfolgte mittels Western Blot. Die Daten wurden aus drei voneinander unabhängig durchgeführten Versuchen erhoben.

\subsubsection{Effekte von Kisspeptin-10 auf die Proteinexpression von CXCR4}

Die MCF-7 Mammakarzinomzellen wurden erneut mit der Osteoblasten-ähnlichen Zelllinie MG-63 für die Dauer von $24 \mathrm{~h}$ kokultiviert und die Behandlung mit Kisspeptin-10 erfolgte dosisabhängig $\left(1 \times 10^{-12} \mathrm{M}, 1 \times 10^{-11} \mathrm{M}, 1 \times 10^{-9} \mathrm{M}, 1 \times 10^{-8} \mathrm{M}\right.$, $\left.1 \times 10^{-7} \mathrm{M}\right)$ alle $12 \mathrm{~h}$. Nach Aufarbeitung der Proteine wurde ein quantitativer Nachweis von CXCR4 im Western Blot mittels Aktinabgleich durchgeführt. Es wurden mindestens drei voneinander unabhängige Versuche ausgewertet.

Die CXCR4 Proteinexpression der unbehandelten Kokultur (KK = 102,0 $\pm 17,1 \%$ ) zeigte im Vergleich zur Kontrolle (monokultivierte Mammakarzinomzellen, $\mathrm{K}=100 \%$ ) keinen Unterschied. Es war aber durch die Kisspeptinbehandlung eine deutliche Abnahme der CXCR4 Proteinexpression in einem Konzentrationsspektrum von 1 $10^{-}$ ${ }^{9} \mathrm{M}$ bis $1 \times 10^{-7} \mathrm{M}$ zu erkennen. Diese Reduktion war bei einer Kisspeptin-10 Konzentration von $1 \times 10^{-8} \mathrm{M}$ bis $1 \times 10^{-7} \mathrm{M}$ signifikant: $\left(1 \times 10^{-12} \mathrm{M}\right.$ : $113,6 \pm 36,6 \%$ (n.s. vs. Kontrolle); $1 \times 10^{-11}$ M: $102,3 \pm 40,5 \%$ (n.s. vs. Kontrolle); $1 \times 10^{-9}$ M: $94,8 \pm 19,2 \%$

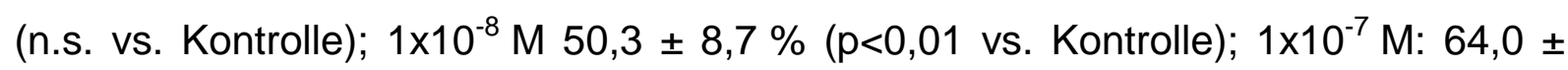
$13,2 \%(p<0,05$ vs. Kontrolle)). 
A

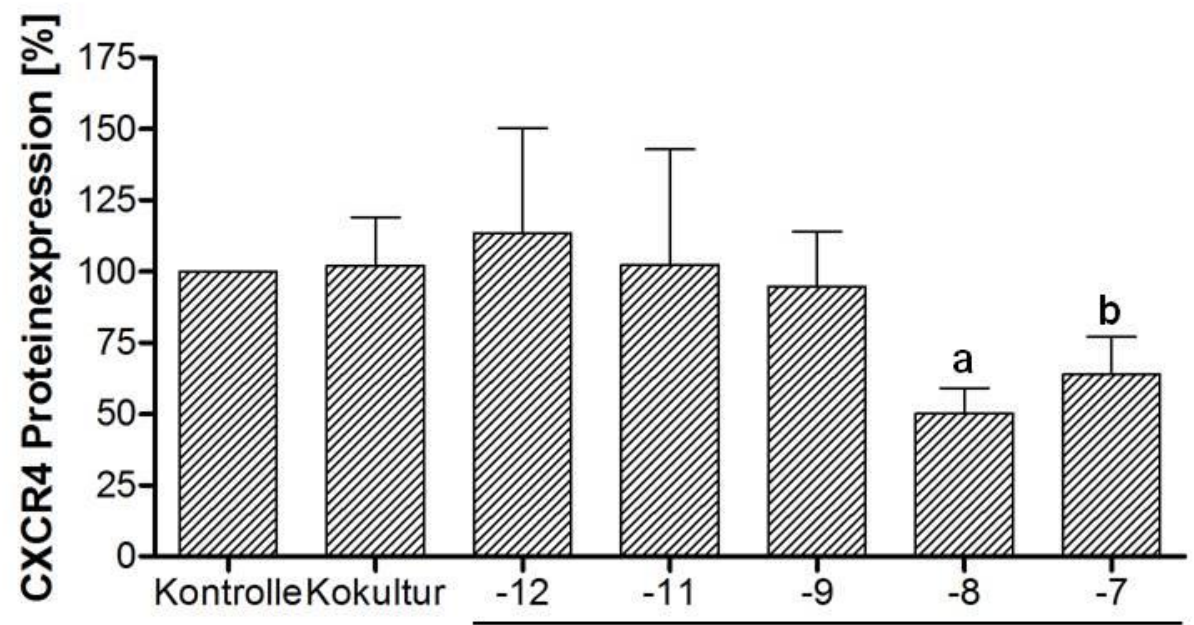

Kisspeptin-10 [1 $\left.1 \times 10^{\times} \mathrm{M}\right]$

B

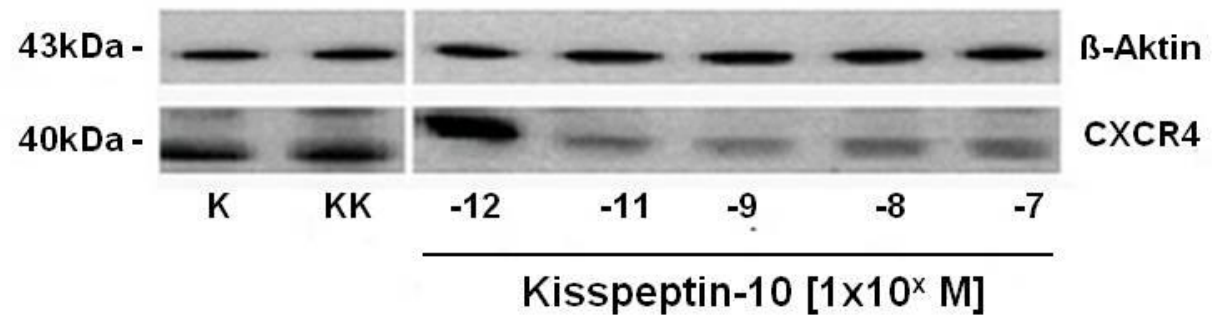

Abb. 3.11: Effekte von Kisspeptin-10 auf die CXCR4 Proteinexpression. Die Inkubation der kokultivierten Zellen erfolgte über $24 \mathrm{~h}$ mit einer dosisabhängigen Behandlung von Kisspeptin-10 alle $12 \mathrm{~h}$. Die unterschiedlichen CXCR4 Proteinexpressionsmuster zeigten sich im Western Blot, mittels Aktin wurde ein quantitativer Abgleich der CXCR4 Proteinexpression durchgeführt (B). Es zeigte sich eine verminderte Expression bei einer Kisspeptin-10 Konzentration von 1×10 ${ }^{9} \mathrm{M}$ bis $1 \times 10^{-7} \mathrm{M}$ im Vergleich zur Kontrolle. Bei einer Kisspeptin- 10 Konzentration von $1 \times 10^{-7} \mathrm{M}$ bis $1 \times 10^{-8} \mathrm{M}$ wurde eine signifikante Abnahme der CXCR4 Proteinexpression festgestellt. Angegeben sind MW \pm SEM, die Daten wurden mittels oneway Analysis of Variance (ANOVA) gefolgt vom Student-Newman-Keuls Test auf signifikante Unterschiede geprüft: $a, p<0,01$ vs. Kontrolle; $b, p<0,05$ vs. Kontrolle (A).

\subsubsection{Effekte von Kisspeptin-10 auf die Proteinsekretion von SDF-1}

Das SDF-1 Protein, sezerniert von Knochenzellen oder von der Osteoblastenähnlichen Zelllinie MG-63, ist der entsprechende Ligand des membranständigen CXCR4 Rezeptors der Mammakarzinomzellen. Die Inkubation der Zellen erfolgte über $24 \mathrm{~h}$ mit einer dosisabhängigen Kisspeptin-10 Behandlung $\left(1 \times 10^{-12} \mathrm{M}, 1 \times 10^{-}\right.$ ${ }^{11} \mathrm{M}, 1 \times 10^{-9} \mathrm{M}, 1 \times 10^{-8} \mathrm{M}, 1 \times 10^{-7} \mathrm{M}$ ), die alle $12 \mathrm{~h}$ durchgeführt wurde. Da es sich bei SDF-1 um ein sekretorisches Protein handelt, wurde mit dem Überstand der MG-63 Zellen gearbeitet. Zusätzlich ist das Protein nur in einer sehr geringen Konzentration 
im Überstand vorhanden, sodass Überstände von drei voneinander unabhängigen Versuchen gepoolt und im Anschluss ultrazentrifugiert wurden, um mit Hilfe des Western Blots das Protein quantifizieren zu können.

Die Kontrolle zeigte monokultivierte MG-63 Zellen, die ohne Einfluss von Mammakarzinomzellen kein SDF-1 Protein sezernierten. In der Kokultur war im Vergleich zur Kontrolle ein deutlicher Anstieg der SDF-1 Proteinsekretion zu erkennen $(\mathrm{KK}=100 \%)$. Bei einer Behandlung mit Kisspeptin-10 in einem Konzentrationsspektrum von $1 \times 10^{-11} \mathrm{M}$ bis $1 \times 10^{-8} \mathrm{M}$ ließ sich eine Reduktion der SDF-1 Proteinsekretion im Vergleich zur unbehandelten Kokultur nachweisen. Besonders in dem Konzentrationsfenster von $1 \times 10^{-11} \mathrm{M}$ bis $1 \times 10^{-9} \mathrm{M}$ war die Abnahme der Sekretion deutlich zu erkennen $\left(1 \times 10^{-12} \mathrm{M}: 168,5 \% ; 1 \times 10^{-11} \mathrm{M}\right.$ : $\left.75,8 \% ; 1 \times 10^{-9} \mathrm{M}: 75,0 \% ; 1 \times 10^{-8} \mathrm{M} 93,6 \% ; 1 \times 10^{-7} \mathrm{M}: 153,7 \%\right)$.

A

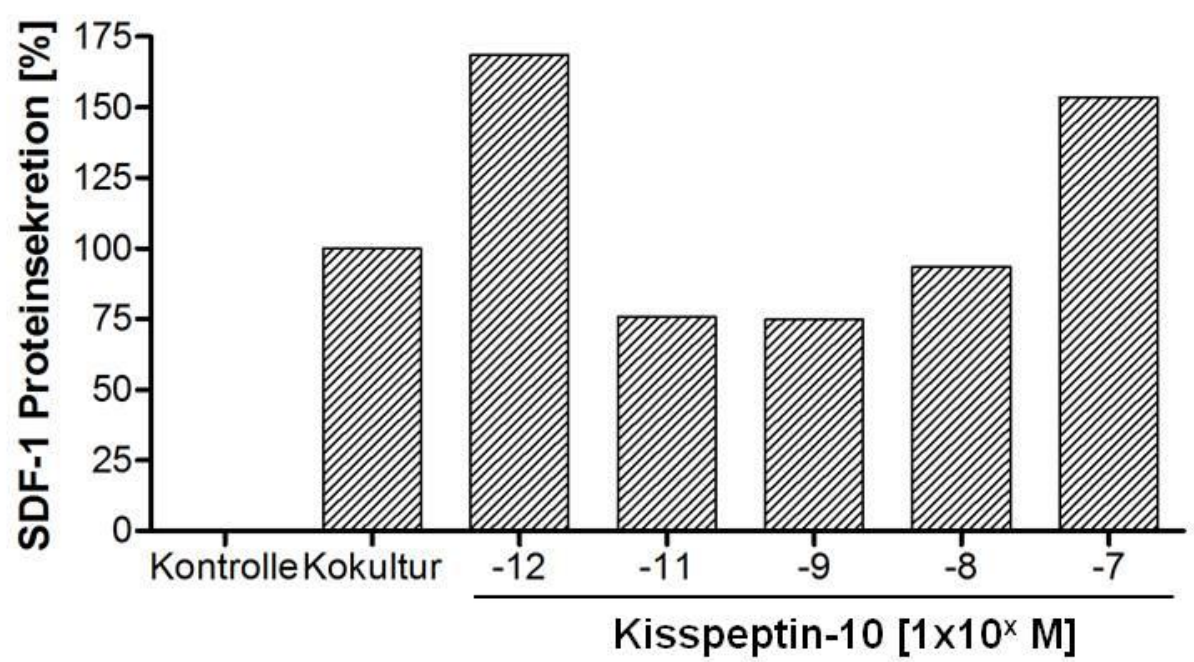

B

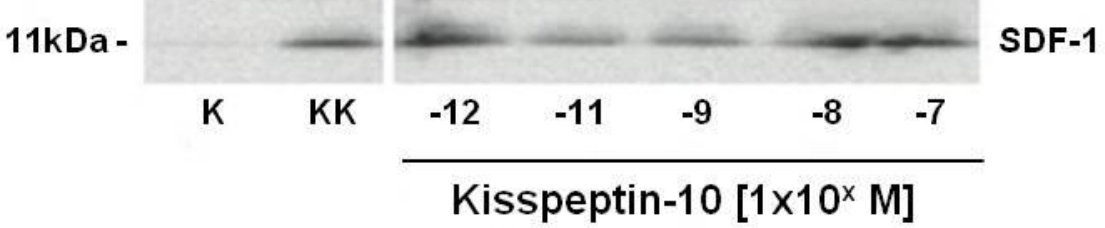

Abb. 3.12: Effekte von Kisspeptin-10 auf die SDF-1 Proteinsekretion. Die Kokultivierung erfolgte über $24 \mathrm{~h}$ bei einer dosisabhängigen Kisspeptin-10 Behandlung $\left(1 \times 10^{-12} \mathrm{M}, 1 \times 10^{-11} \mathrm{M}, 1 \times 10^{-9} \mathrm{M}, 1 \times 10^{-8} \mathrm{M}, 1 \times 10^{-7} \mathrm{M}\right)$, die alle $12 \mathrm{~h}$ durchgeführt wurde. Im Western Blot wurde die SDF-1 Proteinsekretion nachgewiesen (B). Die monokultivierten MG-63 Zellen sezernierten das SDF-1 Protein nicht. In der unbehandelten Kokultur zeigte sich ein Anstieg der Proteinsekretion, bei einer Kisspeptin-10 Konzentration von $1 \times 10^{-11} \mathrm{M}$ bis $1 \times 10^{-8} \mathrm{M}$ zeigte sich eine Reduktion der Proteinsekretion der MG-63 Zellen im Vergleich zur Kokultur. Die stärkste Hemmung ließ sich in einem Dosis-Wirkungsbereich von $1 \times 10^{-11} \mathrm{M}$ bis $1 \times 10^{-9} \mathrm{M}$ nachweisen $(\mathrm{A})$. 
3.4.3 Effekte von Kisspeptin-10 auf die Phosphorylierung der Proteinkinase Akt

Um den Nachweis zu erbringen, dass die Behandlung mit Kisspeptin-10 den SDF1/CXCR4 induzierten Akt-Signalweg der MCF-7 Mammakarzinomzellen beeinträchtigt, wurden erneut Proteinexpressionsversuche durchgeführt. Die Kokultivierung der Zellen erfolgte über $24 \mathrm{~h}$ mit einer dosisabhängigen Kisspeptin-10 Behandlung $\left(1 \times 10^{-12} \mathrm{M}, 1 \times 10^{-11} \mathrm{M}, 1 \times 10^{-9} \mathrm{M}, 1 \times 10^{-8} \mathrm{M}, 1 \times 10^{-7} \mathrm{M}\right)$, die alle $12 \mathrm{~h}$ durchgeführt wurde. Nach Aufarbeitung der Proteine erfolgte ein quantitativer Nachweis des phosphorylierten Akt Proteins (aktivierter Zustand) im Western Blot im Abgleich mit dem dephosphoryliertem Akt Protein (inaktivierter Zustand). Es wurden drei voneinander unabhängige Versuche ausgewertet.

In der Kokultur war im Vergleich zur Kontrolle ( $K=100 \%$ ) eine geringfügige Abnahme des phosphorlyierten Akt Proteins ( $K K=80.8 \pm 17,6 \%$ n.s. vs. Kontrolle) festzustellen. Bei einer Behandlung von Kisspeptin-10 in einem Konzentrationsspektrum von $1 \times 10^{-12} \mathrm{M}$ bis $1 \times 10^{-7} \mathrm{M}$ ließ sich für alle Konzentrationen eine signifikante Reduktion des phosphorylierten Akt Proteins im Vergleich zur Kontrolle nachweisen. Besonders in dem Konzentrationsfenster von $1 \times 10^{-12} \mathrm{M}$ bis

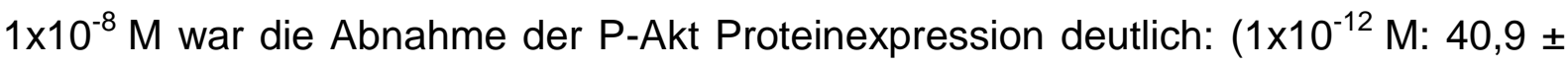
$14,6 \%$ ( $p<0,05$ vs. Kontrolle); $1 \times 10^{-11} \mathrm{M}: 46,4 \pm 9,8 \%$ ( $\mathrm{p}<0,05$ vs. Kontrolle); $1 \times 10^{-}$ ${ }^{9} \mathrm{M}: 39,9 \pm 10,5 \%$ ( $p<0,05$ vs. Kontrolle); $1 \times 10^{-8} \mathrm{M} 48,9 \pm 11,3 \%$ ( $\mathrm{p}<0,05$ vs. Kontrolle); $1 \times 10^{-7} \mathrm{M}: 61,01 \pm 20,0 \%(p<0,05$ vs. Kontrolle)). 
A

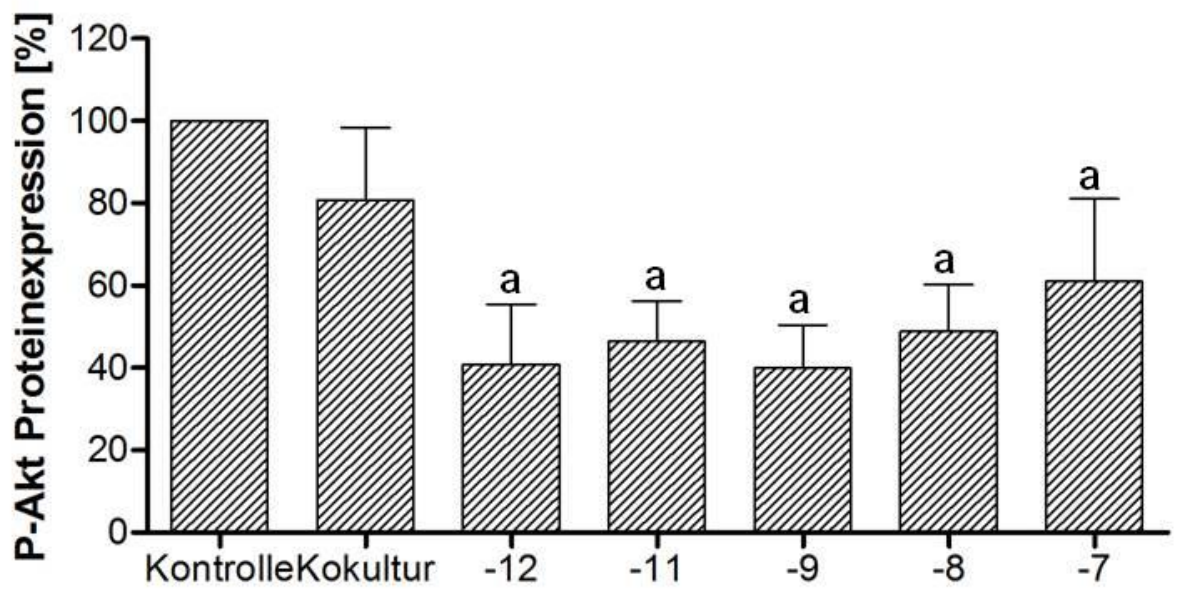

Kisspeptin-10 [1 $\left.\times 10^{\times} \mathrm{M}\right]$

B

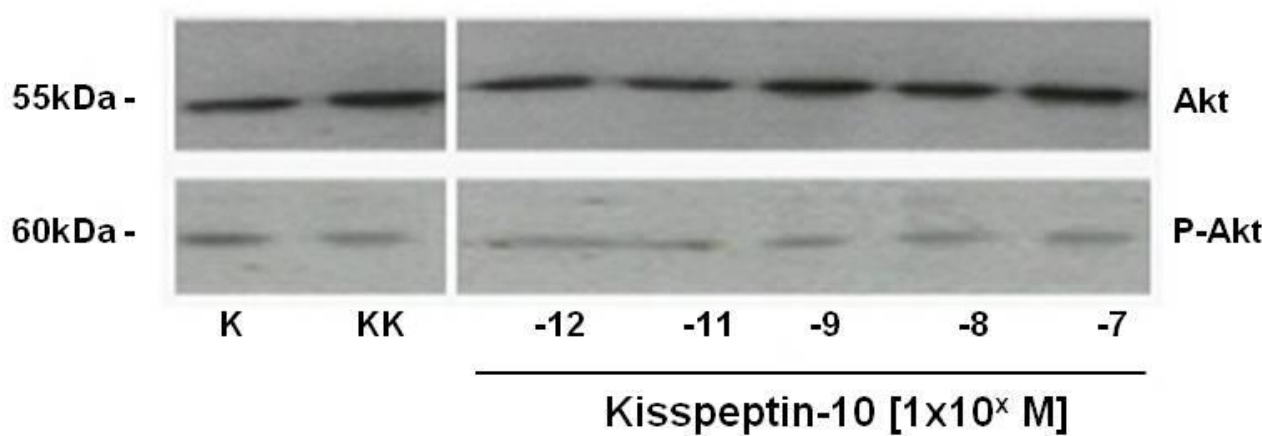

Abb. 3.13: Effekte von Kisspeptin-10 auf die Phosphorylierung der Proteinkinase Akt. Die Inkubation der kokultivierten Zellen erfolgte über $24 \mathrm{~h}$ mit einer dosisabhängigen Behandlung von Kisspeptin-10 alle $12 \mathrm{~h}$. Nach Aufarbeitung der Proteine erfolgte ein quantitativer Nachweis des phoshorylierten Akt Proteins (aktivierter Zustand) im Western Blot im Abgleich mit dem dephosphoryliertem Akt Protein (inaktivierter Zustand) (B). Es zeigte sich eine verminderte Expression des phosphorylierten Akt Proteins in sämtlichen Kisspeptin-10 Konzentrationen. Angegeben sind MW \pm SEM, die Daten wurden mittels one-way Analysis of Variance (ANOVA) gefolgt vom Student-Newman-Keuls Test auf signifikante Unterschiede geprüft: $a, p<0,05$ vs. Kontrolle (A).

\subsection{Einfluss von Kisspeptin-10 auf die Proteinexpression nach GPR54 knock down in der Osteoblasten-ähnlichen Zelllinie MG-63}

Nachdem ein Signalweg des Kisspeptin-10 gefunden war, sollte anschließend untersucht werden, ob Kisspeptin-10 auch auf die GPR54-positiven MG-63 Zellen seine Wirkung entfaltet und den Signalweg maßgeblich beeinflusst. Dafür wurde ein 
GPR54 knock down in der Osteoblasten-ähnliche Zelllinie MG-63 durchgeführt, der nach erfolgreicher Transfektion für mindestens $48 \mathrm{~h}$ anhielt.

\subsubsection{Nachweis des GPR54 knock downs in der Osteoblasten-ähnlichen Zelllinie MG-63}

Für den GPR54 knock down wurde mittels antisense-Technik die Expression des Rezeptors blockiert und die MG-63 Zellen nach $24 \mathrm{~h}$ zur Internalisierung der noch an der Zelloberfläche vorhandenen Rezeptoren mit Kisspeptin-10 (1×10-7 M) behandelt. Nach weiteren $24 \mathrm{~h}$ wurden die Zellen mittels immunzytochemischer Färbung auf die GPR54 Expression untersucht. In Abbildung 3.14 ist exemplarisch die GPR54 Expression der MG-63 Zellen mit und ohne knock down dargestellt. Es konnte gezeigt werden, dass die Expression des Rezeptors nach Transfektion (C) im Vergleich zur Positivkontrolle $(B)$ deutlich reduziert ist und mit der unbehandelten Negativkontrolle (A) korreliert.

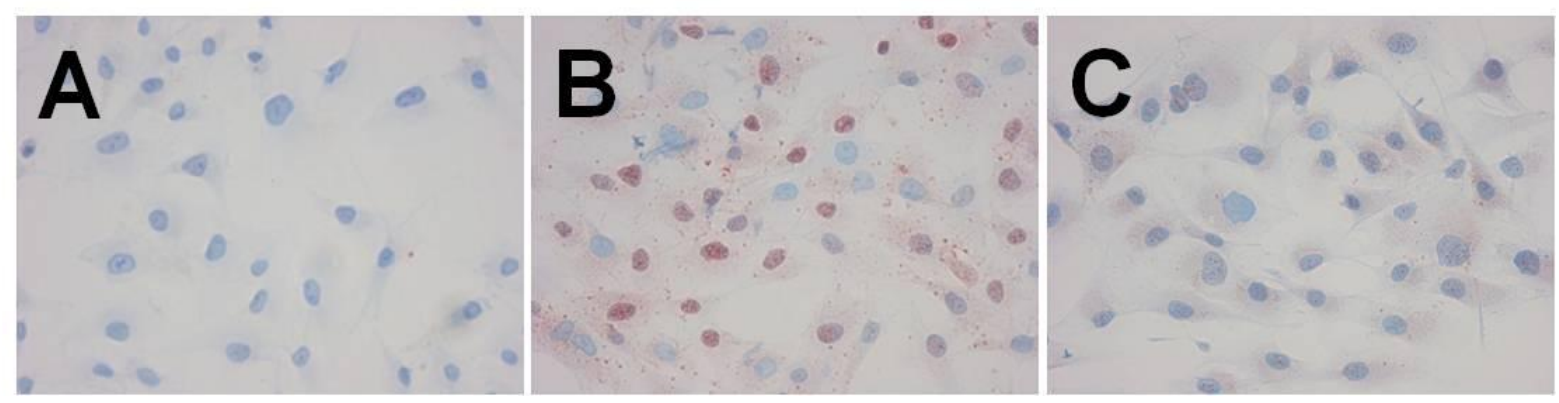

Abb. 3.14: Immunzytochemischer Nachweis des GPR54 knock downs in der Osteoblasten-ähnlichen Zelllinie MG-63. Die Expression des GPR54 ist im Vergleich zur Positivkontrolle (B) nach knock down (C) deutlich reduziert und korreliert mit der Negativkontrolle (A).

3.5.2 Einfluss von Kisspeptin-10 auf die CXCR4 Proteinexpression nach GPR54 knock down

$24 \mathrm{~h}$ nach erfolgreichem GPR54 knock down in den MG-63 Zellen wurden diese zusammen mit den Mammakarzinomzellen MCF-7 für den Migrationsassay ausgesät. Es folgte die Behandlung der MCF-7 Zellen mit Kisspeptin-10 in unterschiedlichen Konzentrationen $\left(1 \times 10^{-12} \mathrm{M}, 1 \times 10^{-11} \mathrm{M}, 1 \times 10^{-10} \mathrm{M}, 1 \times 10^{-9} \mathrm{M}, 1 \times 10^{-}\right.$ ${ }^{8} \mathrm{M}$ ) und in einem Abstand von $12 \mathrm{~h}$ für insgesamt $24 \mathrm{~h}$. Nach Aufarbeitung der 
membranständigen Proteine erfolgte der quantitative Nachweis des CXCR4 Proteins im Western Blot mittels Aktinabgleich (Abb. 3.15).

A

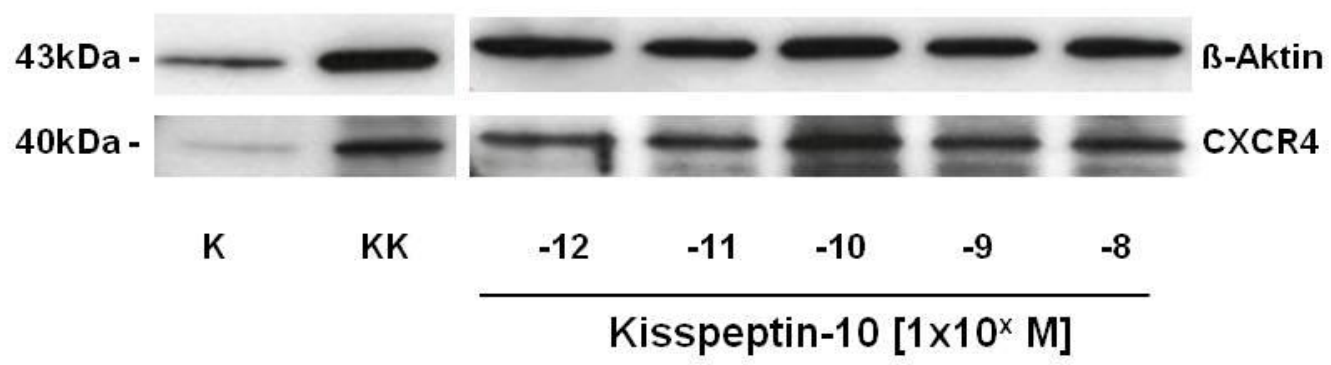

Abb. 3.15: Nachweis der CXCR4 Proteinexpression in MCF-7 Zellen im Western Blot nach GPR54 knock down in der Osteoblasten-ähnlichen Zellinie MG-63. Die CXCR4 Proteinexpression nahm in der Kokultur im Vergleich zur Kontrolle deutlich zu und zeigte aber nach dosisabhängiger Behandlung mit Kisspeptin-10 keine Abnahme (A).

Die kokultivierten Mammakarzinomzellen (KK) zeigten eine geringe Zunahme der CXCR4 Proteinexpression im Vergleich $\mathrm{zu}$ den monokultivierten Mammakarzinomzellen (K). Bei einer Behandlung mit Kisspeptin-10 in einem Konzentrationsspektrum von $1 \times 10^{-12} \mathrm{M}$ bis $1 \times 10^{-8} \mathrm{M}$ war keine Reduzierung der CXCR4 Proteinexpression in den MCF-7 Zellen zu erkennen.

\subsubsection{Einfluss von Kisspeptin-10 auf die SDF-1 Proteinsekretion nach GPR54 knock down}

$24 \mathrm{~h}$ nach Transfektion wurden die MG-63 Zellen zusammen mit der Mammakarzinomzelllinie MCF-7 für den Migrationsassay ausgesät. Die Behandlung der Mammakarzinomzellen mit Kisspeptin-10 erfolgte alle $12 \mathrm{~h}$ in unterschiedlichen Konzentrationen $\left(1 \times 10^{-12} \mathrm{M}, 1 \times 10^{-11} \mathrm{M}, 1 \times 10^{-10} \mathrm{M}, 1 \times 10^{-9} \mathrm{M}, 1 \times 10^{-8} \mathrm{M}\right)$. Zum Zeitpunkt $t_{24}$ wurde der Überstand der MG-63 Zellen abgenommen, gepoolt, ultrazentrifugiert und im Anschluss mittels Western Blot eine Quantifizierung des SDF-1 Proteins vorgenommen. Die Ergebnisse des Western Blots sind in Abbildung 3.16 dargestellt. Monokultivierte MG-63 Zellen dienten als Kontrolle, in der nur eine geringfügige Sekretion des SDF-1 Proteins nachzuweisen ist. Im Vergleich dazu zeigten die in der Kokultur kultivierten MG-63 Zellen eine deutlich stärkere SDF-1 Proteinsekretion. Bei einer dosisabhängigen Behandlung mit Kisspeptin-10 war nach 
GPR54 knock down in den MG-63 Zellen keine Reduzierung der SDF-1 Proteinsekretion zu erkennen.

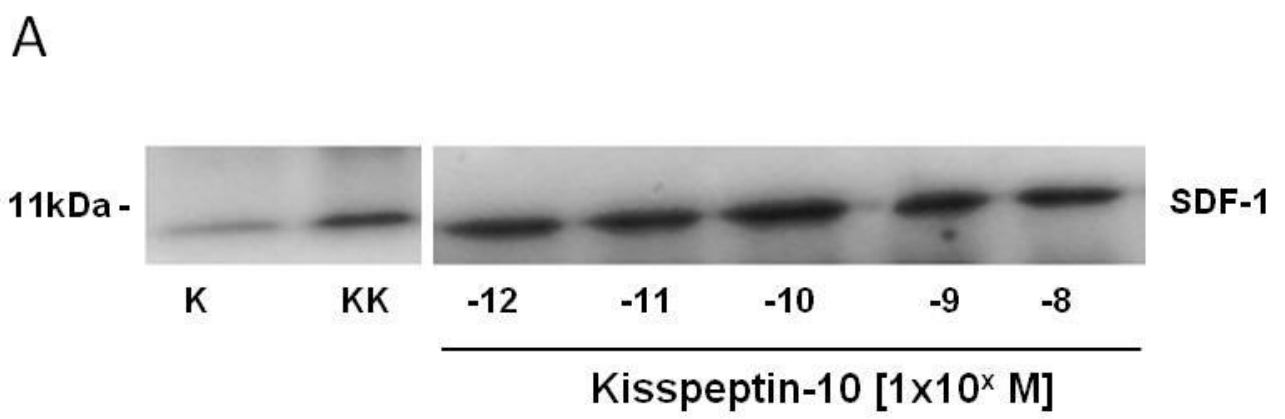

Abb. 3.16: Nachweis der SDF-1 Proteinsekretion nach GPR54 knock down in der Osteoblasten-ähnlichen Zelllinie MG63. Die SDF-1 Proteinsekretion nahm in der Kokultur im Vergleich zur Kontrolle deutlich zu und zeigte aber nach dosisabhängiger Behandlung mit Kisspeptin-10 keine Reduzierung (A).

\subsubsection{Einfluss von Kisspeptin-10 auf die Phosphorylierung der Proteinkinase Akt nach GPR54 knock down}

Erneut wurden die MG-63 Zellen 24 h nach GPR54 knock down zusammen mit den MCF-7 Zellen kokultiviert und alle $12 \mathrm{~h}$ dosisabhängig mit Kisspeptin-10 behandelt $\left(1 \times 10^{-12} \mathrm{M}, 1 \times 10^{-11} \mathrm{M}, 1 \times 10^{-10} \mathrm{M}, 1 \times 10^{-9} \mathrm{M}, 1 \times 10^{-8} \mathrm{M}\right)$. Nach $24 \mathrm{~h}$ erfolgte die Gewinnung der zytosolischen Proteinfraktion und die quantitative Analyse der aktiven Akt Proteinkinase mittels Western Blot Verfahren.

Die kokultivierten Mammakarzinomzellen (KK) zeigten eine geringe Zunahme der aktiven Akt Proteinkinaseexpression (P-Akt) im Vergleich zu den monokultivierten Mammakarzinomzellen (K). Bei einer Behandlung mit Kisspeptin-10 in einem Konzentrationsspektrum von $1 \times 10^{-11} \mathrm{M}$ bis $1 \times 10^{-8} \mathrm{M}$ ist nach GPR54 knock down war in den MG-63 Zellen keine Reduzierung der aktivierten Akt Proteinkinaseexpression zu erkennen. Eine geringfügige Reduzierung der phosphorylierten Proteinkinaseexpression zeigte sich jedoch bei einer Kisspeptin-10 Konzentration von $1 \times 10^{-12} \mathrm{M}$ (Abb. 3.17). 
A

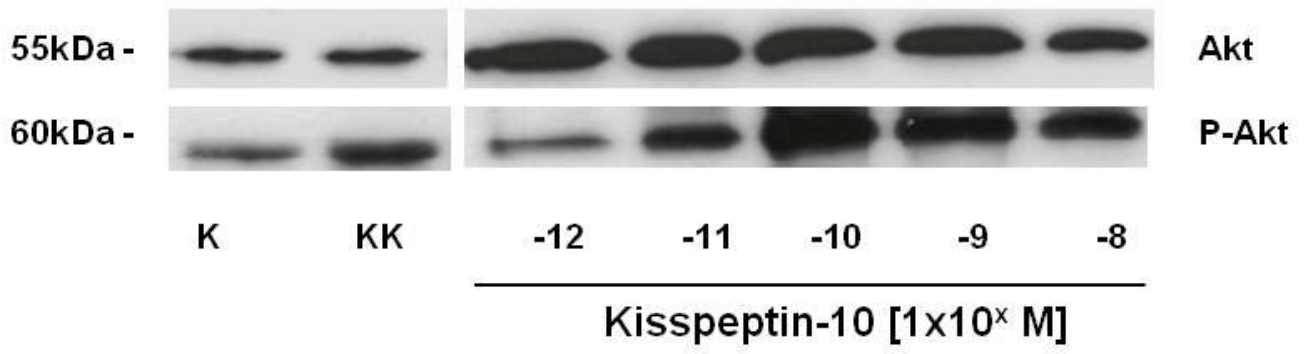

Abb. 3.17: Nachweis der aktivierten Akt Proteinkinase (P-Akt) in den MCF-7 Zellen im Western Blot nach GPR54 knock down in der Osteoblasten-ähnlichen Zelllinie MG-63. In der Kokultur zeiget sich im Vergleich zur Kontrolle nur ein geringer Anstieg des phosphorylierten Akt Proteins. Bei einer Kisspeptin-10 Konzentration von $1 \times 10^{-12} \mathrm{M}$ war eine geringfügige Reduzierung des aktivierten Aktproteins zu erkennen, in allen anderen Konzentration ließ sich keine Abnahme der phosphorylierten Akt Proteinkinase feststellen (A).

\subsection{Einfluss des SDF-1 Antikörpers auf das Migrations- und Invasionsverhalten von MCF-7 Mammakarzinomzellen}

Die Ergebnisse der Gen- und Proteinexpressionsversuche zeigen, dass das SDF1/CXCR4 System eine wichtige Rolle im Migrations- und Invasionsverhalten der Mammakarzinomzellen spielt. Um hierfür einen weiteren Hinweis zu erhalten, wurden Migrationsassays mit der Mammakarzinomzelllinie MCF-7 durchgeführt, in denen die Osteoblasten-ähnliche Zelllinie MG-63 mit einem SDF-1 Antikörper alle $24 \mathrm{~h}$ über $96 \mathrm{~h}$ in einer Konzentration von $1 \times 10^{-7} \mathrm{M}$ behandelt wurde. Es wurden mindestens drei voneinander unabhängige Versuche durchgeführt.

Hierbei zeigte sich in der Kokultur ein signifikanter Anstieg (KK $=610,0 \pm 39,3 \%$; $\mathrm{p}<0,001)$ der invadierten MCF-7 Zellen im Vergleich zur Kontrolle $(K=100 \%)$. 


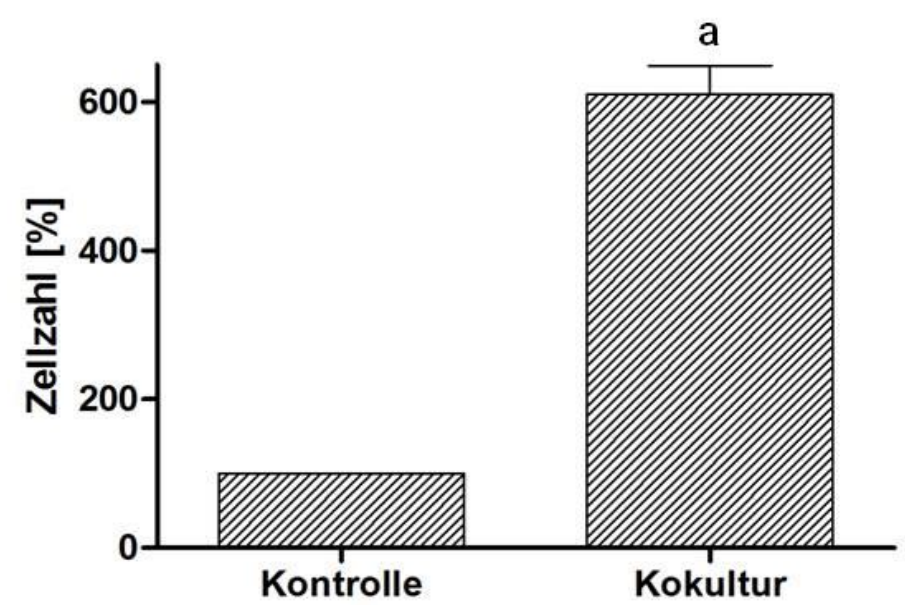

Abb. 3.18: Invasionsverhalten von monokultivierten und kokultivierten MCF-7 Mammakarzinomzellen. Die Kontrolle zeigt die invadierten monokultivierten MCF-7 Zellen während die Kokultur die invadierten kokultivierten (mit MG-63 Zellen) MCF-7 Zellen darstellt. Hierbei war ein signifikanter Anstieg der invadierten MCF-7 Zellen deutlich zu erkennen. Angegeben sind MW \pm SEM, die Daten wurden mittels t-Test (gepaart) auf signifikante Unterschiede geprüft: a, $p<0,001$ vs. Kontrolle.

Bei Behandlung der kokultivierten MG-63 Zellen mit dem SDF-1 Antikörper wurde eine signifikante Hemmung der Migrationsfähigkeit der MCF-7 Zellen im Vergleich zur unbehandelten Kokultur ( $K K=100 \%$ ) erreicht: $84,5 \pm 4,8 \%$; $p<0,01$ vs. Kokultur.

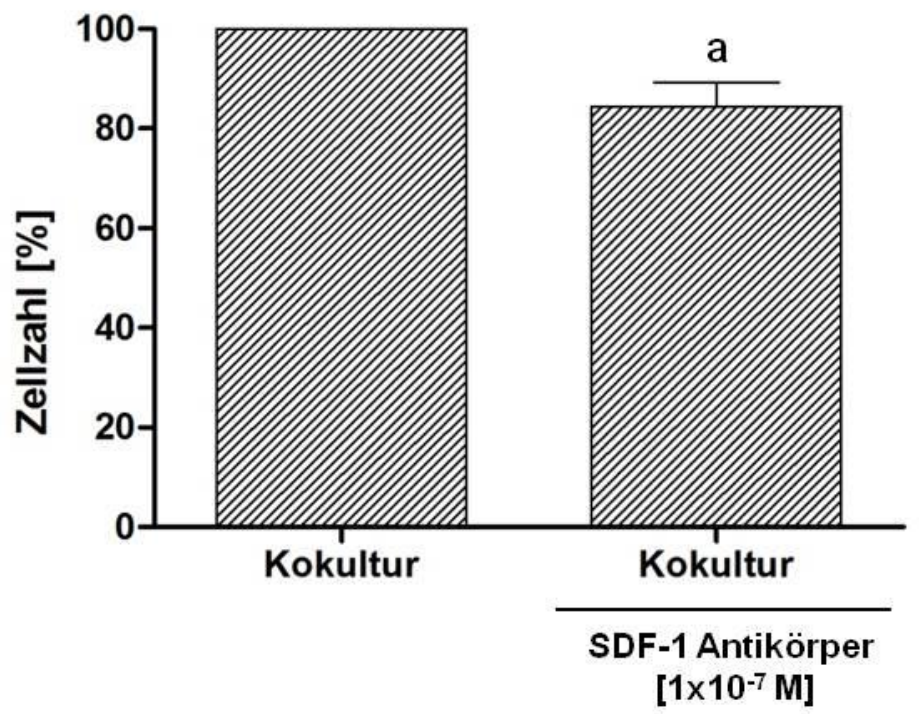

Abb. 3.19: Effekte des SDF-1 Antikörpers auf das Migrationsverhalten kokultivierter MCF-7 Mammakarzinomzellen. Bei Behandlung der MG-63 Zellen mit einem SDF-1 Antikörper zeigte sich eine signifikante Reduzierung der invadierten Mammakarzinomzellen. Angegeben sind MW \pm SEM, die Daten wurden mittels $\mathrm{t}-\mathrm{Test}$ (gepaart) auf signifikante Unterschiede geprüft: $a, p<0,01$ vs. Kokultur. 


\section{DISKUSSION}

Kisspeptin-10 und sein Rezeptor GPR54 sind in der Tumorbiologie Gegenstand der aktuellen Forschung. Kisspeptin-10 entsteht als Degradationsprodukt des Metastasesuppressorgens KiSS-1 (Harms et al. 2003). Metastasesuppressorgene sind Gene, die in ihren subzellulären Funktionen stark variieren und dennoch die gemeinsame Aufgabe besitzen, das Wachstum von disseminierten Tumorzellen zu finalen Tochtergeschwulsten zu verhindern (Coghlin and Murray 2010). Letzteres stellt das Ziel einer antimetastatischen Therapie mit Kisspeptin-10 dar, um die Metastasierung in ferne Organe zu unterbinden.

\subsection{Untersuchung der GPR54 Expression in humanem Mamma- karzinomgewebe}

In dieser Arbeit wurde erstmals die Expression des GPR54 in humanem Mammakarzinomgewebe untersucht. Der GPR54 wird vor allem in der Plazenta exprimiert, aber auch im zentralen Nervensystem, im Ovar, in den Testis, im Pankreas und im Darm (Makri et al. 2008). Da es sich bei der Plazenta um ein Gewebe mit invasiven Eigenschaften handelt, zeigen die Zellen der Plazenta ein ähnliches Verhalten wie invasive Tumorzellen (Murray and Lessey 1999). Eine aktuelle Untersuchung zeigt, dass eine Expression von Kisspeptin und GPR54 im klarzelligen Ovarkarzinom mit einer besseren Prognose einhergeht (Prentice et al. 2007).

Um eine mögliche antihormonelle Therapie in Erwägung zu ziehen, muss der Rezeptorstatus jedes einzelnen Tumors untersucht werden. Für den Östrogen-, Progesteron- und HER2/neu-Rezeptor ist dies heutzutage ein wichtiger Standard und wird bei jedem einzelnen Mammakarzinom durch den Pathologen bestimmt. Es gibt auch Hinweise, dass die unterschiedlichen Rezeptorexpressionen mit verschiedenen Krankheitsverläufen assoziiert sind. Hess et al. (2003) konnten nachweisen, dass unter Patientinnen mit einem Rezidiv des Mammakarzinoms bei einem Östrogenrezeptor-positiven Tumor ein doppelt so hohes Risiko besteht Knochenmetastasen zu entwickeln als bei einem Östrogenrezeptor-negativen Tumor. 
Um eine antihormonelle Therapie mit Kisspeptin-10 in Betracht zu ziehen, müssen die Karzinome auf ihre GPR54 Expression untersucht werden.

Die in der vorliegenden Arbeit untersuchten Tumorfronten waren unabhängig von deren Rezeptorstatus (Östrogen-, Progesteron- und HER2/neu-Rezeptor) alle GPR54-positiv. In den Gewebeschnitten, in denen keine Tumorfront angeschnitten war, war die Expression des GPR54 in Bezug auf den Rezeptorstatus der Karzinome homogen von $<10 \%$ bis $>80 \%$ verteilt. Somit gibt es sowohl Karzinome, die GPR54negativ sind als auch Karzinome die eine starke GPR54 Expression zeigen. Aber auch Karzinome, die nur eine geringe GPR54 Expression zeigen, sind möglicherweise für Kisspeptin-10 als Therapieoption in Betracht zu ziehen, da bei der Beurteilung der Mammakarzinome hinsichtlich ihrer Stereoidhormonrezeptoren nicht mehr ein gewisser Prozentsatz für die Annahme einer Rezeptorpositivität gefordert wird, sondern jegliche Expression als potenziell responsiv auf die Antihormontherapie gilt (Goldhirsch et al. 2009).

\subsection{Inhibition der Migrations- und Invasionsfähigkeit von Mammakarzinomzellen durch Kisspeptin-10}

Zunächst konnte in dieser Arbeit gezeigt werden, dass die Migrations- und Invasionsfähigkeit von Mammakarzinomzellen (MCF-7 und MDA-MB-231) während der Kokultivierung mit der Osteoblasten-ähnlichen Zelllinie MG-63 signifikant zunimmt. Dies entspricht somit einem Metastasierungsmodell in vitro, welches schon im Jahr 2006 für die MCF-7 Zellen in unserer Arbeitsgemeinschaft etabliert worden ist (von Alten et al. 2006). In der vorliegenden Arbeit wurden erstmals gezeigt, dass sich auch die MDA-MB-231 Zellen aufgrund ihrer verstärkten Migrations- und Invasionsfähigkeit in der Kokultur als in vitro-Metastasierungsmodell eignen.

Gleichzeitig wurde durch die gezielte Behandlung der Mammakarzinomzellen mit Kisspeptin-10 eine signifikante Reduzierung der invadierten Mammakarzinomzellen erreicht. Für die Mammakarzinomzelllinie MCF-7 zeigte sich der stärkste Effekt in einem Dosis-Fenster von $1 \times 10^{-11} \mathrm{M}$ bis $1 \times 10^{-9} \mathrm{M}$. Dies ist die erste Arbeit, die dieses Dosis-Fenster für die antimigrative und antiinvasive Wirkung von Kisspeptin-10 beschreibt. In der Mammakarzinomzelllinie MDA-MB-231 wurde eine signifikante Inhibition der Migration und Invasion bei einer Kisspeptinkonzentration von $1 \times 10^{-10} \mathrm{M}$ 
erreicht. Eine weitere Arbeitsgruppe konnte in der invasiven Mammakarzinomzelllinie MDA-MB-435 zeigen, dass bei einer Überexpression des KiSS-1 Gens die Migration und Invasion dieser Karzinomzellen verhindert wird (Lee, J. H. and Welch 1997). Dennoch können keine zusätzlichen endokrinen Effekte ausgeschlossen werden, die durch die Expression von KiSS-1 sowohl in den MCF-7 Zellen als auch in den MDAMB-231 Zellen entstehen könnten (Huijbregts and de Roux 2010; Marot et al. 2007). Die MG-63 Zellen zeigen keine Expression des KiSS-1 Gens (Ergebnisse nicht gezeigt). Des Weiteren wurde vor kurzem von zwei unterschiedlichen Arbeitsgemeinschaften nachgewiesen, dass das KiSS-1 Gen im Tumorgewebe der Brust im Vergleich zu gesundem Brustgewebe vermehrt exprimiert wird (Marot et al. 2007; Martin et al. 2005), obwohl ein KiSS-1 Genexpressionsverlust in invasiven Mammakarzinomzelllinien von mehreren Arbeitsgruppen gezeigt wurde (Lee, J. H. and Welch 1997; Lee, J. H. et al. 1996; Mitchell et al. 2006).

Das KiSS-1 Gen bzw. das Kisspeptin-10 zeigt insgesamt keinen oder nur einen sehr geringen Einfluss auf die Hemmung der Tumorproliferation (Cho et al. 2009; Yoshida et al. 2000). Dieses Ergebnis können wir anhand von Daten, die in unserer Arbeitsgruppe erhoben wurden, bestätigen (Ergebnisse nicht publiziert). Hierbei wurde mittels Proliferationsassays die Inhibition der Proliferationsfähigkeit der Mammakarzinomzelllinie MCF-7 durch verschiedene Kisspeptin-10 Konzentrationen untersucht und es wurde kein inhibierender Effekt auf die Proliferation der Mammakarzinomzellen ermittelt. Es lässt sich daher feststellen, dass das KiSS-1 Gen und Kisspeptin-10 einen deutlichen Effekt auf die Migrations- und Invasionsfähigkeit, nicht aber auf die Proliferationsfähigkeit von Mammakarzinomzellen besitzen.

Für weiterführende Untersuchungen wäre die Überlegung wichtig, ob Kisspeptin-10 zur Prävention von Brustkrebsmetastasen oder als Therapieoption bei vorliegenden Metastasen eingesetzt werden kann. Untersuchungen von Stark et al. (2005) zeigten, dass Hirnmetastasen mit Sitz des Primärtumors in der Brust eine niedrige KiSS1-mRNA-Expression und Proteinsekretion im Vergleich zum Primarius besitzen. Für einen möglichen erfolgreichen klinischen Einsatz von Kisspeptin-10 wäre somit auch ein Vergleich der GPR54 Expression im primären Tumorgewebe versus den dazugehörigen Metastasen wichtig, da die Tumorzellen, die sich im Prozess der Metastasierung befinden, die Expression verschiedener Gene und deren Produkte verändert können (Shi et al. 2010). 


\subsection{Durch Kisspeptin-10 induzierte Signalwege}

Chemokinrezeptoren wurden erstmals im Zusammenhang mit Leukozyten, die im Rahmen von Entzündungsprozessen eine entscheidende Rolle spielen, entdeckt. Mittlerweile sind bei fast allen Zelltypen Chemokinrezeptoren beschrieben (Proudfoot 2002; Schier 2003). Auch Tumorzellen können über ihre eigene Chemokinsekretion und ihre eigenen Chemokinrezeptoren die für sie entscheidenden Prozesse, wie z.B. Angiogenese und somit auch das eigene Wachstum und die Metastasierung, steuern (Wang et al. 2006).

Für den in dieser Arbeit untersuchten Chemokinrezeptor CXCR4 und seinen Liganden SDF-1 gibt es in der Literatur viele Hinweise, dass es sich um einen für die Tumorzelle sehr wichtigen prometastatischen Faktor handelt. CXCR4 ist ein Mitglied der membranständigen G-Protein-gekoppelten Rezeptorfamilie und hat im Rahmen seiner Funktion als Korezeptor, um den Eintritt des X4-tropen HI-Virus in die CD4+ TZellen zu ermöglichen, enorme Aufmerksamkeit bekommen (Caruz et al. 1998; Gupta and Pillarisetti 1999). Eine Expression des Rezeptors konnte auch auf Monozyten, B-Zellen und naiven T-Zellen im peripheren Blut, sowie auf frühen hämatopoetischen Stammzellen nachgewiesen werden (Aiuti et al. 1999). Die Tatsache, dass eine Gendeletion des CXCR4 Rezeptors durch ZNS- und Immundefekte und hämatopoetische Entwicklungsstörungen letale Folgen hat (Nagasawa et al. 1996), zeigt deutlich die unbestrittene physiologisch wertvolle Funktion. Des Weiteren wurde kürzlich entdeckt, dass das SDF-1/CXCR4 System auch eine wichtige Rolle in der normalen mikrovaskulären Angiogenese spielt, indem es reife Endothelzellen im Kolon zur Migration und zur Ausbildung Kapillar-ähnlicher Strukturen stimuliert (Salvucci et al. 2002). Die proangiogenetischen Effekte des CXCR4 signaling könnten durch eine Erhöhung des Vascular endothelial growth factor (VEGF) vermittelt werden, welcher selbst ein in der Literatur äußerst bekanntes proangiogenetisches Molekül darstellt (Kijowski et al. 2001). VEGF selbst erhöht die CXCR4 Expression in Mammakarzinomzellen. Dadurch entsteht eine positive Feedback-Schleife, die die Angiogenese des Tumors vorantreibt (Bachelder et al. 2002). Hierbei wäre die Untersuchung von VEGF in Mammakarzinomzellen im Zusammenhang mit Kisspeptin-10 in weiteren Arbeiten ein interessanter Ansatz.

Muller et al. (2001) untersuchten die CXCR4 Expression in gesundem Mamma- und Ovarialgewebe und zeigten, dass der Rezeptor in diesem Gewebe nur schwach 
exprimiert oder nicht nachweisbar ist. Im Vergleich dazu wiesen sie aber eine erhöhte CXCR4 Expression in Mammakarzinomzellen, malignem Mammakarzinomgewebe und dessen Metastasen nach. In dieser Arbeit konnte ebenfalls gezeigt werden, dass CXCR4 sowohl auf Gen- als auch auf Proteinebene in der Mammakarzinomzelllinie MCF-7 exprimiert wird. In der Kokultur ist ein signifikanter Anstieg der CXCR4 mRNA-Expression zu erkennen und dieser Anstieg wird durch Kisspeptin-10 wiederum signifikant inhibiert. Auf Proteinebene lässt sich ebenfalls eine signifikante Reduzierung der CXCR4 Expression durch Kisspeptin-10 feststellen. Navenot et al. (2005) publizierten, dass der unter Kisspeptin-10 induzierte Signalweg des GPR54 die über CXCR4 vermittelte chemotaktische Antwort vermindert. Die Fähigkeit von Kisspeptin-10 die direkte durch SDF-1 induzierte Migration zu inhibieren, wurde in den mit GPR54- und CXCR4-kotransfizierten Chinese Hamster Ovary ( $\mathrm{CHO}$ ) Zellen nachgewiesen. Die vorliegende Arbeit ist aber die erste, die einen direkten Effekt von Kisspeptin-10 auf die CXCR4 Expression in Mammakarzinomzellen zeigt. Dennoch ist der Mechanismus, der den direkten Effekt von Kisspeptin-10 auf die verminderte CXCR4 Expression erklärt, noch weitestgehend ungeklärt und verlangt weitere Aufklärung.

Der Stromal derived factor-1 (SDF-1) oder auch CXCL12 (Chemokine (C-X-C motif) ligand 12) ist der bisher einzige in der Literatur beschriebene Ligand des CXCR4 Rezeptors und der CXCR4 Rezeptor ist der einzige identifizierte Rezeptor für den SDF-1 Liganden (Horuk 2001). Die Tatsache, dass für den Rezeptor und seinen Liganden bisher keine weiteren passenden Moleküle existieren, ist eine einzigartige Konstellation in der Familie der Chemokine und deren Rezeptoren (Luker and Luker 2006). Verschiedene Arbeitsgruppen entdeckten, dass vor allem hohe Level an SDF1 von denjenigen Organen produziert werden, die häufig von Metastasen des Mammakarzinoms betroffen sind wie Knochen, Leber, Lunge, Gehirn und Lymphknoten (Muller et al. 2001; Nagasawa et al. 1998; Shirozu et al. 1995). Die Abbildung 4.1 zeigt die Effekte des SDF-1/CXCR4 Systems im primären Mammakarzinom und seinen Metastasen. Kang et al. (2005) berichtete über eine CXCR4-positive Mammakarzinomzelllinie MDA-MB-231-SDF1 ${ }^{+/+}$, die mit SDF-1 transfiziert wurde und dadurch eine signifikante Erhöhung in ihrer Invasivität sowie eine noch schnellere Migrationsfähigkeit aufwies. 


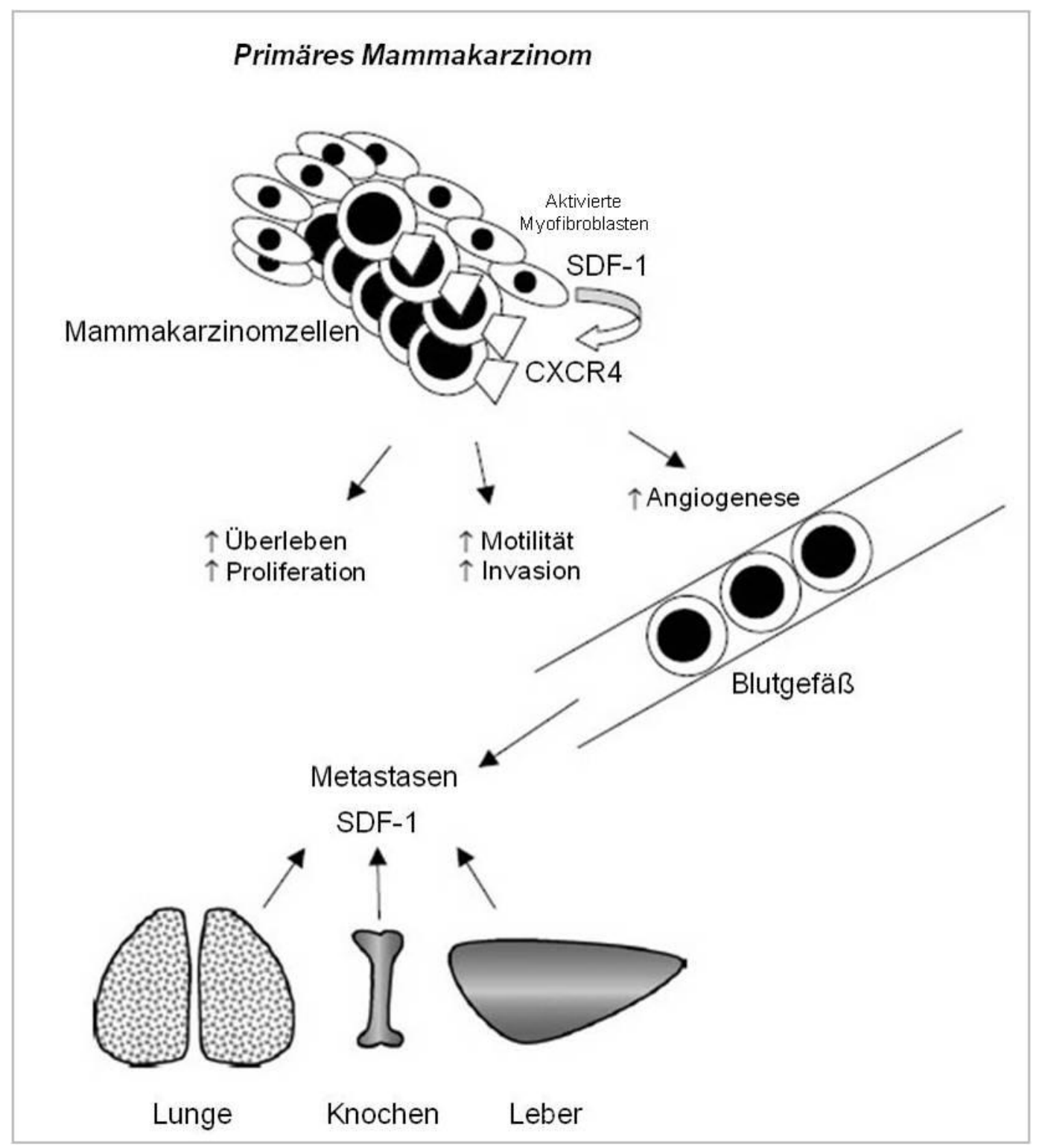

Abb. 4.1: Effekte von SDF-1 und CXCR4 im primären Mammakarzinom und seinen Metastasen. Modifiziert nach Luker and Luker (2006, S.34).

Andere Gewebe und Zellverbände, die SDF-1 sezernieren, sind u.a. Myokardzellen (Askari et al. 2003), Skelettmuskelzellen (Ratajczak et al. 2003), Leberzellen (Kollet et al. 2003) und Nierenparenchymgewebe (Schrader et al. 2002). Die Sekretion wird gesteigert bei kardialen Gewebeschäden, hervorgerufen durch ischämische Prozesse (Peled et al. 1999), bei toxischem Leberschaden (Kollet et al. 2003), bei exzessiven Blutungen (Ratajczak et al. 2004) und bei Ganzkörperbestrahlung und Gewebeschädigung verursacht durch Chemotherapie (Ponomaryov et al. 2000). Das SDF-1 spielt u.a. nicht nur in der Tumorbiologie eine wichtige Rolle, sondern auch als Chemokin für das homing von hämatopoetischen Stammzellen im Knochenmark und vermittelt sowohl das weitere Überleben als auch die Proliferation von humanen und 
murinen Progenitorzellen (Aiuti et al. 1997). Im Knochenmark wird SDF-1 hauptsächlich von Osteoblasten, Fibroblasten und Endothelzellen produziert (Aust et al. 2001; Yun and Jo 2003). Auch in den meisten humanen Osteosarkomzelllinien kann eine hohe SDF-1 mRNA-Expression nachgewiesen werden (Ponomaryov et al. 2000). Die Untersuchungen, die in der vorliegenden Arbeit durchgeführt wurden, zeigen eine erhöhte SDF-1 Sekretion der MG-63 Zellen vor allem auf Proteinebene. Die monokultivierten Osteoblasten-ähnlichen MG-63 Zellen sezernieren kaum nachweisbares SDF-1, sind diese hingegen mit Mammakarzinomzellen kokultiviert lässt sich eine deutliche Steigerung der SDF-1 Sekretion nachweisen. Hierbei sei erwähnt, dass eine Schädigung der DNA durch Bestrahlung oder durch Gabe von Chemotherapeutika wie Cyclophosphamide oder 5-Flourouracil zu einer Erhöhung der SDF-1 Expression im Knochenmark von Mäusen aber auch in kultivierten Zellen führt (Petit et al. 2002; Ponomaryov et al. 2000). Somit ist es fraglich, ob diese etablierten Therapieverfahren möglicherweise einen Beitrag zum Voranschreiten des Metastasierungsprozesses leisten. Durch Kisspeptin-10 lässt sich die Produktion des SDF-1 Proteins sowohl auf Gen- als auch auf Proteinebene deutlich senken. Auch bei einer Behandlung des Migrationsassays mit einem SDF-1 Antikörper ist eine signifikante Reduzierung der Migrations- und Invasionsfähigkeit der Mammakarzinomzellen festzustellen. Es ist somit davon auszugehen, dass das SDF1/CXCR4 System auch für die Invasions- und Migrationsfähigkeit von Mammakarzinomzellen in der Kokultur eine entscheidende Rolle spielt. Auf der Suche nach den zugrunde liegenden molekularen Mechanismen, die die Inhibitionsfähigkeit von Kisspeptin-10 betreffen, wurde die Expression des GPR54 auf der Osteoblasten-ähnlichen Zelllinie MG-63 festgestellt. Damit kann die Wirkung von Kisspeptin-10 und die damit verbundene signifkante Reduzierung der SDF-1 Expression und Sekretion in den MG-63 Zellen erklärt werden. Dennoch muss der genaue Signaltransduktionsweg, der zur Kisspeptin-10 induzierten Inhibition der SDF-1 Expression und Sekretion in den MG-63 Zellen führt, genauer untersucht werden.

Weitergehende Untersuchungen dieser Arbeit wurden an der Proteinkinase Akt durchgeführt. In der Literatur wird beschrieben, dass SDF-1 und CXCR4 den Phosphatidyl-Inositol-3-Kinase Signalweg stimulieren, der daraufhin die Proteinkinase Akt aktiviert (Kayali et al. 2003; Rubin et al. 2003; Vlahakis et al. 
2002). Des Weiteren ist bekannt, dass die aktivierte Proteinkinase Akt eine Vielzahl an intrazellulären Zielmolekülen phosphoryliert mit der Absicht die Apoptose verschiedener Arten von Tumorzellen zu inhibieren und deren Zellüberleben zu prolongieren (Luo et al. 2003). Prasad et al. (2004) behandelten Mammakarzinomzellen in vitro mit SDF-1 und konnten damit zeigen, dass durch SDF-1 die Akt Kinase Aktivität innerhalb von 15 min stimuliert wird und diese für mindestens $4 \mathrm{~h}$ anhält. Die Akt Proteinkinase wurde auch mit der Wirkung von CXCR4 auf die Migration in Richtung eines chemotaktischen SDF-1 Gradienten in Zusammenhang gebracht (Curnock et al. 2003; Peng et al. 2005). Kürzlich wurde darüber berichtet, dass das SDF-1/CXCR4 System die Phosphorylierung von Akt induziert (Manning and Cantley 2007). Kisspeptin-10 hingegen verursachte keine vergleichbare Aktivierung und hebt diesen SDF-1 Effekt sogar wieder auf. Dieser Effekt stand aber eher mit einer Interaktion auf der Signaltransduktionsebene als mit der CXCR4 Expression in Verbindung (Castano et al. 2009; Navenot et al. 2005). Dennoch schließt der eine Mechanismus den anderen nicht aus. Einen Zusammenhang zwischen dem SDF-1/CXCR4 System und der Akt Proteinkinase wurde auch in dieser Arbeit gezeigt. Obwohl kein Anstieg der aktivierten (phosphorylierten) Akt Proteinkinase in den kokultivierten Mammakarzinomzellen im Vergleich zu den monokultivierten Mammakarzinomzellen festzustellen ist, wird durch Kisspeptin-10 in allen untersuchten Konzentrationen eine signifikante Reduzierung der aktivierten Akt Proteinkinase erreicht.

Die Abbildung 4.2 zeigt, dass aus dieser Arbeit resultierende Modell für die Rolle von Kisspeptin-10 in Knochenmetastasen mit Primarius in der Mamma. Hierbei ist zu beachten, dass wie bereits erwähnt sowohl die MCF-7 Zellen als auch die MG-63 Zellen für den Kisspeptin-10 Rezeptor GPR54-positiv sind. Um eine weitere Bestätigung dieses Modells zu erhalten, wurde ein GPR54 knock down in der Osteoblasten-ähnlichen Zelllinie MG-63 durchgeführt. Wie erwartet, wurden sowohl die Effekte von Kisspeptin-10 auf die CXCR4 und P-Akt Expression in den Mammakarzinomzellen als auch die SDF-1 Sekretion in den MG-63 Zellen nach dem GPR54 knock down aufgehoben. Dies ist ein starkes Indiz dafür, dass Kisspeptin-10 nicht nur am GPR54 der Mammakarzinomzellen bindet sondern auch den GPR54 der Osteoblasten-ähnlichen Zelllinie MG-63 aktiviert und somit auch in die Expression und Sekretion des SDF-1 Moleküls mit eingreift. Die spezifischen 
Mechanismen der Signaltransduktion in den MG-63 Zellen müssen in weiteren Arbeiten erforscht werden. Es zeigt sich aber, dass es sich hierbei um eine komplexe Interaktion zwischen zweier verschiedenen Zelllinien unterschiedlicher Gewebeherkunft handelt und dass die hemmende Wirkung von Kisspeptin-10 auf die Migration und Invasion der Mammakarzinomzellen nicht nur auf die Interaktion von Kisspeptin-10 mit dem GPR54 der Mammakarzinomzellen zurückzuführen ist sondern ebenso der GPR54 der MG-63 Zellen von großer Bedeutung ist.

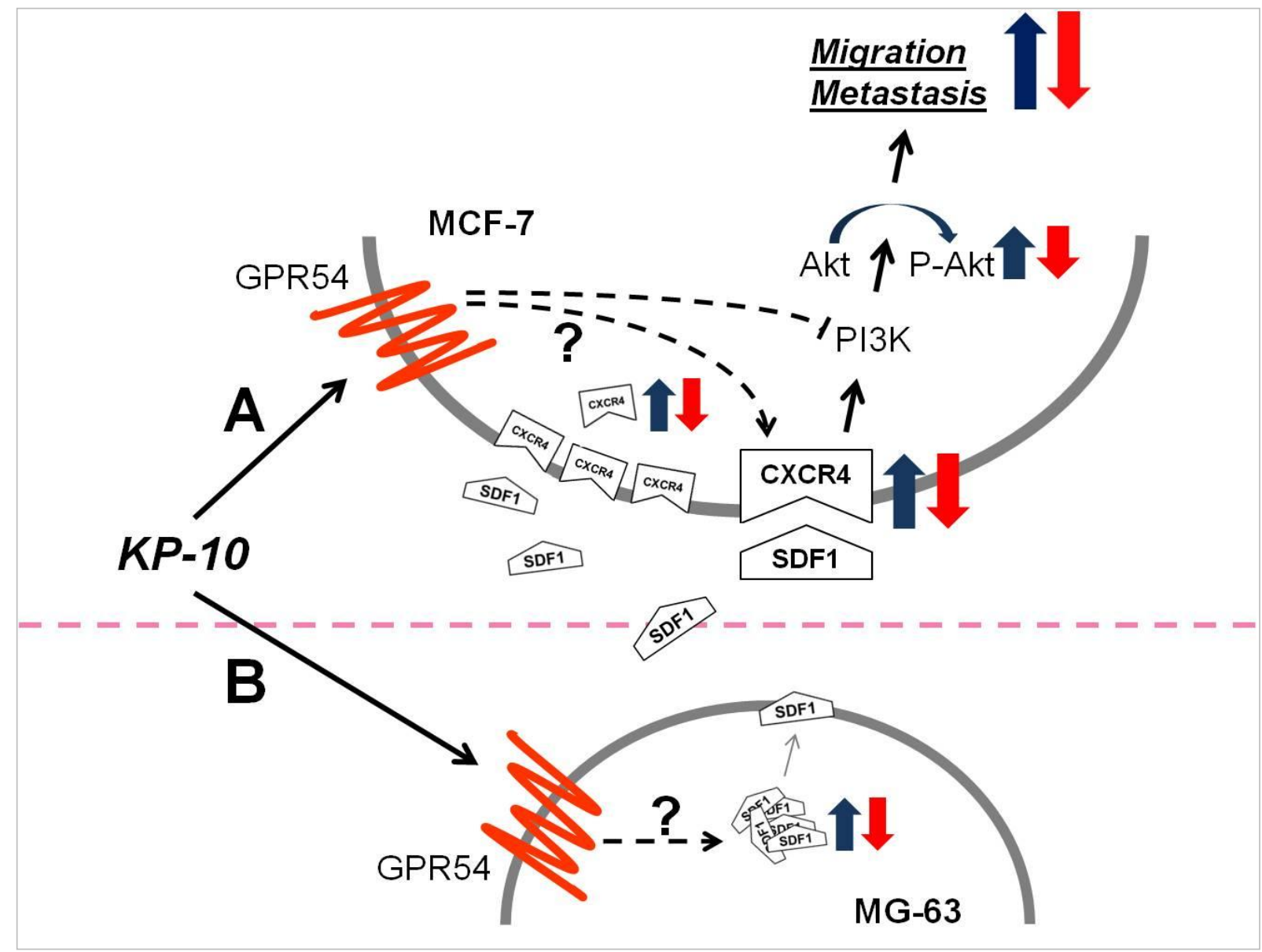

Abb. 4.2: Modell für die Rolle von Kisspeptin-10 in Knochenmetastasen mit Primarius in der Mamma. Kisspeptin-10 verringert durch die Inhibition des prometastatischen SDF-1/CXCR4 Systems die Fähigkeit der Mammakarzinomzellen durch die mit Matrigel beschichtete Membran aufgrund des zellulären Stimulus der Osteoblasten-ähnlichen Zellinie MG-63 zu migrieren. Die Aktivierung des GPR54 auf den Mammakarzinomzellen inhibiert die CXCR4 Expression und das CXCR4 signaling (A). Die Aktivierung des GPR54 der MG-63 Zellen hemmt sowohl die SDF-1 mRNA-Expression als auch die SDF-1 Proteinsekretion (B). 


\subsection{Fazit und Ausblick}

Durch diese Arbeit wurde einerseits die Existenz des GPR54 in unterschiedlichen Mammakarzinomtypen bezogen auf deren Rezeptorstatus nachgewiesen. Andererseits zeigen die in vitro Arbeiten erstmalig, dass der stärkste GPR54 Agonist, das Kisspeptin-10, die Migrations- und Invasionsfähigkeit von Mammakarzinomzellen im Kokultursystem signifikant verringert. Hierbei sind sowohl die in dieser Arbeit verwendeten Mammakarzinomzellen als auch die Osteoblasten-ähnliche Zelllinie MG-63 für den Kisspeptin-10 Rezeptor GPR54-positiv. Des Weiteren wurde nachgewiesen, dass Kisspeptin-10 einen direkten inhibierenden Einfluss auf das SDF-1/CXCR4 System und auch auf die damit verbundene Akt Proteinkinase besitzt. Um weitere Hinweise auf die komplexe Signaltransduktion von Kisspeptin-10 zu erlangen, wurde ein GPR54 knock down in den MG-63 Zellen durchgeführt. Hierbei zeigte sich, dass der inhibierende Effekt des Kisspeptin-10 auf die untersuchten Moleküle aufgehoben wird. Somit wird deutlich, dass es sich bei der inhibierenden Wirkung von Kisspeptin-10 auf die Migrations- und Invasionsfähigkeit von Mammakarzinomzellen um eine komplexe Interaktion zwischen zweier aus verschiedenen Geweben stammenden Zelllinien (Brust und Knochen) handelt und weitere Forschungsarbeiten durchgeführt werden müssen, um die Mechanismen des Kisspeptin-10 noch genauer beschreiben zu können.

In die Zukunft blickend muss Kisspeptin-10 als antimetastatisches Therapeutikum in vivo getestet werden, um die vielversprechenden in vitro Ergebnisse zu bestätigen. Des Weiteren sollten Kisspeptin-10 Analoga synthetisiert und getestet werden, da aufgrund der geringen Halbwertszeit von Kisspeptin-10 davon auszugehen ist, dass die im Blut befindlichen Enzyme diese noch einmal um ein Vielfaches minimiert und die vollständige antimetastatische Wirkung von Kisspeptin-10 in vivo sich dadurch nicht entfalten kann.

Insgesamt lässt sich feststellen, dass Kisspetin-10 nach heutigem Forschungsstand als eine antimetastatische Therapieoption beim Mammakarzinom in Frage kommt und die vorliegenden vielversprechenden Forschungsergebnisse Anlass für weitere Untersuchungen sein müssen. 


\section{ZUSAMMENFASSUNG}

Metastasen im Knochen sind ein häufiges Problem beim fortgeschrittenen Mammakarzinom, da die Morbidität der Patientinnen zunimmt und dadurch ihre Lebensqualität abnimmt. Die Analyse der dem Metastasierungsprozess zugrunde liegenden Mechanismen ist daher von großer Bedeutung für die Entwicklung neuer Therapiekonzepte. Mit dem in unserer Arbeitsgruppe etablierten Zellkultursystem wurden in der vorliegenden Arbeit die Interaktion von Mammakarzinomzellen mit Knochenzellen, ihre Migration und Invasion vor und nach der Behandlung mit Kisspeptin-10 untersucht. Bei Kisspeptin-10 handelt es sich um eine posttranslational modifizierte Variante des KiSS-1 Genproduktes, für welches bisher die stärkste agonistische Wirkung am GPR54 gezeigt werden konnte.

In der vorliegenden Arbeit wurde zunächst humanes Mammakarzinomgewebe von 98 Patientinnen auf die Expression des GPR54 untersucht. Hierbei zeigte sich ein homogenes Verteilungsmuster der GPR54 Expression unabhängig vom individuellen Rezeptorstatus der Tumore. Des Weiteren wurde in vitro untersucht, ob Kisspeptin10 die knochengerichtete Migration und Invasion GPR54-positiver Mammakarzinomzelllinien (MCF-7 und MDA-MB-231) beeinflussen kann. Die Migration und Invasion der Mammakarzinomzellen wurde signifikant gesteigert, wenn diese mit der GPR54positiven Osteoblasten-ähnlichen Zelllinie MG-63 kokultiviert waren. Die Behandlung mit Kisspeptin-10 führte in beiden Mammakarzinomzelllinien zu einer signifikanten Hemmung der knochen-gerichteten Migration und Invasion und zeigte in der MCF-7 Zelllinie einen dosisabhängigen Fenstereffekt.

Bei der Aufklärung der molekularen Mechanismen konnte gezeigt werden, dass Kisspeptin-10 einen inhibierenden Effekt auf das prometastatische SDF-1/CXCR4 System besitzt. Ebenso konnte dieser hemmende Effekt für die aktivierte Akt Proteinkinase nachgewiesen werden, der in der Signaltransduktion des SDF-1/CXCR4 Systems eine wichtige Rolle zugesprochen wird. Nach GPR54 knock down in der Osteoblasten-ähnlichen Zelllinie MG-63 zeigte sich, dass der inhibierende Effekt des Kisspeptin-10 auf den SDF-1/CXCR4-Akt-Signalweg aufgehoben wird.

Nach heutigem Forschungsstand besitzt Kisspeptin-10 das Potential einer antimetastatischen Therapieoption beim Mammakarzinom. Für den noch fernen Weg in die Klinik sind aber weitere Forschungsarbeiten an Kisspeptin-10 nötig. 


\section{LITERATURVERZEICHNIS}

Adachi, S., Yamada, S., Takatsu, Y., Matsui, H., Kinoshita, M., Takase, K., Sugiura, H., Ohtaki, T., Matsumoto, H., Uenoyama, Y., et al. (2007) Involvement of anteroventral periventricular metastin/kisspeptin neurons in estrogen positive feedback action on luteinizing hormone release in female rats. $J$ Reprod Dev, $53,367-378$.

Aiuti, A., Webb, I. J., Bleul, C., Springer, T., and Gutierrez-Ramos, J. C. (1997) The chemokine SDF-1 is a chemoattractant for human CD34+ hematopoietic progenitor cells and provides a new mechanism to explain the mobilization of CD34+ progenitors to peripheral blood. J Exp Med, 185, 111-120.

Aiuti, A., Tavian, M., Cipponi, A., Ficara, F., Zappone, E., Hoxie, J., Peault, B., and Bordignon, C. (1999) Expression of CXCR4, the receptor for stromal cellderived factor-1 on fetal and adult human lympho-hematopoietic progenitors. Eur J Immunol, 29, 1823-1831.

Al-Hajj, M., Wicha, M. S., Benito-Hernandez, A., Morrison, S. J., and Clarke, M. F. (2003) Prospective identification of tumorigenic breast cancer cells. Proc Natl Acad Sci U S A, 100, 3983-3988.

Albrektsen, G., Heuch, I., Hansen, S., and Kvale, G. (2005) Breast cancer risk by age at birth, time since birth and time intervals between births: exploring interaction effects. Br J Cancer, 92, 167-175.

Amar, S., Roy, V., and Perez, E. A. (2009) Treatment of metastatic breast cancer: looking towards the future. Breast Cancer Res Treat, 114, 413-422.

Askari, A. T., Unzek, S., Popovic, Z. B., Goldman, C. K., Forudi, F., Kiedrowski, M., Rovner, A., Ellis, S. G., Thomas, J. D., DiCorleto, P. E., et al. (2003) Effect of stromal-cell-derived factor 1 on stem-cell homing and tissue regeneration in ischaemic cardiomyopathy. Lancet, 362, 697-703. 
Aust, G., Steinert, M., Kiessling, S., Kamprad, M., and Simchen, C. (2001) Reduced expression of stromal-derived factor 1 in autonomous thyroid adenomas and its regulation in thyroid-derived cells. J Clin Endocrinol Metab, 86, 3368-3376.

Bachelder, R. E., Wendt, M. A., and Mercurio, A. M. (2002) Vascular endothelial growth factor promotes breast carcinoma invasion in an autocrine manner by regulating the chemokine receptor CXCR4. Cancer Res, 62, 7203-7206.

Balkwill, F. (2004) Cancer and the chemokine network. Nat Rev Cancer, 4, 540-550.

Bilban, M., Ghaffari-Tabrizi, N., Hintermann, E., Bauer, S., Molzer, S., Zoratti, C., Malli, R., Sharabi, A., Hiden, U., Graier, W., et al. (2004) Kisspeptin-10, a KiSS-1/metastin-derived decapeptide, is a physiological invasion inhibitor of primary human trophoblasts. J Cell Sci, 117, 1319-1328.

Billiau, A., Edy, V. G., Heremans, H., Van Damme, J., Desmyter, J., Georgiades, J. A., and De Somer, P. (1977) Human interferon: mass production in a newly established cell line, MG-63. Antimicrob Agents Chemother, 12, 11-15.

Bloom, H. J., and Richardson, W. W. (1957) Histological grading and prognosis in breast cancer; a study of 1409 cases of which 359 have been followed for 15 years. Br J Cancer, 11, 359-377.

Böcker, W., Denk, H., and Heitz, P.: "Pathologie." 3.Auflage; Urban \& Fischer, München 2004

Bordier, C. (1981) Phase separation of integral membrane proteins in Triton X-114 solution. J Biol Chem, 256, 1604-1607.

Brabletz, T., Jung, A., Spaderna, S., Hlubek, F., and Kirchner, T. (2005) Opinion: migrating cancer stem cells - an integrated concept of malignant tumour progression. Nat Rev Cancer, 5, 744-749.

Brinkley, B. R., Beall, P. T., Wible, L. J., Mace, M. L., Turner, D. S., and Cailleau, R. M. (1980) Variations in cell form and cytoskeleton in human breast carcinoma cells in vitro. Cancer Res, 40, 3118-3129. 
Brown, J. E., Neville-Webbe, H., and Coleman, R. E. (2004) The role of bisphosphonates in breast and prostate cancers. Endocr Relat Cancer, 11, 207-224.

Caruz, A., Samsom, M., Alonso, J. M., Alcami, J., Baleux, F., Virelizier, J. L., Parmentier, M., and Arenzana-Seisdedos, F. (1998) Genomic organization and promoter characterization of human CXCR4 gene. FEBS Lett, 426, 271278.

Castano, J. P., Martinez-Fuentes, A. J., Gutierrez-Pascual, E., Vaudry, H., TenaSempere, M., and Malagon, M. M. (2009) Intracellular signaling pathways activated by kisspeptins through GPR54: do multiple signals underlie function diversity? Peptides, 30, 10-15.

Castellano, J. M., Navarro, V. M., Fernandez-Fernandez, R., Roa, J., Vigo, E., Pineda, R., Dieguez, C., Aguilar, E., Pinilla, L., and Tena-Sempere, M. (2006) Expression of hypothalamic KiSS-1 system and rescue of defective gonadotropic responses by kisspeptin in streptozotocin-induced diabetic male rats. Diabetes, 55, 2602-2610.

Chambers, A. F. (1999) The metastatic process: basic research and clinical implications. Oncol Res, 11, 161-168.

Cho, S. G., Li, D., Stafford, L. J., Luo, J., Rodriguez-Villanueva, M., Wang, Y., and Liu, M. (2009) KiSS1 suppresses TNFalpha-induced breast cancer cell invasion via an inhibition of RhoA-mediated NF-kappaB activation. J Cell Biochem, 107, 1139-1149.

Coghlin, C., and Murray, G. I. (2010) Current and emerging concepts in tumour metastasis. J Pathol, 222, 1-15.

Coleman, M. P., Quaresma, M., Berrino, F., Lutz, J. M., De Angelis, R., Capocaccia, R., Baili, P., Rachet, B., Gatta, G., Hakulinen, T., et al. (2008) Cancer survival in five continents: a worldwide population-based study (CONCORD). Lancet Oncol, 9, 730-756.

Coleman, R. E. (1997) Skeletal complications of malignancy. Cancer, 80, 1588-1594. 
Coleman, R. E. (2006) Clinical features of metastatic bone disease and risk of skeletal morbidity. Clin Cancer Res, 12, 6243s-6249s.

Coleman, R. E., Guise, T. A., Lipton, A., Roodman, G. D., Berenson, J. R., Body, J. J., Boyce, B. F., Calvi, L. M., Hadji, P., McCloskey, E. V., et al. (2008) Advancing treatment for metastatic bone cancer: consensus recommendations from the Second Cambridge Conference. Clin Cancer Res, 14, 6387-6395.

Costa, L., and Major, P. P. (2009) Effect of bisphosphonates on pain and quality of life in patients with bone metastases. Nat Clin Pract Oncol, 6, 163-174.

Crowell, J. A., Steele, V. E., and Fay, J. R. (2007) Targeting the AKT protein kinase for cancer chemoprevention. Mol Cancer Ther, 6, 2139-2148.

Curnock, A. P., Sotsios, Y., Wright, K. L., and Ward, S. G. (2003) Optimal chemotactic responses of leukemic $T$ cells to stromal cell-derived factor-1 requires the activation of both class IA and IB phosphoinositide 3-kinases. $J$ Immunol, 170, 4021-4030.

Emons, G., Grundker, C., Gunthert, A. R., Westphalen, S., Kavanagh, J., and Verschraegen, C. (2003) $\mathrm{GnRH}$ antagonists in the treatment of gynecological and breast cancers. Endocr Relat Cancer, 10, 291-299.

Esteva, F. J., Sahin, A. A., Cristofanilli, M., Arun, B., and Hortobagyi, G. N. (2002) Molecular prognostic factors for breast cancer metastasis and survival. Semin Radiat Oncol, 12, 319-328.

Ferlay, J., Parkin, D. M., and Steliarova-Foucher, E. (2010) Estimates of cancer incidence and mortality in Europe in 2008. Eur J Cancer, 46, 765-781.

Fleisch, H. (2002) Development of bisphosphonates. Breast Cancer Res, 4, 30-34.

Gibson, L. J., Dawson, C. K., Lawrence, D. H., and Bliss, J. M. (2007) Aromatase inhibitors for treatment of advanced breast cancer in postmenopausal women. Cochrane Database Syst Rev, CD003370.

Glasel, J. A. (1995) Validity of nucleic acid purities monitored by $260 \mathrm{~nm} / 280 \mathrm{~nm}$ absorbance ratios. Biotechniques, 18, 62-63. 
Goldhirsch, A., Ingle, J. N., Gelber, R. D., Coates, A. S., Thurlimann, B., and Senn, H. J. (2009) Thresholds for therapies: highlights of the St Gallen International Expert Consensus on the primary therapy of early breast cancer 2009. Ann Oncol, 20, 1319-1329.

Gottsch, M. L., Cunningham, M. J., Smith, J. T., Popa, S. M., Acohido, B. V., Crowley, W. F., Seminara, S., Clifton, D. K., and Steiner, R. A. (2004) A role for kisspeptins in the regulation of gonadotropin secretion in the mouse. Endocrinology, 145, 4073-4077.

Gupta, S. K., and Pillarisetti, K. (1999) Cutting edge: CXCR4-Lo: molecular cloning and functional expression of a novel human CXCR4 splice variant. $J$ Immunol, 163, 2368-2372.

Harms, J. F., Welch, D. R., and Miele, M. E. (2003) KISS1 metastasis suppression and emergent pathways. Clin Exp Metastasis, 20, 11-18.

Hart, I. R. (2009) New evidence for tumour embolism as a mode of metastasis. J Pathol, 219, 275-276.

Hess, K. R., Pusztai, L., Buzdar, A. U., and Hortobagyi, G. N. (2003) Estrogen receptors and distinct patterns of breast cancer relapse. Breast Cancer Res Treat, 78, 105-118.

Hiden, U., Bilban, M., Knofler, M., and Desoye, G. (2007) Kisspeptins and the placenta: regulation of trophoblast invasion. Rev Endocr Metab Disord, 8, 3139.

Horikoshi, Y., Matsumoto, H., Takatsu, Y., Ohtaki, T., Kitada, C., Usuki, S., and Fujino, M. (2003) Dramatic elevation of plasma metastin concentrations in human pregnancy: metastin as a novel placenta-derived hormone in humans. J Clin Endocrinol Metab, 88, 914-919.

Horuk, R. (2001) Chemokine receptors. Cytokine Growth Factor Rev, 12, 313-335.

Huijbregts, L., and de Roux, N. (2010) KISS1 is down-regulated by 17beta-estradiol in MDA-MB-231 cells through a nonclassical mechanism and loss of 
ribonucleic acid polymerase II binding at the proximal promoter. Endocrinology, 151, 3764-3772.

Janneau, J. L., Maldonado-Estrada, J., Tachdjian, G., Miran, I., Motte, N., Saulnier, P., Sabourin, J. C., Cote, J. F., Simon, B., Frydman, R., et al. (2002) Transcriptional expression of genes involved in cell invasion and migration by normal and tumoral trophoblast cells. J Clin Endocrinol Metab, 87, 5336-5339.

Kang, H., Watkins, G., Parr, C., Douglas-Jones, A., Mansel, R. E., and Jiang, W. G. (2005) Stromal cell derived factor-1: its influence on invasiveness and migration of breast cancer cells in vitro, and its association with prognosis and survival in human breast cancer. Breast Cancer Res, 7, R402-410.

Kats-Ugurlu, G., Roodink, I., de Weijert, M., Tiemessen, D., Maass, C., Verrijp, K., van der Laak, J., de Waal, R., Mulders, P., Oosterwijk, E., et al. (2009) Circulating tumour tissue fragments in patients with pulmonary metastasis of clear cell renal cell carcinoma. J Pathol, 219, 287-293.

Kayali, A. G., Van Gunst, K., Campbell, I. L., Stotland, A., Kritzik, M., Liu, G., Flodstrom-Tullberg, M., Zhang, Y. Q., and Sarvetnick, N. (2003) The stromal cell-derived factor-1alpha/CXCR4 ligand-receptor axis is critical for progenitor survival and migration in the pancreas. J Cell Biol, 163, 859-869.

Kijowski, J., Baj-Krzyworzeka, M., Majka, M., Reca, R., Marquez, L. A., ChristofidouSolomidou, M., Janowska-Wieczorek, A., and Ratajczak, M. Z. (2001) The SDF-1-CXCR4 axis stimulates VEGF secretion and activates integrins but does not affect proliferation and survival in lymphohematopoietic cells. Stem Cells, 19, 453-466.

Kingsley, L. A., Fournier, P. G., Chirgwin, J. M., and Guise, T. A. (2007) Molecular biology of bone metastasis. Mol Cancer Ther, 6, 2609-2617.

Kollet, O., Shivtiel, S., Chen, Y. Q., Suriawinata, J., Thung, S. N., Dabeva, M. D., Kahn, J., Spiegel, A., Dar, A., Samira, S., et al. (2003) HGF, SDF-1, and MMP-9 are involved in stress-induced human CD34+ stem cell recruitment to the liver. J Clin Invest, 112, 160-169. 
Kostadima, L., Pentheroudakis, G., and Pavlidis, N. (2007) The missing kiss of life: transcriptional activity of the metastasis suppressor gene KiSS1 in early breast cancer. Anticancer Res, 27, 2499-2504.

Kotani, M., Detheux, M., Vandenbogaerde, A., Communi, D., Vanderwinden, J. M., Le Poul, E., Brezillon, S., Tyldesley, R., Suarez-Huerta, N., Vandeput, F., et al. (2001) The metastasis suppressor gene KiSS-1 encodes kisspeptins, the natural ligands of the orphan G protein-coupled receptor GPR54. J Biol Chem, 276, 34631-34636.

Kozlow, W., and Guise, T. A. (2005) Breast cancer metastasis to bone: mechanisms of osteolysis and implications for therapy. J Mammary Gland Biol Neoplasia, 10, $169-180$.

Kreipe, H. H., Ahrens, P., Christgen, M., Lehmann, U., and Langer, F. (2010) [Beyond staging, typing and grading. New challenges in breast cancer pathology]. Pathologe, 31, 54-59.

Lacey, J. V., Jr., Kreimer, A. R., Buys, S. S., Marcus, P. M., Chang, S. C., Leitzmann, M. F., Hoover, R. N., Prorok, P. C., Berg, C. D., and Hartge, P. (2009) Breast cancer epidemiology according to recognized breast cancer risk factors in the Prostate, Lung, Colorectal and Ovarian (PLCO) Cancer Screening Trial Cohort. BMC Cancer, 9, 84.

Laemmli, U. K. (1970) Cleavage of structural proteins during the assembly of the head of bacteriophage T4. Nature, 227, 680-685.

Lapidot, T., Sirard, C., Vormoor, J., Murdoch, B., Hoang, T., Caceres-Cortes, J., Minden, M., Paterson, B., Caligiuri, M. A., and Dick, J. E. (1994) A cell initiating human acute myeloid leukaemia after transplantation into SCID mice. Nature, 367, 645-648.

Lee, D. K., Nguyen, T., O'Neill, G. P., Cheng, R., Liu, Y., Howard, A. D., Coulombe, N., Tan, C. P., Tang-Nguyen, A. T., George, S. R., et al. (1999) Discovery of a receptor related to the galanin receptors. FEBS Lett, 446, 103-107. 
Lee, J. H., and Welch, D. R. (1997) Suppression of metastasis in human breast carcinoma MDA-MB-435 cells after transfection with the metastasis suppressor gene, KiSS-1. Cancer Res, 57, 2384-2387.

Lee, J. H., Miele, M. E., Hicks, D. J., Phillips, K. K., Trent, J. M., Weissman, B. E., and Welch, D. R. (1996) KiSS-1, a novel human malignant melanoma metastasis-suppressor gene. J Natl Cancer Inst, 88, 1731-1737.

Legha, S. S., and Carter, S. K. (1976) Antiestrogens in the treatment of breast cancer. Cancer Treat Rev, 3, 205-216.

Luker, K. E., and Luker, G. D. (2006) Functions of CXCL12 and CXCR4 in breast cancer. Cancer Lett, 238, 30-41.

Luo, J., Manning, B. D., and Cantley, L. C. (2003) Targeting the PI3K-Akt pathway in human cancer: rationale and promise. Cancer Cell, 4, 257-262.

Mackey, J., McLeod, D., Ragaz, J., Gelmon, K., Verma, S., Pritchard, K., Laing, K., Provencher, L., and Charbonneau, L. F. (2009) Adjuvant targeted therapy in early breast cancer. Cancer, 115, 1154-1168.

Maeda, K., Adachi, S., Inoue, K., Ohkura, S., and Tsukamura, H. (2007) Metastin/kisspeptin and control of estrous cycle in rats. Rev Endocr Metab Disord, 8, 21-29.

Makri, A., Pissimissis, N., Lembessis, P., Polychronakos, C., and Koutsilieris, M. (2008) The kisspeptin (KiSS-1)/GPR54 system in cancer biology. Cancer Treat Rev, 34, 682-692.

Manning, B. D., and Cantley, L. C. (2007) AKT/PKB signaling: navigating downstream. Cell, 129, 1261-1274.

Marot, D., Bieche, I., Aumas, C., Esselin, S., Bouquet, C., Vacher, S., Lazennec, G., Perricaudet, M., Kuttenn, F., Lidereau, R., et al. (2007) High tumoral levels of Kiss 1 and G-protein-coupled receptor 54 expression are correlated with poor prognosis of estrogen receptor-positive breast tumors. Endocr Relat Cancer, 14, 691-702. 
Martin, T. A., Watkins, G., and Jiang, W. G. (2005) KiSS-1 expression in human breast cancer. Clin Exp Metastasis, 22, 503-511.

McDonell, M. W., Simon, M. N., and Studier, F. W. (1977) Analysis of restriction fragments of T7 DNA and determination of molecular weights by electrophoresis in neutral and alkaline gels. J Mol Biol, 110, 119-146.

Mead, E. J., Maguire, J. J., Kuc, R. E., and Davenport, A. P. (2007) Kisspeptins are novel potent vasoconstrictors in humans, with a discrete localization of their receptor, $\mathrm{G}$ protein-coupled receptor 54, to atherosclerosis-prone vessels. Endocrinology, 148, 140-147.

Miller, K., Wang, M., Gralow, J., Dickler, M., Cobleigh, M., Perez, E. A., Shenkier, T., Cella, D., and Davidson, N. E. (2007) Paclitaxel plus bevacizumab versus paclitaxel alone for metastatic breast cancer. N Engl J Med, 357, 2666-2676.

Mitchell, D. C., Abdelrahim, M., Weng, J., Stafford, L. J., Safe, S., Bar-Eli, M., and Liu, M. (2006) Regulation of KiSS-1 metastasis suppressor gene expression in breast cancer cells by direct interaction of transcription factors activator protein-2alpha and specificity protein-1. J Biol Chem, 281, 51-58.

Muller, A., Homey, B., Soto, H., Ge, N., Catron, D., Buchanan, M. E., McClanahan, T., Murphy, E., Yuan, W., Wagner, S. N., et al. (2001) Involvement of chemokine receptors in breast cancer metastasis. Nature, 410, 50-56.

Mullis, K., Faloona, F., Scharf, S., Saiki, R., Horn, G., and Erlich, H. (1986) Specific enzymatic amplification of DNA in vitro: the polymerase chain reaction. Cold Spring Harb Symp Quant Biol, 51 Pt 1, 263-273.

Murray, M. J., and Lessey, B. A. (1999) Embryo implantation and tumor metastasis: common pathways of invasion and angiogenesis. Semin Reprod Endocrinol, 17, 275-290.

Nagasawa, T., Tachibana, K., and Kishimoto, T. (1998) A novel CXC chemokine PBSF/SDF-1 and its receptor CXCR4: their functions in development, hematopoiesis and HIV infection. Semin Immunol, 10, 179-185. 
Nagasawa, T., Nakajima, T., Tachibana, K., lizasa, H., Bleul, C. C., Yoshie, O., Matsushima, K., Yoshida, N., Springer, T. A., and Kishimoto, T. (1996) Molecular cloning and characterization of a murine pre-B-cell growthstimulating factor/stromal cell-derived factor 1 receptor, a murine homolog of the human immunodeficiency virus 1 entry coreceptor fusin. Proc Natl Acad Sci U S A, 93, 14726-14729.

Navenot, J. M., Wang, Z., Chopin, M., Fujii, N., and Peiper, S. C. (2005) Kisspeptin10-induced signaling of GPR54 negatively regulates chemotactic responses mediated by CXCR4: a potential mechanism for the metastasis suppressor activity of kisspeptins. Cancer Res, 65, 10450-10456.

Neville-Webbe, H. L., Gnant, M., and Coleman, R. E. (2010) Potential anticancer properties of bisphosphonates. Semin Oncol, 37 Suppl 1, S53-65.

O'Brien, C. A., Pollett, A., Gallinger, S., and Dick, J. E. (2007) A human colon cancer cell capable of initiating tumour growth in immunodeficient mice. Nature, 445, 106-110.

Ohtaki, T., Shintani, Y., Honda, S., Matsumoto, H., Hori, A., Kanehashi, K., Terao, Y., Kumano, S., Takatsu, Y., Masuda, Y., et al. (2001) Metastasis suppressor gene KiSS-1 encodes peptide ligand of a G-protein-coupled receptor. Nature, 411, 613-617.

Paget, S. (1989) The distribution of secondary growths in cancer of the breast. 1889. Cancer Metastasis Rev, 8, 98-101.

Pardal, R., Clarke, M. F., and Morrison, S. J. (2003) Applying the principles of stemcell biology to cancer. Nat Rev Cancer, 3, 895-902.

Peled, A., Petit, I., Kollet, O., Magid, M., Ponomaryov, T., Byk, T., Nagler, A., BenHur, H., Many, A., Shultz, L., et al. (1999) Dependence of human stem cell engraftment and repopulation of NOD/SCID mice on CXCR4. Science, 283, 845-848.

Peng, S. B., Peek, V., Zhai, Y., Paul, D. C., Lou, Q., Xia, X., Eessalu, T., Kohn, W., and Tang, S. (2005) Akt activation, but not extracellular signal-regulated 
kinase activation, is required for SDF-1alpha/CXCR4-mediated migration of epitheloid carcinoma cells. Mol Cancer Res, 3, 227-236.

Petit, I., Szyper-Kravitz, M., Nagler, A., Lahav, M., Peled, A., Habler, L., Ponomaryov, T., Taichman, R. S., Arenzana-Seisdedos, F., Fujii, N., et al. (2002) G-CSF induces stem cell mobilization by decreasing bone marrow SDF-1 and upregulating CXCR4. Nat Immunol, 3, 687-694.

Ponomaryov, T., Peled, A., Petit, I., Taichman, R. S., Habler, L., Sandbank, J., Arenzana-Seisdedos, F., Magerus, A., Caruz, A., Fujii, N., et al. (2000) Induction of the chemokine stromal-derived factor-1 following DNA damage improves human stem cell function. J Clin Invest, 106, 1331-1339.

Prasad, A., Fernandis, A. Z., Rao, Y., and Ganju, R. K. (2004) Slit protein-mediated inhibition of CXCR4-induced chemotactic and chemoinvasive signaling pathways in breast cancer cells. J Biol Chem, 279, 9115-9124.

Prentice, L. M., Klausen, C., Kalloger, S., Kobel, M., McKinney, S., Santos, J. L., Kenney, C., Mehl, E., Gilks, C. B., Leung, P., et al. (2007) Kisspeptin and GPR54 immunoreactivity in a cohort of 518 patients defines favourable prognosis and clear cell subtype in ovarian carcinoma. BMC Med, 5, 33 .

Proudfoot, A. E. (2002) Chemokine receptors: multifaceted therapeutic targets. Nat Rev Immunol, 2, 106-115.

Ratajczak, M. Z., Kucia, M., Reca, R., Majka, M., Janowska-Wieczorek, A., and Ratajczak, J. (2004) Stem cell plasticity revisited: CXCR4-positive cells expressing mRNA for early muscle, liver and neural cells 'hide out' in the bone marrow. Leukemia, 18, 29-40.

Ratajczak, M. Z., Majka, M., Kucia, M., Drukala, J., Pietrzkowski, Z., Peiper, S., and Janowska-Wieczorek, A. (2003) Expression of functional CXCR4 by muscle satellite cells and secretion of SDF-1 by muscle-derived fibroblasts is associated with the presence of both muscle progenitors in bone marrow and hematopoietic stem/progenitor cells in muscles. Stem Cells, 21, 363-371. 
Revel, F. G., Ansel, L., Klosen, P., Saboureau, M., Pevet, P., Mikkelsen, J. D., and Simonneaux, V. (2007) Kisspeptin: a key link to seasonal breeding. Rev Endocr Metab Disord, 8, 57-65.

Riemsma, R., Forbes, C. A., Kessels, A., Lykopoulos, K., Amonkar, M. M., Rea, D. W., and Kleijnen, J. (2010) Systematic review of aromatase inhibitors in the first-line treatment for hormone sensitive advanced or metastatic breast cancer. Breast Cancer Res Treat, 123, 9-24.

Roa, J., and Tena-Sempere, M. (2007) KiSS-1 system and reproduction: comparative aspects and roles in the control of female gonadotropic axis in mammals. Gen Comp Endocrinol, 153, 132-140.

Rometo, A. M., Krajewski, S. J., Voytko, M. L., and Rance, N. E. (2007) Hypertrophy and increased kisspeptin gene expression in the hypothalamic infundibular nucleus of postmenopausal women and ovariectomized monkeys. J Clin Endocrinol Metab, 92, 2744-2750.

Rose, A. A., and Siegel, P. M. (2010) Emerging therapeutic targets in breast cancer bone metastasis. Future Oncol, 6, 55-74.

Rubin, J. B., Kung, A. L., Klein, R. S., Chan, J. A., Sun, Y., Schmidt, K., Kieran, M. W., Luster, A. D., and Segal, R. A. (2003) A small-molecule antagonist of CXCR4 inhibits intracranial growth of primary brain tumors. Proc Natl Acad Sci US A, 100, 13513-13518.

Ruiterkamp, J., Voogd, A. C., Bosscha, K., Tjan-Heijnen, V. C., and Ernst, M. F. (2009) Impact of breast surgery on survival in patients with distant metastases at initial presentation: a systematic review of the literature. Breast Cancer Res Treat, 120, 9-16.

Saiki, R. K., Gelfand, D. H., Stoffel, S., Scharf, S. J., Higuchi, R., Horn, G. T., Mullis, K. B., and Erlich, H. A. (1988) Primer-directed enzymatic amplification of DNA with a thermostable DNA polymerase. Science, 239, 487-491.

Salvucci, O., Yao, L., Villalba, S., Sajewicz, A., Pittaluga, S., and Tosato, G. (2002) Regulation of endothelial cell branching morphogenesis by endogenous chemokine stromal-derived factor-1. Blood, 99, 2703-2711. 
Sanchez-Carbayo, M., Capodieci, P., and Cordon-Cardo, C. (2003) Tumor suppressor role of KiSS-1 in bladder cancer: loss of KiSS-1 expression is associated with bladder cancer progression and clinical outcome. Am J Pathol, 162, 609-617.

Schier, A. F. (2003) Chemokine signaling: rules of attraction. Curr Biol, 13, R192194.

Schrader, A. J., Lechner, O., Templin, M., Dittmar, K. E., Machtens, S., Mengel, M., Probst-Kepper, M., Franzke, A., Wollensak, T., Gatzlaff, P., et al. (2002) CXCR4/CXCL12 expression and signalling in kidney cancer. Br J Cancer, 86, 1250-1256.

Scotton, C. J., Wilson, J. L., Milliken, D., Stamp, G., and Balkwill, F. R. (2001) Epithelial cancer cell migration: a role for chemokine receptors? Cancer Res, 61, 4961-4965.

Seminara, S. B., Messager, S., Chatzidaki, E. E., Thresher, R. R., Acierno, J. S., Jr., Shagoury, J. K., Bo-Abbas, Y., Kuohung, W., Schwinof, K. M., Hendrick, A. G., et al. (2003) The GPR54 gene as a regulator of puberty. N Engl J Med, 349, 1614-1627.

Shahab, M., Mastronardi, C., Seminara, S. B., Crowley, W. F., Ojeda, S. R., and Plant, T. M. (2005) Increased hypothalamic GPR54 signaling: a potential mechanism for initiation of puberty in primates. Proc Natl Acad Sci U S A, 102, 2129-2134.

Shi, M., Liu, D., Duan, H., Shen, B., and Guo, N. (2010) Metastasis-related miRNAs, active players in breast cancer invasion, and metastasis. Cancer Metastasis Rev, 29, 785-799.

Shirozu, M., Nakano, T., Inazawa, J., Tashiro, K., Tada, H., Shinohara, T., and Honjo, T. (1995) Structure and chromosomal localization of the human stromal cell-derived factor 1 (SDF1) gene. Genomics, 28, 495-500.

Singletary, S. E., Allred, C., Ashley, P., Bassett, L. W., Berry, D., Bland, K. I., Borgen, P. I., Clark, G., Edge, S. B., Hayes, D. F., et al. (2002) Revision of the 
American Joint Committee on Cancer staging system for breast cancer. J Clin Oncol, 20, 3628-3636.

Slamon, D. J., Godolphin, W., Jones, L. A., Holt, J. A., Wong, S. G., Keith, D. E., Levin, W. J., Stuart, S. G., Udove, J., Ullrich, A., et al. (1989) Studies of the HER-2/neu proto-oncogene in human breast and ovarian cancer. Science, 244, 707-712.

Smid, M., Wang, Y., Zhang, Y., Sieuwerts, A. M., Yu, J., Klijn, J. G., Foekens, J. A., and Martens, J. W. (2008) Subtypes of breast cancer show preferential site of relapse. Cancer Res, 68, 3108-3114.

Sorlie, T., Tibshirani, R., Parker, J., Hastie, T., Marron, J. S., Nobel, A., Deng, S., Johnsen, H., Pesich, R., Geisler, S., et al. (2003) Repeated observation of breast tumor subtypes in independent gene expression data sets. Proc Natl Acad Sci U S A, 100, 8418-8423.

Sorlie, T., Perou, C. M., Tibshirani, R., Aas, T., Geisler, S., Johnsen, H., Hastie, T., Eisen, M. B., van de Rijn, M., Jeffrey, S. S., et al. (2001) Gene expression patterns of breast carcinomas distinguish tumor subclasses with clinical implications. Proc Natl Acad Sci U S A, 98, 10869-10874.

Sotiriou, C., Neo, S. Y., McShane, L. M., Korn, E. L., Long, P. M., Jazaeri, A., Martiat, P., Fox, S. B., Harris, A. L., and Liu, E. T. (2003) Breast cancer classification and prognosis based on gene expression profiles from a population-based study. Proc Natl Acad Sci U S A, 100, 10393-10398.

Soule, H. D., Vazguez, J., Long, A., Albert, S., and Brennan, M. (1973) A human cell line from a pleural effusion derived from a breast carcinoma. $J$ Natl Cancer Inst, 51, 1409-1416.

Stark, A. M., Tongers, K., Maass, N., Mehdorn, H. M., and Held-Feindt, J. (2005) Reduced metastasis-suppressor gene mRNA-expression in breast cancer brain metastases. J Cancer Res Clin Oncol, 131, 191-198.

Steinborn, M., Tiling, R., Heuck, A., Brugel, M., Stabler, A., and Reiser, M. (2000) [The diagnosis of metastases in the bone marrow by MRT]. Radiologe, 40, 826-834. 
Thiery, J. P. (2003) Epithelial-mesenchymal transitions in development and pathologies. Curr Opin Cell Biol, 15, 740-746.

Towbin, H., Staehelin, T., and Gordon, J. (1979) Electrophoretic transfer of proteins from polyacrylamide gels to nitrocellulose sheets: procedure and some applications. Proc Natl Acad Sci U S A, 76, 4350-4354.

Tsuji, T., Ibaragi, S., and Hu, G. F. (2009) Epithelial-mesenchymal transition and cell cooperativity in metastasis. Cancer Res, 69, 7135-7139.

van den Brandt, P. A., Spiegelman, D., Yaun, S. S., Adami, H. O., Beeson, L., Folsom, A. R., Fraser, G., Goldbohm, R. A., Graham, S., Kushi, L., et al. (2000) Pooled analysis of prospective cohort studies on height, weight, and breast cancer risk. Am J Epidemiol, 152, 514-527.

Veres, G., Gibbs, R. A., Scherer, S. E., and Caskey, C. T. (1987) The molecular basis of the sparse fur mouse mutation. Science, $237,415-417$.

Vlahakis, S. R., Villasis-Keever, A., Gomez, T., Vanegas, M., Vlahakis, N., and Paya, C. V. (2002) G protein-coupled chemokine receptors induce both survival and apoptotic signaling pathways. J Immunol, 169, 5546-5554.

von Alten, J., Fister, S., Schulz, H., Viereck, V., Frosch, K. H., Emons, G., and Grundker, C. (2006) $\mathrm{GnRH}$ analogs reduce invasiveness of human breast cancer cells. Breast Cancer Res Treat, 100, 13-21.

Wang, J., Loberg, R., and Taichman, R. S. (2006) The pivotal role of CXCL12 (SDF1)/CXCR4 axis in bone metastasis. Cancer Metastasis Rev, 25, 573-587.

Ward, H. W. (1973) Anti-oestrogen therapy for breast cancer: a trial of tamoxifen at two dose levels. Br Med J, 1, 13-14.

WHO: "The global burden of disease: 2004 update." World Health Organization 2008, Switzerland 2008

Williams, B. J., Fox, B. D., Sciubba, D. M., Suki, D., Tu, S. M., Kuban, D., Gokaslan, Z. L., Rhines, L. D., and Rao, G. (2009) Surgical management of prostate cancer metastatic to the spine. J Neurosurg Spine, 10, 414-422. 
Yang, J., and Weinberg, R. A. (2008) Epithelial-mesenchymal transition: at the crossroads of development and tumor metastasis. Dev Cell, 14, 818-829.

Yang, J., Mani, S. A., Donaher, J. L., Ramaswamy, S., Itzykson, R. A., Come, C., Savagner, P., Gitelman, I., Richardson, A., and Weinberg, R. A. (2004) Twist, a master regulator of morphogenesis, plays an essential role in tumor metastasis. Cell, 117, 927-939.

Yoshida, B. A., Sokoloff, M. M., Welch, D. R., and Rinker-Schaeffer, C. W. (2000) Metastasis-suppressor genes: a review and perspective on an emerging field. J Natl Cancer Inst, 92, 1717-1730.

Yun, H. J., and Jo, D. Y. (2003) Production of stromal cell-derived factor-1 (SDF1)and expression of CXCR4 in human bone marrow endothelial cells. $J$ Korean Med Sci, 18, 679-685.

Zhou, X., Tan, M., Stone Hawthorne, V., Klos, K. S., Lan, K. H., Yang, Y., Yang, W., Smith, T. L., Shi, D., and Yu, D. (2004) Activation of the Akt/mammalian target of rapamycin/4E-BP1 pathway by ErbB2 overexpression predicts tumor progression in breast cancers. Clin Cancer Res, 10, 6779-6788. 


\section{ANHANG}

\subsection{Abbildungsverzeichnis}

ABb. 1.1: Schematische DaRStellung des Metastasierungsprozesses am Beispiel des MAMMAKARZINOMS.

AbB. 1.2: Schematische Darstellung der Mikroumgebung Des PRimären Tumorgewebes und der Metastasen. Progenitorzellen des Knochenmarks, AKTIVIERTE FIBROBLASTEN UND ENDOTHELIALE ZELLEN STEHEN IN STÄNDIGER INTERAKTION MIT DEN TUMORZELLEN VON DER IN SITU PROLIFERATION AN, ÜBER DIE INVASION UND INTRAVASATION BIS HIN ZUR BILDUNG DER TOCHTERGESCHWULST. PrÄMETASTATISCHE ZELLULÄRE ANHÄUfUngEN SEZERNIEREN LÖSLICHE MEDIATOREN WIE SDF-1, WELCHES DAS HOMING DER CXCR4-POSITIVEN MIGRIERENDEN TUMORZELLEN FÖRDERT. MODIFIZIERT NACH COGHLIN AND MURRAY (2010).

AbB. 1.3: Proteolyse des VorläUfermoleküls Von KISSPePtin-10. Die biOlogisch AKTIVEN KISSPEPTINE ENTSTEHEN INTRAZELLULÄR DURCH SPEZFIFISCHE PROTEOLYSE AUS DEM VORLÄUFERPEPTID KISSPEPTIN-145 (MAKRI ET AL. 2008). .11

ABb. 1.4: AminosÄURESEQUENZ VON KISSPEPTIN-10. KISSPEPTIN-10 BESTEHT AUS ZEHN AMINOSÄUREN UND ZEIGT DIE HÖCHSTE AFFINITÄT ZUM GPR54 IM VERGLEICH ZU DEN RESTLICHEN BIOLOGISCH AKTIVEN KISSPEPTINEN. .11

Abb. 2.1: Schematische Darstellung des Migrationsassays. Die MCF-7 MAMMAKARZINOMZELLEN SIND GELB DARGESTELLT UND WERDEN AUF INSERTS AUSGESÄT, DIE MIT MATRIGEL BESCHICHTET SIND. IN DER WELLPLATTE BEFINDET SICH MEDIUM (A). UNTERHALB DER AUF DEM INSERT SITZENDEN MAMMAKARZINOMZELLEN MCF-7 BEFINDET SICH BLAU DARGESTELLT DIE OSTEOBLASTEN-ÄHNLICHE ZELLLINIE MG-63. DIES IST DAS IN UNSEREM LABOR ETABLIERTE KOKULTURSYSTEM (B). .22

AbB. 3.1: IMMUNHISTOCHEMISCHER NACHWEIS DES GPR54 IN HUMANEM

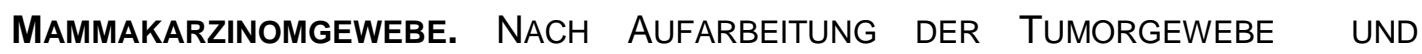
ANSCHLIEBENDER IMMUNHISTOCHEMISCHER FÄRBUNG MIT DEM GPR54 ANTIKÖRPER ZEIGTEN DIE KARZINOME EINE UNTERSCHIEDLICHE GPR54 EXPRESSION. EXEMPLARISCH HANDELT ES SICH IN DER ABBILDUNG UM ÖSTROGEN- UND Progesteronrezeptor positive aber her2/neu Rezeptor negative MAMMAKARZINOME, DIE EINERSEITS FÜR DEN KISSPEPTINREZEPTOR GPR54-NEGATIV (A) UND ANDERERSEITS ZU ÜBER 80 \% GPR54-POSITIV SIND (B UND C) .39 
ABB. 3.2: IMMUNZYTOCHEMISCHER NACHWEIS VON GPR54 IN DEN MAMMAKARZINOMZELLLINIEN MCF-7 UND MDA-MB-231 SOWIE IN DER OSTEOBLASTEN-ÄHNLICHEN ZELLLINIE MG63. Die Rezeptor-Positiven MCF-7 Zellen (B) Sind ebenso Wie die ReZeptorPOSITIVEN MDA-MB-231 ZELLEN (D) SOWIE DIE REZEPTOR-POSITIVEN MG-63 ZELLEN (F) DURCH IHRE RÖTLICHE FÄRBUNG IM VERGLEICH ZUR KONTROLLE (MCF-7 ZELLEN (A), MDA-MB-231 Zellen (C) UND MG-63 Zellen (E)), IN DER Die ZelLen OHNE PRIMÄRANTIKÖRPERN INKUBIERT WURDEN, DEUTLICH ZU ERKENNEN. .40

ABB. 3.3: INVASION VON MCF-7 ZELLEN OHNE UND WÄHREND DER KOKULTUR MIT MG-63 Zellen (Hämalaunfärbung). Die KokUltivierung der Zellen erfolgte ÜBer 96 H. MONOKUltiVieRTe MCF-7 MammakarzinOMZELLEN ÜBER MEDIUM ZEIGTEN EIN WENIGER STARKES INVASIONSVERMÖGEN (A) ALS KOKULTIVIERTE MCF-7 MAMMAKARZINOMZELLEN ÜBER MG-63 ZELLEN (B).

ABB. 3.4: INVASIONSVERHALTEN VON MONOKULTIVIERTEN UND KOKULTIVIERTEN MCF-7 MAMmAKARZINOMZELLEN. IN DER KONTROLLE WURDEN DIE MCF-7 ZELLEN MIT MEDIUM KULTIVIERT UND IN DER KOKULTUR MIT DER OSTEOBLASTEN-ÄHNLICHEN ZELLLINIE MG-63 KOKULTIVIERT. ES ZEIGTE SICH EIN SIGNIFIKANTER ANSTIEG DER INVADIERTEN MAMMAKARZINOMZELLEN WÄHREND DER KOKULTUR IM VERGLEICH ZUR Kontrolle. ANGEgeben SIND MW \pm SEM, DIE DATEN WURDEN MITTELS T-TEST (GEPAART) AUF SIGNIFIKANTE UNTERSCHIEDE GEPRÜFT: A, P<0,001 VS. KONTROLLE.42

ABB. 3.5: HeMmUng DeR INVASIONSFÄHIGKEIT VON KOKULtIVIERTEN MCF-7 ZeLLEN DURCH KISSPEPTIN-10 (HÄMALAUNFÄRBUNG). DIE KOKULTIVIERUNG DER ZELLEN ERFOLGTE ÜBER 96 H. BEI EINER BEHANDLUNG DER MCF-7 ZELLEN MIT KISSPEPTIN-10 (1X10-9 M) alle $12 \mathrm{H}$ (C) WAR EINE REDUZIERUNG DER ANZAHL DER INVADIERTEN MammakarzinOMZelLen IM Vergleich ZUR UnBehandelten KOKULtUR (B) DEUTLICH ZU BEOBACHTEN.

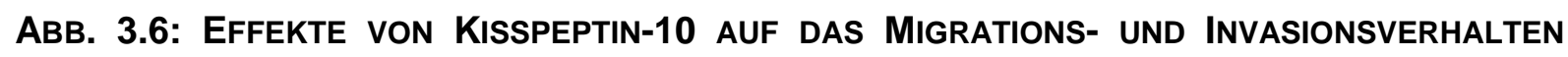
KOKULTIVIERTER MCF-7 MAMMAKARZINOMZELLEN. DIE DOSISABHÄNGIGE BEHANDLUNG DER KOKULTIVIERTEN MAMMAKARZINOMZELLEN MIT KISSPEPTIN-10 WURDE ALLE 12 H ÜBER 96 H DURCHGEFÜHRT. EINE SIGNIFIKANTE HEMMUNG ZEIGTE SICH IN EINEM KONZENTRATIONSBEREICH VON $1 \times 10^{-11} \mathrm{M}$ BIS $1 \times 10^{-9} \mathrm{M}$. HIERBEI HANDELT ES SICH UM EINEN FENSTEREFFEKT, DA KISSPEPTIN-10 NUR IN DIESEM KONZENTRATIONSBEREICH DIE HEMMENDE WIRKUNG ENTFALTET. ANGEGEBEN SIND $\mathrm{MW} \pm \mathrm{SEM}$, DIE DATEN WURDEN MITTELS ONE-WAY ANALYSIS OF VARIANCE (ANOVA) GEFOLGT VOM STUDENT-NEWMAN-KEULS TEST AUF SIGNIFIKANTE UNTERSCHIEDE GEPRÜFT: A, $P<0,05$ VS. KOKULTUR 
ABB. 3.7: INVASIONSVERHALTEN MONOKULTIVIERTER UND KOKULTIVIERTER MDA-MB-231 MAMmAKARZINOMZELLEN. IN DER KONTROLLE WURDEN DIE MDA-MB-231 MammakarZinOMZELLEN Mit MEDIUM KULtiVIERT UND IN DER KOKULtUR MIT DER OSTEOBLASTEN-ÄHNLICHEN ZELLLINIE MG-63 KOKULTIVIERT. ES ZEIGTE SICH EIN SIGNIFIKANTER ANSTIEG DER INVADIERTEN MAMMAKARZINOMZELLEN WÄHREND DER KOKULtur IM Vergleich ZUR Kontrolle. ANGEgEBEN SIND MW \pm SEM, DIE DATEN WURDEN MITTELS T-TEST (GEPAART) AUF SIGNIFIKANTE UNTERSCHIEDE GEPRÜFT: A, $\mathrm{P}<0,001$ VS. KONTROLLE.

ABb. 3.8: EfFEKTE VON KISSPEPTIN-10 AUf DIE Migration UND INVASION KOKULTIVIERTER MDA-MB-231 MammaKaRzinomzellen. Die dosisabHäNGIGE BEHANDLUNG DER KOKULTIVIERTEN MAMMAKARZINOMZELLEN MIT KISSPEPTIN-10 WURDE ALLE 12 H ÜBER $96 \mathrm{H}$ DURCHGEFÜHRT. EINE SIGNIFIKANTE HEMMUNG DER MigRATIONS- UND INVASIONSFÄHIGKEIT WURDE BEI EINER KONZENTRATION VON $1 \times 10^{-10} \mathrm{M}$ ERREICHT. ANGEGEBEN SIND MW \pm SEM, DIE DATEN WURDEN MITTELS ONE-WAY ANALYSIS OF VARIANCE (ANOVA) GEFOLGT VOM STUDENT-NEWMAN-KEULS TEST AUF SIGNIFIKANTE UNTERSCHIEDE GEPRÜFT: A, P<0,05 VS. KOKULTUR.

ABb. 3.9: EfFEKTE VON KISSPEPTIN-10 AUf DIE CXCR4 MRNA-EXPRESSION. DIE INKUBATION ERFOLGTE FÜR 24 H MIT EINEM GEMISCH AUS 0,06\% DMSO IN AMPUWA WASSER (KONTROLLE UND KOKULTUR) UND MIT KISSPEPTIN-10 [1 $\left.1 \times 10^{-9} \mathrm{M}\right]$ IN DER BEHANDELTEN Kontrolle und KokUltur. Die quantitative Bestimmung DER CXCR4 MRNAEXPRESSION ERFOLGTE MITTELS RT-PCR IM BEZUG AUF DAS HOUSEKEEPING GENE L7 (B). EIN ANSTIEG DER CXCR4 MRNA-EXPRESSION IN DER KOKULTUR $(P<0,001)$ IM VERGLEICH ZUR KONTROLLE WAR ZU BEOBACHTEN. BEI BEHANDLUNG MIT KISSPEPTIN10 ZEIGTE SICH EINE SIGNIFIKANTE ABNAHME DER CXCR4 MRNA-EXPRESSION IM Vergleich ZUR UnBeHANDELTEN KOKULtur. ANGEGeben SIND MW \pm SEM, DiE DATEN WURDEN MITTELS ONE-WAY ANALYSIS OF VARIANCE (ANOVA) GEFOLGT VOM StUdENT-NEWMAN-KEULS TEST AUF SIGNIFIKANTE UNTERSCHIEDE GEPRÜFT: A, $\mathrm{P}<0,001$ VS. KONTROLLE; $\mathrm{B}, \mathrm{P}<0,001$ VS. KOKULTUR; $\mathrm{C}, \mathrm{P}<0,05$ VS. KOKULTUR (A) ..46

ABB. 3.10: EfFEKTE von KISSPEPTIN-10 AUf die SDF1 mRNA-EXPRESSION. DIE KOKULTIVIER-

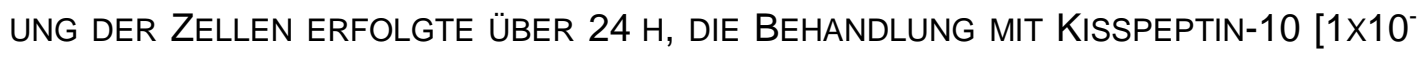
$\left.{ }^{9} \mathrm{M}\right]$ WURDE ALLE 12 H DURCHGEFÜHRT. DIE QUANTITATIVE BESTIMMUNG DER MRNAEXPRESSION WURDE MITTELS RT-PCR UND ABGLEICH DURCH DAS HOUSEKEEPING GENE L7 DURCHGEFÜHRT (B). ZU BEOBACHTEN WAR EINE SIGNIFIKANTE ABNAHME DER SDF-1 MRNA-EXPRESSION BEI DEN KOKULTIVIERTEN MG-63 ZELLEN IN DER

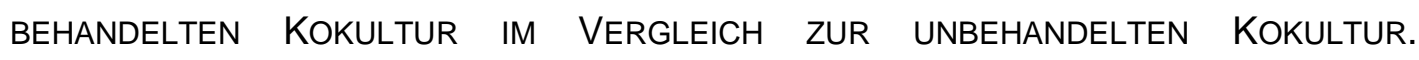
ANGEGEBEN SIND MW \pm SEM, DIE DATEN WURDEN MITTELS T-TEST (GEPAART) AUF SIGNIFIKANTE UNTERSCHIEDE GEPRÜFT: A, P<0,05 VS. KOKULTUR (A). 
ABb. 3.11: EfFEKTE von KISSPEPTIN-10 AUf DIE CXCR4 PROTEINEXPRESSION. DIE INKUBATION DER KOKULTIVIERTEN ZELLEN ERFOLGTE ÜBER $24 \mathrm{H}$ MIT EINER DOSISABHÄNGIGEN BEHANDLUNG VON KISSPEPTIN-10 ALLE $12 \mathrm{H}$. DIE UNTERSCHIEDLICHEN CXCR4 ProteineXPRESSIONSMUSteR ZEIGTEN SICH IM WESteRN BLOT, MITTELS AKTIN WURDE EIN QUANTITATIVER ABgleich DER CXCR4 PROTEINEXPRESSION DURCHGEFÜHRT (B). ES ZEIGTE SICH EINE VERMINDERTE EXPRESSION BEI EINER KISSPEPTIN-10 KONZENTRATION VON $1 \times 10^{-9} \mathrm{M}$ BIS $1 \times 10^{-7} \mathrm{M}$ IM VERGLEICH ZUR KONTROLLE. BEI EINER KISSPEPTIN-10 KONZENTRATION VON $1 \times 10^{-7} \mathrm{M}$ BIS $1 \times 10^{-8} \mathrm{M}$ WURDE EINE SIGNIFIKANTE ABNAHME DER CXCR4 PROTEINEXPRESSION FESTGESTELLT. ANGEGEBEN SIND MW \pm SEM, DIE DATEN WURDEN MITTELS ONE-WAY ANALYSIS OF VARIANCE (ANOVA) GEFOLGT VOM STUDENT-NEWMAN-KEULS TEST AUF SIGNIFIKANTE UNTERSCHIEDE GEPRÜFT: A, P<0,01 VS. KONTROLLE; B, P<0,05 VS. $\operatorname{KONTROLLE}(\mathrm{A})$.

Abb. 3.12: Effekte von KISSPePtin-10 aUf die SDF-1 Proteinsekretion. Die KOKULtiVIERUNG ERFOLGTE ÜBER 24 H BEI EINER DOSISABHÄNGIGEN KISSPEPTIN-10 BEHANDLUNG $\left(1 \times 10^{-12} \mathrm{M}, 1 \times 10^{-11} \mathrm{M}, 1 \times 10^{-9} \mathrm{M}, 1 \times 10^{-8} \mathrm{M}, 1 \times 10^{-7} \mathrm{M}\right)$, DIE ALLE $12 \mathrm{H}$ DURCHGEFÜHRT WURDE. IM WESTERN BLOT WURDE DIE SDF-1 PROTEINSEKRETION NACHGEWIESEN (B). Die mONOKultivierten MG-63 Zellen SeZernierten das SDF-1 Protein NICHT. IN DER UNBEHANDELTEN KOKULtUR ZEIGTE SICH EIN ANSTIEG DER PROTEINSEKRETION, BEI EINER KISSPEPTIN-10 KONZENTRATION VON $1 \times 10^{-11} \mathrm{M}$ BIS $1 \times 10^{-8} \mathrm{M}$ ZEIGTE SICH EINE REDUKTION DER PROTEINSEKRETION DER MG-63 ZELLEN IM VERGLEICH ZUR KOKULtUR. DIE STÄRKSTE HEMMUNG LIEß SICH IN EINEM DOSISWIRKUNGSBEREICH VON $1 \times 10^{-11} \mathrm{M}$ BIS $1 \times 10^{-9} \mathrm{M}$ NACHWEISEN (A). 50

AbB. 3.13: Effekte von Kisspeptin-10 auf die Phosphorylierung der Proteinkinase AKt. Die INKUBATION DER KOKULTIVIERTEN ZELLEN ERFOLGTE ÜBER 24 H MIT EINER DOSISABHÄNGIGEN BEHANDLUNG VON KISSPEPTIN-10 ALLE 12 H. NACH AUFARBEITUNG DER Proteine ERFolgte EIN QUANTITATIVER NACHWEIS DES PHOSHORYLIERTEN AKT PRoteins (AKTIVIERTER ZUStAND) IM Western Blot IM ABgleich Mit DEM DEPHOSPHORYLIERTEM AKT PROTEIN (INAKTIVIERTER ZUSTAND) (B). ES ZEIGTE SICH EINE VERMINDERTE EXPRESSION DES PHOSPHORYLIERTEN AKT PROTEINS IN SÄMTLICHEN KISSPEPTIN-10 KONZENTRATIONEN. ANGEGEBEN SIND MW \pm SEM, DIE DATEN WURDEN MITTELS ONE-WAY ANALYSIS OF VARIANCE (ANOVA) GEFOLGT VOM StUdENT-NEWMAN-KEULS TEST AUF SIGNIFIKANTE UNTERSCHIEDE GEPRÜFT: A, $\mathrm{P}<0,05$ VS. KONTROLLE $(\mathrm{A})$. .52

ABB. 3.14: IMMUNZYTOCHEMISCHER NACHWEIS DES GPR54 KNOCK DOWNS IN DER OSTEOBLASTEN-ÄHNLICHEN Zelllinie MG-63. DiE EXPRESSION DES GPR54 IST IM 
VERGLEICH ZUR POSITIVKONTROLle (B) NACH KNOCK DOWN (C) DEUTLICH REDUZIERT UND KORRELIERT MIT DER NEGATIVKONTROLLE (A).

AbB. 3.15: NaChWeis der CXCR4 ProteineXPRession IN MCF-7 ZelLen IM WeStern Blot NACH GPR54 KNOCK DOWN IN DER OSTEOBLASTEN-ÄHNLICHEN ZELLLINIE MG-63. DiE CXCR4 PROTEINEXPRESSION NAHM IN DER KOKULtUR IM VERGLEICH ZUR KONTROLLE DEUTLICH ZU UND ZEIGTE ABER NACH DOSISABHÄNGIGER BEHANDLUNG MIT KISSPEPTIN-10 KEINE ABNAHME (A).

AbB. 3.16: NACHWEIS DeR SDF-1 PROTEINSEKRETION NACH GPR54 KNOCK DOWN IN DER OSteoblasten-ÄHNLICHEN Zelllinie MG-63. Die SDF-1 ProteinSEKRETION NAHM IN DER KOKULTUR IM VERGLEICH ZUR KONTROLLE DEUTLICH ZU UND ZEIGTE ABER NACH DOSISABHÄNGIGER BEHANDLUNG MIT KISSPEPTIN-10 KEINE REDUZIERUNG (A). .55

AbB. 3.17: NAChWeIS der aKtivierten AKt Proteinkinase (P-AKT) IN DEN MCF-7 ZelLen IM WESTERN BLOT NACH GPR54 KNOCK DOWN IN DER OSTEOBLASTEN-ÄHNLICHEN ZELLLINIE MG-63. IN DER KOKULTUR ZEIGET SICH IM VERGLEICH ZUR KONTROLLE NUR

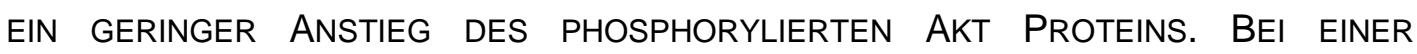
KISSPEPTIN-10 KONZENTRATION VON $1 \times 10^{-12} \mathrm{M}$ WAR EINE GERINGFÜGIGE REDUZIERUNG DES AKTIVIERTEN AKTPROTEINS ZU ERKENNEN, IN ALLEN ANDEREN KONZENTRATION LIEß SICH KEINE ABNAHME DER PHOSPHORYLIERTEN AKT PROTEINKINASE FESTSTELLEN (A). 56

ABB. 3.18: INVASIONSVERHALTEN VON MONOKULTIVIERTEN UND KOKULTIVIERTEN MCF-7 MammaKaRZINOMZellen. DIE KONTROLlE ZEIGT DIE INVADIERTEN MONOKULTIVIERTEN MCF-7 ZELLEN WÄHREND DIE KOKULTUR DIE INVADIERTEN

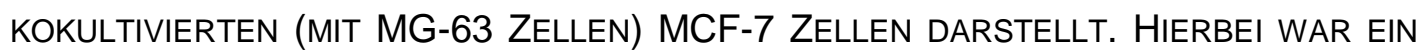
SIGNIFIKANTER ANSTIEG DER INVADIERTEN MCF-7 ZELLEN DEUTLICH ZU ERKENNEN. ANGEGEBEN SIND MW \pm SEM, DIE DATEN WURDEN MITTELS T-TEST (GEPAART) AUF SIGNIFIKANTE UNTERSCHIEDE GEPRÜFT: A, P<0,001 VS. KONTROLLE.

ABB. 3.19: EFFEKTE deS SDF-1 ANTIKÖRPERS AUF DAS MigRATIONSVERHALTEN KOKULTIVIERTER MCF-7 MAMmaKaRZINOMZELLEN. BEI BEHANDLUNG DER MG-63 ZELLEN MIT EINEM SDF-1 ANTIKÖRPER ZEIGTE SICH EINE SIGNIFIKANTE REDUZIERUNG DER

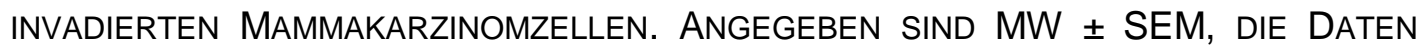
WURDEN MITTELS T-TEST (GEPAART) AUF SIGNIFIKANTE UNTERSCHIEDE GEPRÜFT: A, $P<0,01$ VS. KOKULTUR.

ABb. 4.1: EFFEKTE VON SDF-1 UND CXCR4 IM PRIMÄREN MAMMAKARZINOM UND SEINEN METASTASEN. MODIFIZIERT NACH LUKER AND LUKER (2006). .63 
ABB. 4.2: MODELL FÜR DIE ROLLE VON KISSPEPTIN-10 IN KNOCHENMETASTASEN MIT PRIMARIUS IN DER MAMma. KISSPEPTIN-10 VERRINGERT DURCH DIE INHIBITION DES PROMETASTATISCHEN SDF-1/CXCR4 SYSTEMS DIE FÄHIGKEIT DER MAMmaKaRZINOMZELlEN DURCH DIE MIT MATRIGEL BESCHICHTETE MEMBRAN AUFGRUND DES ZELLULÄREN STIMULUS DER OSTEOBLASTEN-ÄHNLICHEN ZELLLINIE MG-63 ZU MIGRIEREN. DIE AKTIVIERUNG DES GPR54 AUF DEN MAMMAKARZINOMZELLEN INHIBIERT DIE CXCR4 EXPRESSION UND DAS CXCR4 SIGNALING (A). DIE AKTIVIERUNG DES GPR54 DER MG-63 ZELLEN HEMMT SOWOHL DIE SDF-1 MRNA-EXPRESSION ALS AUCH DIE SDF-1 PROTEINSEKRETION (B). 66

\subsection{Tabellenverzeichnis}

TAB. 1.1: GeWEBespeZfISCHE EXPRESSION DES KISS-1 GENS UND DES GPR54 (MAKRI ET AL. 2008)

TAB. 2.1: IN DER ARBEIT VERWENDETE ZELLLINIEN .... 18

TAB. 2.2: PRIMÄRANTIKÖRPER 19

TAB. 2.3: SEKUNDÄRANTIKÖRPER 19

TAB. 2.4: AufBereitung DES MATRIGELS. 23

TAB. 2.5: ANZAHL DER AUSGESÄTEN ZELLEN PRO INSERT ODER WELL 23

TAB. 2.6: FAKTOR ZUR KONZENTRATIONSBESTIMMUNG VON RNA. .26

TAB. 2.7: ENZYM-MIX FÜR REVERSE TRANSKRIPTION. .27

TAB. 2.8: STANDARD-REAKTIONSANSATZ FÜR DIE PCR. 28

TAB. 2.9: PCR-Programme: TeMPERATUR Und ZeIT 28

TAB. 2.10: $5 \%$ IGES SAMMELGEL .31

TAB. 2.11: $10 \%$ IGES UND 15\%IGES TRENNGEL .31

TAB. 2.12: HÄMALAUNFÄRBUNG .35

TAB. 3.1: GPR54 EXPRESSION AN DER TUMORFRONT IN HUMANEM MAMMAKARZINOMGEWEBE..38

TAB. 3.2: GPR54 EXPRESSION IN HUMANEM MAMMAKARZINOMGEWEBE OHNE ANGESCHNITTENE TUMORFRONT .39 


\subsection{Abkürzungsverzeichnis}

Abb.

Abbildung

APS

Ammoniumperoxodisulfat

ATCC

American Type Culture Collection

$\mathrm{Bp}$

Basenpaare

BRCA

breast cancer genes

bzw.

beziehungsweise

${ }^{\circ} \mathrm{C}$

Grad Celsius

CD-FCS

charcoal dextran-treated FCS

cDNA

complementary DNA

CHO Zellen

Chinese Hamster Ovary Zellen

CIS

Carcinoma in situ

CXCL12

Chemokine (C-X-C motif) ligand 12

CXCR4

Chemokine (C-X-C motif) receptor 4

$\mathrm{Da}$

Dalton

DCIS

duktale Carcinoma in situ

dd $\mathrm{H}_{2} \mathrm{O}$

doppelt destilliertes Wasser

DEPC

Diethylpyrocarbonat

DMSO

Dimethylsulfoxid

DNA

Desoxyribonukleinsäure

dNTP

Deoxyribonukleosid-Triphosphat

DTT

Dithiothreitol

ECL

enhanced chemiluminescens reaction

EDTA

Ethylendiamin-N,N,N',N'-Tetraessigsäure-Na-Salz

EGFR

epidermal growth factor receptor

EHS

Engelberth-Holm-Swarm

EMT

epitheliale-mesenchymale Transition

FCS

fötales Kälberserum (fetal calf serum)

g

Erdbeschleunigung

$\mathrm{GnRH}$

Gonadotropin-Releasing Hormon

GPR54

G protein-coupled receptor 54

$\mathrm{h}$

Stunde(n) (hour(s))

HER2/neu

human epidermal growth factor receptor 2 


\begin{tabular}{|c|c|}
\hline $\mathrm{K}$ & Kontrolle \\
\hline Kap. & Kapitel \\
\hline $\mathrm{kDa}$ & Kilodalton \\
\hline KiSS1R & KiSS1 Rezeptor \\
\hline $\mathrm{KK}$ & Kokultur \\
\hline KP-10 & Kisspeptin-10 \\
\hline LCIS & lobuläres Carcinoma in situ \\
\hline LH & luteinisierendes Hormon \\
\hline$\mu l$ & Mikroliter \\
\hline M & Molar \\
\hline MEM & minimal essential medium \\
\hline $\min$ & Minute(n) \\
\hline mRNA & messenger-RNA \\
\hline n.s. & nicht signifikant \\
\hline P-Akt & phosphorylated Akt \\
\hline PAGE & Polyacrylamid-Gelelektrophorese \\
\hline PCR & Polymerase Kettenreaktion (polymerase chain reaction) \\
\hline PH-Domäne & Pleckstrin Homologie Domäne \\
\hline $\mathrm{PI3K}$ & Phosphatidylinositol-3-Kinase \\
\hline $\mathrm{P} / \mathrm{S}$ & Penicillin/Streptomycin \\
\hline RNA & Ribonukleinsäure (ribonucleic acid) \\
\hline rpm & Umdrehungen pro Minute (rounds per minute) \\
\hline RT & Raumtemperatur \\
\hline $\mathrm{RT}$ & Reverse Transkription \\
\hline SDF-1 & stromal derived factor-1 \\
\hline SDS & Natriumdodecylsulfat (sodium dodecyl sulfate) \\
\hline sec & Sekunde $(\mathrm{n})(\operatorname{second}(s))$ \\
\hline SERM & selective estrogen receptor modulators \\
\hline Tab. & Tabelle \\
\hline Taq & thermus aquaticus \\
\hline TBE & Tris-Borat-EDTA-Puffer \\
\hline TBST & Tween-TBS Puffer \\
\hline TEMED & N,N,N',N',-Tetramethylethyldiamin \\
\hline Tris & Tris(hydroxymethyl)aminomethan \\
\hline
\end{tabular}


u.a.

UV

$\mathrm{V}$

VEGF

vs.

$\mathrm{v} / \mathrm{v}$

WHO

w

w/o

$\mathrm{w} / \mathrm{v}$ unter anderem

ultraviolett

Volt

vascular endothelial growth factor

versus

volume/volume

World Health Organization

mit (with)

ohne (without)

weight/volume

\subsection{Aminosäurecode für natürliche Aminosäuren}

$\begin{array}{ll}\text { Alanin } & \text { Ala } \\ \text { Arginin } & \text { Arg } \\ \text { Asparagin } & \text { Asn } \\ \text { Aspartat } & \text { Asp } \\ \text { Cystein } & \text { Cys } \\ \text { Glutamat } & \text { Glu } \\ \text { Glutamin } & \text { Gln } \\ \text { Glycin } & \text { Gly } \\ \text { Histidin } & \text { His } \\ \text { Isoleucin } & \text { Ile } \\ \text { Leucin } & \text { Leu } \\ \text { Lysin } & \text { Lys } \\ \text { Methionin } & \text { Met } \\ \text { Phenylalanin } & \text { Phe } \\ \text { Prolin } & \text { Pro } \\ \text { Serin } & \text { Ser } \\ \text { Threonin } & \text { Thr } \\ \text { Tryptophan } & \text { Trp } \\ \text { Tyrosin } & \text { Tyr } \\ \text { Valin } & \text { Val }\end{array}$




\section{PUBLIKATIONEN}

Die in dieser Arbeit durchgeführten Untersuchungen haben $z u$ folgenden Publikationen beigetragen:

\section{Originalarbeiten:}

Olbrich T, Ziegler E, Türk G, Schubert A, Emons G, Gründker C (2010) Kisspeptin10 inhibits bone-directed migration of GPR54-positive breast cancer cells: evidence for a dose-window effect. Gynecol Oncol, 119, 571-578.

In Vorbereitung:

Olbrich T, Ziegler E, Emons G, Gründker C Effects of GPR54 knock down and SDF1 depletion on breast cancer cells and osteoblast-like cells during coculture.

\section{Kongressbeiträge:}

Olbrich T., Schubert A., Ziegler E., Emons G., Gründker C. (2010) Kisspeptin-10 hemmt die knochengerichtete Migration GPR54-positiver Mammakarzinomzellen. 29. Deutscher Krebskongress, Berlin - Freier Vortrag.

Olbrich T., Ziegler E., Emons G., Gründker C. (2010) Kisspeptin-10 hemmt das SDF-1/CXCR4 System während der knochengerichteten Migration GPR54-positiver Mammakarzinomzellen. 126. Tagung der Norddeutschen Gesellschaft für Gynäkologie und Geburtshilfe, Schwerin - Postersessionbeitrag.

Ziegler E., Olbrich T., Emons G., Gründker C. (2010) Einfluss von Kisspeptin-10 auf die Expression migrationsrelevanter Gene beim Mammakarzinom. 126. Tagung der Norddeutschen Gesellschaft für Gynäkologie und Geburtshilfe, Schwerin Postersessionbeitrag. 


\section{DANKSAGUNG}

Ich bedanke mich bei Herrn Prof. Dr. Günter Emons für die Möglichkeit, dass ich die vorliegende Arbeit im Forschungslabor der Universitätsfrauenklinik Göttingen unter der Leitung von Prof. Dr. Carsten Gründker anfertigen konnte.

Mein besonderer Dank gilt Herrn Prof. Dr. Carsten Gründker, meinem Doktorvater, der mich stets forderte und förderte. Seine lehrreiche, engagierte Betreuung und immer währende Diskussionsbereitschaft trugen wesentlich $\mathrm{zu}$ meinem ausgesprochenen Interesse an dieser Forschungsarbeit bei. Dafür und für die persönlichen Gespräche über die Arbeit hinaus möchte ich ihm hiermit meinen besonderen Dank aussprechen.

Für die schönen, produktiven, arbeitsreichen und fallweise unterhaltsamen Stunden im Labor der Molekularen Gynäkologie bedanke ich mich bei allen Mitarbeitern und Mitarbeiterinnen und Ehemaligen recht herzlich. Das tolle Arbeitsklima trug entscheidend dazu bei, die eine oder andere Stunde mehr im Labor zu verweilen.

Ich bedanke mich auch bei Frau Hiltrud Schulz, Herrn Matthias Läsche, Frau Renate Dietrich, Frau Sonja Blume und Frau Kathrin Eckhardt für die Hilfe zur Einarbeitung, die weitere zuverlässige Unterstützung und die schönen Gespräche über die Laborarbeit hinaus.

Frau Elke Ziegler und Herrn PD Dr. Rainer Girgert danke ich insbesondere für die wissenschaftliche Unterstützung im Labor in allen erdenklichen Situationen und für viele interessante Gespräche.

Besonders großer Dank gilt auch Frau Dr. Antje Schubert, die unermüdlich und immerzu unterstützend im Labor an meiner Seite stand und mit der mich neben der Arbeit eine ganz besondere Freundschaft verbindet.

Bei der Mildred-Scheel-Stiftung bedanke ich mich für die finanzielle Förderung der materiellen Mittel, die für diese Arbeit nötig waren. 